UNIVERSIDADE DE SÃO PAULO

ESCOLA DE ENGENHARIA DE SÃO CARLOS

ANA LAURA RAYMUNDO PAVAN

ANÁLISE DE MODELOS DE CARACTERIZAÇÃO DE IMPACTOS DO USO DA TERRA PARA A AVALIAÇÃO DE IMPACTO DO CICLO DE VIDA E RECOMENDAÇÕES PARA SUBSIDIAR A APLICAÇÃO NO BRASIL 


\section{ANÁLISE DE MODELOS DE CARACTERIZAÇÃO DE IMPACTOS DO USO DA TERRA PARA A AVALIAÇÃO DE IMPACTO DO CICLO DE VIDA E RECOMENDAÇÕES PARA SUBSIDIAR A APLICAÇÃO NO} BRASIL

Dissertação apresentada à Escola de Engenharia de São Carlos da Universidade de São Paulo, como parte dos requisitos necessários à obtenção do título de mestre em Ciências da Engenharia Ambiental.

Orientador: Prof. Dr. Aldo Roberto Ometto 
AUTORIZO A REPRODUÇÃO TOTAL OU PARCIAL DESTE TRABALHO, POR QUALQUER MEIO CONVENCIONAL OU ELETRÔNICO, PARA FINS DE ESTUDO E PESQUISA, DESDE QUE CITADA A FONTE.

Pavan, Ana Laura Raymundo

Análise de modelos de caracterização de impactos do uso da terra para a Avaliação de Impacto do Ciclo de Vida e recomendações para subsidiar a aplicação no Brasil / Ana Laura Raymundo Pavan; orientador Aldo Roberto Ometto. São Carlos, 2014.

Dissertação (Mestrado) - Programa de Pós-Graduação em Ciências da Engenharia Ambiental e Área de Concentração em Ciências da Engenharia Ambiental -Escola de Engenharia de São Carlos da Universidade de São Paulo, 2014.

1. Avaliação do Ciclo de Vida. 2. Avaliação de Impacto do Ciclo de Vida . 3. Uso da Terra. 4. Biodiversidade. 5. Serviços Ecossistêmicos. I. Título. 
FOLHA DE JULGAMENTO

Candidata: Licenciada ANA LAURA RAYMUNDO PAVAN.

Título da dissertação: "Análise de modelos de caracterização de impactos do uso da terra para a avaliação de impacto do ciclo de vida e recomendações para subsidiar a aplicação no Brasil".

Data da defesa: 02/06/2014

\section{Comissão Julgadora:}

Prof. Dr. Aldo Roberto Ometto (Orientador)

(Escola de Engenharia de São Carlos/EESC)

Prof. Dr. Marcelo Montaño

Escola de Engenharia de São Carlos/EESC)

Profa. Dra. Cássia Maria Lie Ugaya

(Universidade Tecnológica Federal do Paraná/UTFPR)

\section{Resultado:}

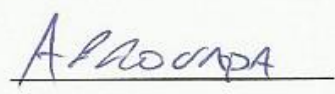

ARNOUADA

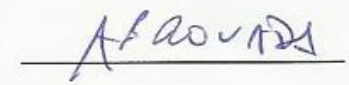

Coordenador do Programa de Pós-Graduação em Ciências da Engenharia Ambiental:

Prof. Dr. Frederico Fabio Mauad

Presidente da Comissão de Pós-Graduação:

Prof. Titular Denis Vinicius Coury 


\section{AGRADECIMENTOS}

A Deus, que sempre me guia e ilumina e deu forças para completar essa jornada.

Aos meus pais Maria Inês e Luís, que são a base da minha educação. Obrigada pelo amor e apoio incondicional.

À minha irmã Ana Carolina, que tanto me deu coragem e apoio a concluir este desafio. Não há distância que atrapalhe nossa ligação!

Aos meus tios, Sebastião e Maria Antonieta e toda minha família pelo carinho e apoio.

Às amigas: Ana Paula Acerbi, Bárbara Codonho, Elisa Uliana, Karla Palmieri, Magda Carneiro e Noelly Queiroz. Obrigada pela amizade que vão além dos anos de faculdade.

À Raíssa Baldochi, Ana Carolina Ricci, Aline Arcara e Flávia Bombonato, por todos os anos de amizade, companheirismo e carinho.

À Natalia Crespo Mendes, pela amizade, histórias compartilhadas e as incontáveis risadas. Ao Professor Dr. Aldo Roberto Ometto pela orientação, contribuições e incentivo ao longo destes anos pesquisa.

Aos colegas do Grupo de Pesquisa em Engenharia e Gestão do Ciclo de Vida e do Laboratório de Gestão de Operações, pela motivação e pelos momentos de descontração que ajudam o dia-a-dia ser mais fácil.

Aos professores e funcionários do Centro de Ciências da Engenharia Aplicadas ao Meio Ambiente (CCEAMA) que contribuíram para a realização deste trabalho.

À CAPES pela concessão do apoio financeiro fundamental para a viabilização deste mestrado. Agradeço a todos que de maneira direta ou indireta colaboraram para realização do meu mestrado. 
PAVAN, A. L. R. Análise de modelos de caracterização de impactos do uso da terra para a Avaliação do Impacto do Ciclo de Vida e recomendações para subsidiar a aplicação no Brasil. 133. Dissertação (Mestrado) - Escola de Engenharia de São Carlos, Universidade de São Paulo, São Carlos, 2014.

\section{RESUMO}

O principal instrumento de avaliação dos impactos ambientais do ciclo de vida de produtos é a Avaliação do Ciclo de Vida (ACV). Uma de suas fases, a Avaliação de Impacto do Ciclo de Vida (AICV) refere-se ao processo quantitativo e/ou qualitativo aplicado na caracterização e avaliação dos impactos associados ao inventário do ciclo de vida. Dentre os impactos ambientais avaliados, estão aqueles relacionados ao uso da terra. Um dos grandes desafios no campo da ACV refere-se diferenciação espacial e temporal nos métodos de AICV, sobretudo para impactos devido à transformação e ocupação da terra. Torna-se necessário o desenvolvimento de modelos de caracterização e/ou adaptação daqueles já existentes de maneira que possam considerar as características ambientais regionais de cada país, visando à obtenção de resultados mais consistentes e precisos. Assim, este trabalho tem o objetivo de analisar a aplicabilidade e a regionalização dos principais modelos de caracterização de impactos do uso da terra para a Avaliação do Impacto do Ciclo de Vida no Brasil. Para tanto foi conduzida uma revisão bibliográfica sistemática, a qual subsidiou a descrição e análise de dezesseis principais modelos de caracterização para avaliação de impactos do uso da terra. Durante a etapa de análise, as informações referentes a cada modelo foram classificadas de acordo com diferentes critérios, como: abordagem midpoint/endpoint, área de cobertura, área de coleta dos dados, diferenciação bio-geográfica, tempo de recuperação, situação de referência, robustez científica e relevância ambiental. Observou-se que seis modelos, de abrangência de aplicação global, apresentam robustez científica e relevância ambiental satisfatória para a avaliação dos impactos nos serviços ecossistêmicos e na biodiversidade: Brandão \& Milà i Canals (2013); Müller-Wenk \& Brandão (2010); Nunez et al. (2010); Saad, Koellner, Margni (2013); Souza (2010); Souza et al. (2013). Outra contribuição do trabalho refere-se às recomendações para a adaptação de modelos de caracterização, visando a regionalização, para a qual uma série de elementos-chave deve ser considerada, tais como o

mecanismo ambiental modelado, a tipologia de uso do solo, o nível de diferenciação biogeográfica usado para o cálculo dos fatores de caracterização e a situação de referência utilizada.

Palavras-chave: Avaliação do Ciclo de Vida (ACV); Avaliação de Impacto do Ciclo de Vida (AICV); Uso da Terra; Biodiversidade; Serviços Ecossistêmicos. 
PAVAN, A. L. R. Análise de modelos de caracterização de impactos do uso da terra para a Avaliação do Impacto do Ciclo de Vida e recomendações para subsidiar a aplicação no Brasil. 133. Dissertação (Mestrado) - Escola de Engenharia de São Carlos, Universidade de São Paulo, São Carlos, 2014.

\begin{abstract}
The main technique for assessing the environmental impacts of the product life cycle is the Life Cycle Assessment (LCA). One of its phases, the Life Cycle Impact Assessment (LCIA) refers to quantitative and / or qualitative process applied to the characterization and assessment of impacts associated with the life cycle inventory. Among the environmental impacts evaluated in LCA are those related to land use. A major challenge in the field of LCA refers to spatial and temporal differentiation in LCIA methods, especially for impacts due to land occupation and land transformation. It becomes necessary to develop models for the characterization and / or adapting existing ones so that they can consider regional environmental characteristics of each country, in order to obtain more consistent and accurate results. Therefore, this work aims to analyze the applicability and regionalization of the land use impacts characterization models in the Life Cycle Impact Assessment in Brazil. To achieve that, a systematic literature review was performed, which subsidized the description and analysis of sixteen major characterization models for land use impact assessment. During the analysis, the information regarding each model were classified according to different criteria, such as midpoint/ endpoint approach, coverage area, area of data collection, biogeographical differentiation, recovery time, reference land use situation, scientific robustness and environmental relevance. It was observed that six models, with a global scope, present scientific robustness and environmental relevance sufficient for the assessment of impacts on biodiversity and ecosystem services: Brandão \& Milà i Canals (2013); Müller-Wenk \& Brandão (2010); Nunez et al. (2010); Saad, Koellner, Margni (2013); Souza (2010); Souza et al. (2013). Another contribution of this work were the recommendations for adapting characterization models, for which a number of key elements must be considered, such as the modelled land use impact pathways, the land use typology, the level of bio-geographical differentiation used for the characterization factors and the reference land use situation.
\end{abstract}

Keywords: Life Cycle Assessment (LCA); Life Cycle Impact Assessment (LCIA), Land Use, Biodiversity, Ecosystem Services. 


\section{LISTA DE FIGURAS}

Figura 1: Estado da terra em relação à capacidade dos serviços ecossistêmicos, degradação e tendência de mudanças.

Figura 2: Modelo para a condução da revisão bibliográfica sistemática. .......................... 22

Figura 3: Filtros do procedimento de análise da Revisão Bibliográfica Sistemática......... 25

Figura 4: Modelo de quadro síntese das características analisadas.................................. 27

Figura 5: Modelo de quadro usado na síntese dos parâmetros dos modelos de caracterização.

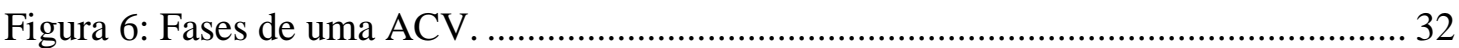

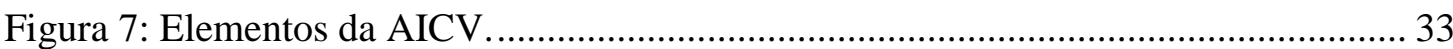

Figura 8: Representação dos impactos decorrentes da ocupação e transformação da terra.

Figura 9: Cadeia de causa e efeito para os impactos do uso da terra. ................................ 48

Figura 10: Resultado da Revisão Bibliográfica Sistemática. ............................................. 51

Figura 11: Mecanismo ambiental do método Ecoindicator 99. ..........................................52

Figura 12: Esquema geral do método IMPACT 2002+................................................... 57

Figura 13: Relação entre os parâmetros do ICV, indicadores midpoint e endpoint no método ReCiPe.

Figura 14: Ilustração da área conectada e não conectada da transformação de um tipo referência de uso da terra para um tipo i.

Figura 15: Framework do método LUCAS..................................................................... 70

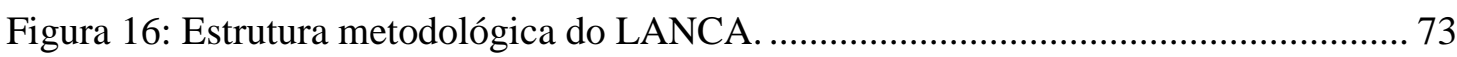

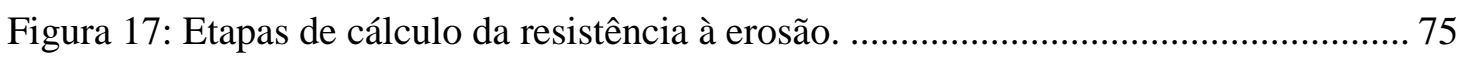

Figura 18: Etapas de cálculo para filtração mecânica....................................................... 76

Figura 19: Etapas de cálculo para filtração físico-química. ................................................. 77

Figura 20: Etapas de cálculo para reposição de águas subterrâneas. .................................. 78

Figura 21: Etapas de cálculo para produção biótica............................................................... 79

Figura 22: Etapas do desenvolvimento do modelo adotadas por Saad et al. (2011).......... 82

Figura 23: Esquema metodológico aplicado no cálculo dos fatores de caracterização no

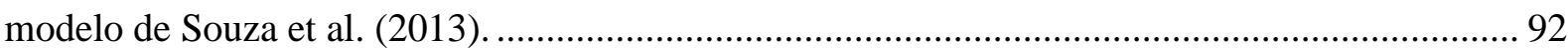

Figura 24: Abordagens de avaliação dos impactos do uso da terra na ACV . .................. 116

Figura 25: Cadeia de causa e efeito para impactos do uso da terra e modelos recomendados.

Figura 26: Elementos chave e possíveis fontes de dados para a construção de uma metodologia de avaliação de impactos do uso da terra para o contexto brasileiro. 


\section{LISTA DE QUADROS}

Quadro 1: Strings de pesquisa.

Quadro 2: Conjunto de critérios utilizados para a avaliação da robustez científica e relevância

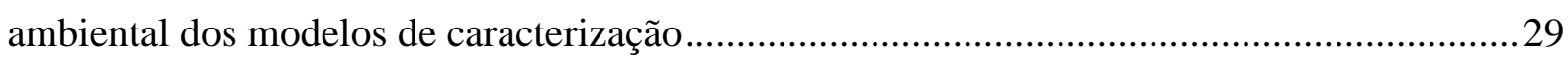

Quadro 3: Diferenças entre as categorias de impacto no método Ecoindicator 99 .................54

Quadro 4: Visão geral dos parâmetros determinantes dos quatro tipos de uso da terra...........56

Quadro 5: Indicadores da metodologia LANCA.............................................................. 74

Quadro 6: Características dos modelos de caracterização para impactos do uso da terra: Abordagem midpoint (M) ou endpoint (E), Impactos de ocupação (O) e transformação (T), Implementado em método de AICV e Abrangência de aplicação......................................... 104

Quadro 7: Características dos modelos de caracterização: Área de coleta, Diferenciação biogeográfica, Tempo de recuperação e Situação de referência................................................. 107

Quadro 8: Análise dos modelos de caracterização quanto à robustez científica e relevância ambiental.

\section{LISTA DE TABELAS}

Tabela 1: Fatores de caracterização midpoint para os três impactos do uso da terra. 63 


\section{SUMÁRIO}

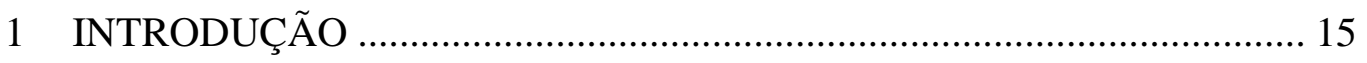

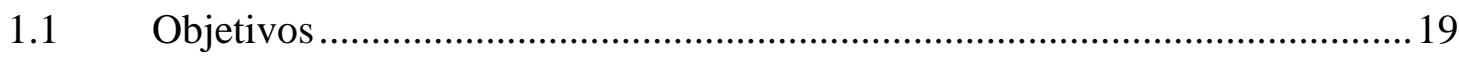

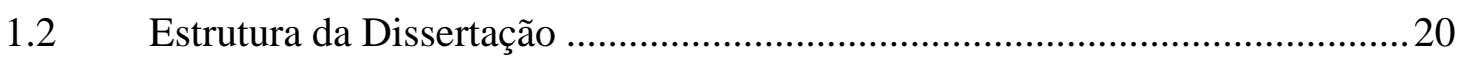

2 MATERIAIS E MÉTODOS _................................................................ 21

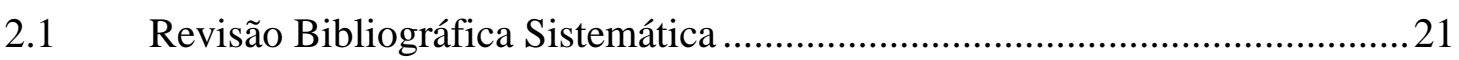

2.2 Análise dos modelos de caracterização para avaliação de impactos do uso da terra

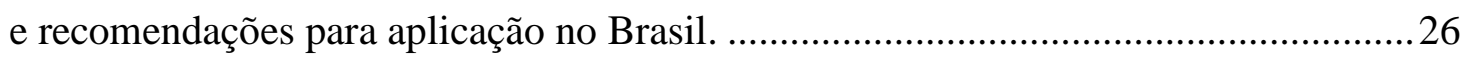

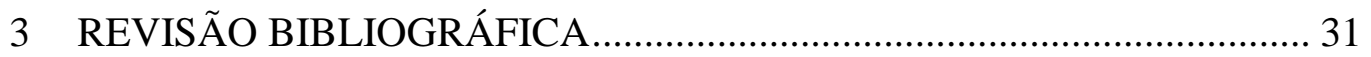

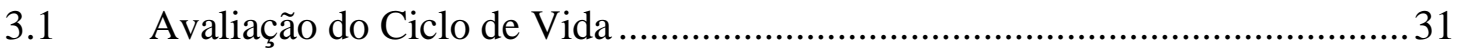

3.2 Avaliação de Impacto do Ciclo de Vida ............................................................

4 O USO DA TERRA NA AVALIAÇÃO DE IMPACTO DO CICLO DE VIDA 39

4.1 O uso da terra no Inventário do Ciclo de Vida ........................................................40

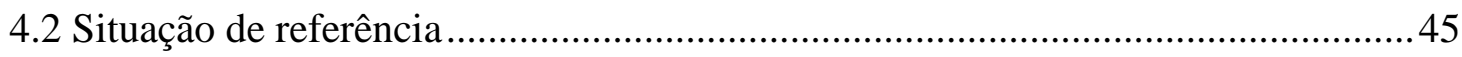

4.3 Reversibilidade dos impactos do uso da terra e tempo de recuperação...................46

4.4 Uso da terra e seus impactos na qualidade do ecossistema ...................................4 47

5 MODELOS DE CARACTERIZAÇÃO DOS IMPACTOS DO USO DA TERRA 51

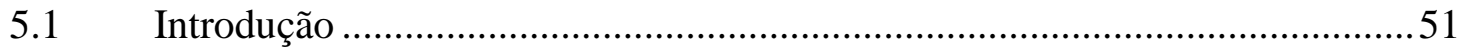

5.2 O Modelo de Goedkoop e Spriensma (2001) - Ecoindicator 99 ....................51

$5.3 \quad$ O modelo de Jolliet et al. 2003 - Impact 2002+........................................57

5.4 O modelos de Itsubo et al., 2004 - LIME ......................................................58

5.6 O modelo de Goedkoop et al. (2013) - ReCiPe...............................................62

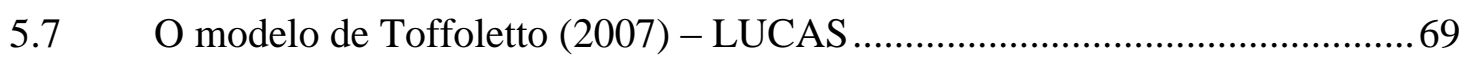

5.8 O modelo de Beck et al. (2010) - LANCA …......................................................... 73

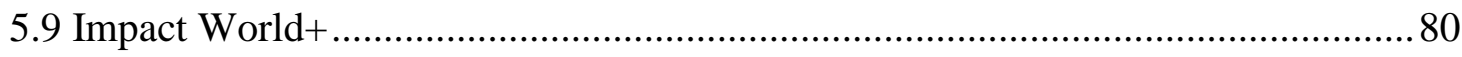

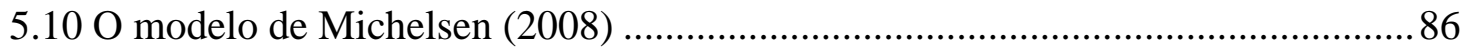

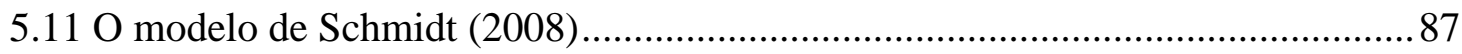

$5.12 \mathrm{O}$ modelo de Brandão e Milà i Canals (2013) ....................................................... 88

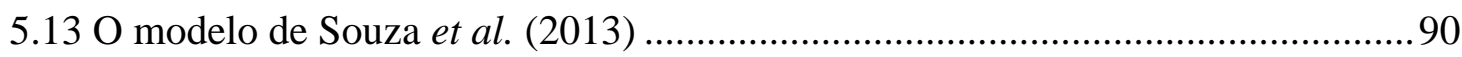




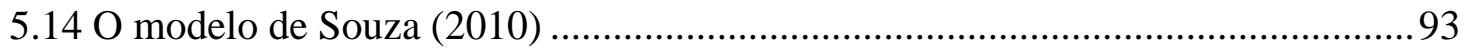

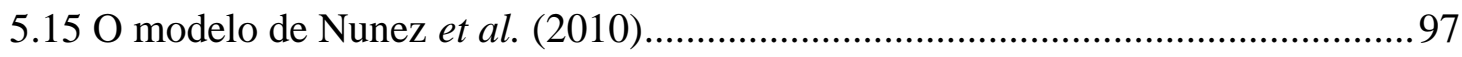

5.16 O modelo de Müller-Wenk e Brandão (2010) ......................................................99

6 ANÁLISE DA APLICABILIDADE E REGIONALIZAÇÃO DOS MODELOS DE CARACTERIZAÇÃO E RECOMENDAÇÕES PARA A AVALIAÇÃO DOS IMPACTOS DO USO DA TERRA NO BRASIL

6.1 Análise comparativa dos modelos de caracterização de impactos do uso da terra 103

6.2 Recomendações para a avaliação dos impactos do uso da terra no Brasil 116

7 CONCLUSÕES.. 125

8 REFERÊNCIAS BIBLIOGRÁFICAS 


\section{INTRODUÇÃO}

Com o reconhecimento da crescente pressão sob os recursos naturais, a temática ambiental assumiu uma maior importância na sociedade como um todo, tanto para os órgãos de governo como para as indústrias e comunidade. Além disso, o crescente interesse e a responsabilidade percebida pelos consumidores e empresas de países importadores, bem como o aumento da extração de recursos naturais nos países produtores, salientam a necessidade de obter mais informações sobre os impactos gerados ao longo da cadeia de valor dos produtos (TEEB, 2010).

Esse contexto impulsiona a busca por instrumentos de auxílio no conhecimento dos impactos ambientais bem como na identificação de práticas mais sustentáveis, ou seja, aquelas que visam melhorar o desempenho das dimensões da sustentabilidade de forma integrada: ambiental, social e econômica (ELKINGTON, 1998). Neste sentido, a Gestão do Ciclo de Vida (Life Cycle Management - LCM) surge como uma abordagem de gestão de negócio para melhorar continuamente o desempenho em sustentabilidade da organização e de seus produtos e serviços, por meio da incorporação do pensamento do ciclo de vida ${ }^{1}$ nas práticas de negócio (UNEP, 2007; JORGENSEN, 2008; UNEP, SETAC, 2009).

A Avaliação do Ciclo de Vida (ACV) é um instrumento eficaz que possibilita uma visão abrangente sobre os potenciais impactos, oferecendo benefícios além daqueles inerentes ao campo ambiental (FINNVEDEN et al., 2009; HAUSCHILD;WENZEL,1998; HERTWICH, 2005).

A Norma NBR ISO 14040 descreve os princípios e marcos teóricos para conduzir e informar os estudos de ACV, incluindo alguns requisitos mínimos. Além disso, define as quatro fases da estrutura metodológica: definição de objetivo e escopo, análise de inventário, avaliação de impactos e interpretação dos resultados (ABNT, 2009a).

${ }^{1}$ O pensamento do ciclo de vida representa uma abordagem holística, examinando os impactos de um produto a partir da extração e beneficiamento de suas matérias-primas, produção, uso, pós uso e disposição final. 
A fase de Avaliação de Impacto do Ciclo de Vida (AICV) visa ao entendimento e à avaliação da magnitude e significância dos impactos ambientais potenciais de um sistema de produto ao longo do ciclo de vida do produto (ABNT, 2009b). Essa fase deve incluir três elementos obrigatórios:

- Seleção das categorias de impacto, indicadores de categoria e modelos de caracterização;

- Correlação dos resultados do ICV às categorias de impacto selecionadas (classificação);

- $\quad$ Cálculo dos resultados dos indicadores de categoria (caracterização).

$\mathrm{Na}$ caracterização, o impacto potencial é modelado quantitativamente de acordo com o mecanismo ambiental relevante, por categoria de impacto, utilizando um modelo de caracterização previamente selecionado. Através deste são calculados fatores de caracterização específicos que expressam o impacto potencial de um aspecto ambiental em termos da unidade comum do indicador de categoria.

Segundo a Norma NBR ISO 14044, é importante que as categorias de impacto, indicadores de categoria e modelos de caracterização sejam aceitos internacionalmente. Além disso, é importante que o modelo de caracterização seja científica e tecnicamente válido, sendo baseado em um mecanismo ambiental específico e identificável e/ou em observação empírica reprodutível (ABNT, 2009b).

A norma também determina que:

Dependendo do mecanismo ambiental e do objetivo e escopo, convém considerar a diferenciação espacial e temporal do modelo de caracterização que correlaciona os resultados do ICV ao indicador de categoria. (pag. 22 ABNT, 2009b).

Em geral, estes modelos são desenvolvidos na Europa, América do Norte e Japão e apesar de aplicados em todo o mundo, não é possível afirmar que os procedimentos e parâmetros utilizados são capazes de representar e avaliar os potenciais impactos ambientais regionais em todo o mundo (MENDES, 2013).

Este trabalho parte do entendimento de que os modelos de caracterização em AICV atualmente existentes têm sua aplicação mais apropriada para regiões ou países para as quais foram concebidos. Portanto, há a necessidade do desenvolvimento de modelos de 
caracterização e/ou adaptação de modelos existentes, de maneira a representar a realidade brasileira, incluindo categorias de impactos relevantes.

O Programa Brasileiro de Avaliação do Ciclo de Vida (PBACV) tem como alguns de seus objetivos apoiar mecanismos de disseminação de informações sobre o pensamento do ciclo de vida e identificar as principais categorias de impactos ambientais para o Brasil. Dentre os temas abordados no programa está a Avaliação de Impacto do Ciclo de Vida, sendo que algumas das metas definidas envolvem a análise de categorias de impacto e modelos de caracterização relevantes para o Brasil, além de realizar a adequação de metodologias existentes de maneira a obter um método validado aplicável no país (BRASIL, 2010).

Neste sentido destacam-se os impactos ambientais relacionados ao uso da terra, os quais tem sido objeto de investigação e debate na comunidade científica (MÜLLER-WENK, 1998; LINDEIJER, 2000; BAITZ, 2002; PENNINGTON et al., 2004; MILÀ I CANALS et al., 2007; KOELLNER, SCHOLZ, 2008a; SOUZA, 2010; KOELLNER et al., 2013b).

O uso da terra pode causar consequências ambientais que incluem a degradação e erosão do solo, mudanças na disponibilidade de água, perda de biodiversidade, dentre outros. Ao longo dos últimos 25 anos, cerca de $24 \%$ da área global já sofreu declínios na qualidade e produtividade do solo como resultado do uso insustentável da terra. Reconhecendo a relevância destes impactos, a UNEP (2014) apresenta na Figura 1, a situação global em relação à capacidade dos serviços do ecossistema, a degradação do solo e tendências de mudanças. 


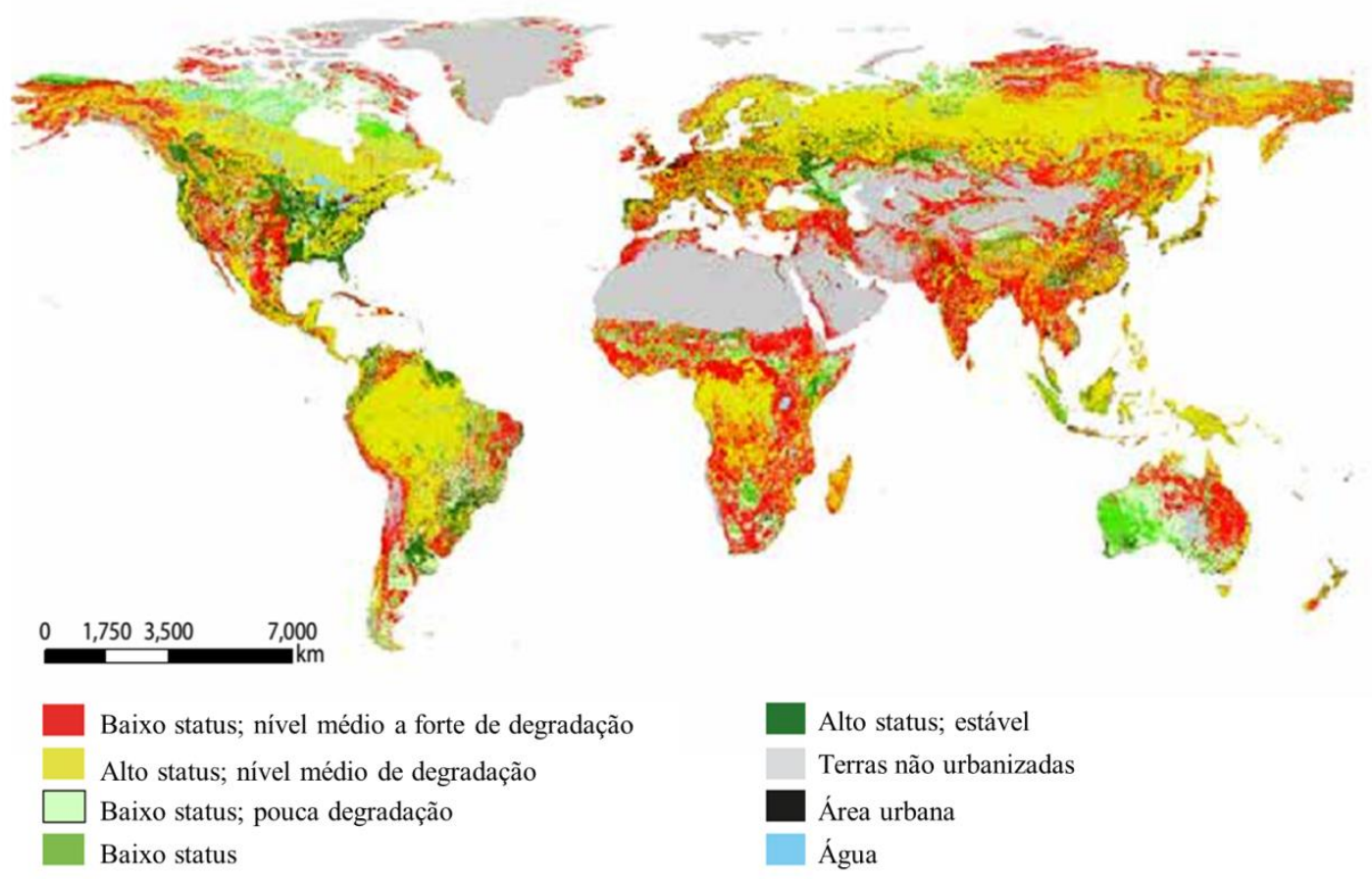

Figura 1: Estado da terra em relação à capacidade dos serviços ecossistêmicos, degradação e tendência de mudanças.

Fonte: UNEP, 2014.

Avaliações publicadas pela UNEP (2012) indicam que em determinadas áreas, a agricultura convencional e intensiva provocam a erosão do solo em uma taxa 100 vezes maior do que a natureza pode regenerar o solo.

Destaca-se, também, que durante os últimos 40 a 50 anos a expansão das terras agrícolas se deu em detrimento das florestas, em especial em regiões tropicais, e indica que a perda de florestas nestas regiões provavelmente irá continuar (UNEP, 2014).

No Brasil o desmatamento e atividades agrícolas são considerados os principais fatores de degradação da terra sendo que em 2012, a área desmatada na Amazônia chegou a 15\%; a conversão do Cerrado para fins de cultivo chegou a 49\% em 2010; a Caatinga perdeu $46 \%$ de sua cobertura vegetal; dos 1,3 milhão de quilômetros quadrados originais da Mata Atlântica, restam cerca de $26 \%$ de sua cobertura vegetal nativa (CUNHA \& GUEDES, 2013) e o Pantanal, 15\% de sua área total em 2009 (GARDI et al., 2014).

Além disso, impactos relacionados às mudanças climáticas devido ao uso da terra são um dos principais desafios deste século. Segundo o PBMC (2013), todos os biomas brasileiros apresentam pontos de vulnerabilidade: 
[...] a) a Mata Atlântica, por sua pequena e fragmentada cobertura florestal remanescente; b) o Cerrado, por sua pequena cobertura de áreas protegidas frente à rápida expansão agrícola; c) a Caatinga, pela degradação ambiental acelerada que em alguns pontos já leva à desertificação; d) o Pantanal, vulnerável a mudanças no seu regime de inundações, principalmente diante dos cenários de seca projetados; e) os Pampas, pelas profundas mudanças de uso da terra combinadas com susceptibilidade à invasoras; e, finalmente, f) a Amazônia, pela demanda de expansão infraestrutural.

Portanto, reconhecendo a diversidade ambiental brasileira e os desafios científicos relacionados à falta de um padrão consensual disponível sobre a avaliação dos impactos do uso da terra formulou-se os objetivos do trabalho apresentados a seguir.

\subsection{Objetivos}

\subsubsection{Objetivo Geral}

O objetivo deste trabalho é analisar a aplicabilidade e a regionalização de modelos de caracterização de impactos do uso da terra para a Avaliação do Impacto do Ciclo de Vida no Brasil.

\subsubsection{Objetivos Específicos}

Para atingir o objetivo geral, os objetivos específicos são:

- Analisar os modelos de caracterização relacionados aos impactos do uso da terra.

- Comparar as características e parâmetros dos modelos de caracterização.

- Indicar as principais tendências metodológicas na avaliação de impactos do uso da terra.

- Fornecer recomendações para a avaliação dos impactos do uso da terra no Brasil. 


\subsection{Estrutura da Dissertação}

A estrutura desde trabalho está dividida em sete capítulos:

- Capítulo 1: apresenta uma breve contextualização do objeto de estudo, a justificativa e os objetivos da pesquisa.

- Capítulo 2: descreve os procedimentos metodológicos adotados no desenvolvimento da pesquisa.

- Capítulo 3: contém a revisão bibliográfica sobre a Avaliação do Ciclo de Vida e sua estrutura metodológica, de maneira a proporcionar a melhor compreensão de termos empregados neste trabalho.

- Capítulo 4: apresenta aspectos conceituais sobre a avaliação dos impactos do uso da terra na ACV.

- Capítulo 5: descreve os principais modelos de caracterização disponíveis para a avaliação de impactos do uso da terra na ACV.

- Capítulo 6: compõe uma análise dos modelos de caracterização descritos no capítulo anterior e recomendações para a avaliação dos impactos do uso da terra no Brasil.

- Capítulo 7: apresenta as conclusões obtidas durante a realização desta pesquisa. 


\section{MATERIAIS E MÉTODOS}

Os materiais que respaldam a elaboração deste trabalho são documentos normativos, guias de órgãos de pesquisa internacionais, livros, dissertações, teses e artigos científicos publicados em periódicos de abrangência internacional. Dentre os documentos normativos e guias destacam-se respectivamente as Normas NBR ISO 14040, NBR ISO 14044, International Reference Life Cycle Data System (ILCD) Handbook - Framework and requirements for Life Cycle Impact Assessment models and indicators (EC-JRC, 2010b) e International Reference Life Cycle Data System (ILCD) Handbook - Recommendations for Life Cycle Impact Assessment in the European context (EC-JRC, 2011).

O procedimento metodológico é composto por duas fases:

- Revisão Bibliográfica Sistemática;

- Análise dos modelos de caracterização para avaliação de impactos do uso da terra e recomendações para aplicação no Brasil.

\subsection{Revisão Bibliográfica Sistemática}

A revisão bibliográfica sistemática pode ser vista como um procedimento de revisão bibliográfica específica desenvolvida de maneira formal, seguindo um protocolo característico de investigação, desenvolvido previamente e que utiliza como fonte de dados estudos já publicados relacionados a determinado tema.

A escolha da revisão bibliográfica sistemática para este trabalho justifica-se pelo fato desta se basear na aplicação de métodos com maior rigor científico, possibilitando alcançar melhores resultados, reduzir erros e o viés do pesquisador responsável pela investigação. Segundo Mulrow (1994), o uso de procedimentos sistemáticos aumenta a confiabilidade e acurácia das conclusões e resultados do estudo.

Ademais, a revisão sistemática permite a compilação de dados, o refinamento de hipóteses e a definição do melhor método de pesquisa para um dado problema. Trata-se de um instrumento para mapear trabalhos publicados no tema de pesquisa específico possibilitando elaborar uma síntese do conhecimento existente sobre o assunto (BIOLCHINI et al., 2007). Para tanto, é necessário adotar um procedimento, um conjunto de passos, técnicas e ferramentas específicas. 
Foi adotado o roteiro desenvolvido para a condução de revisão bibliográfica sistemática de Conforto et al. (2011), intitulado RBS Roadmap, o qual tem base em roteiros existentes, como a proposta de Biolchini et al. (2007) e o modelo de Levy e Ellis (2006).

O roteiro, organizado em quinze etapas distribuídas em três fases (Figura 2) será detalhado a seguir:

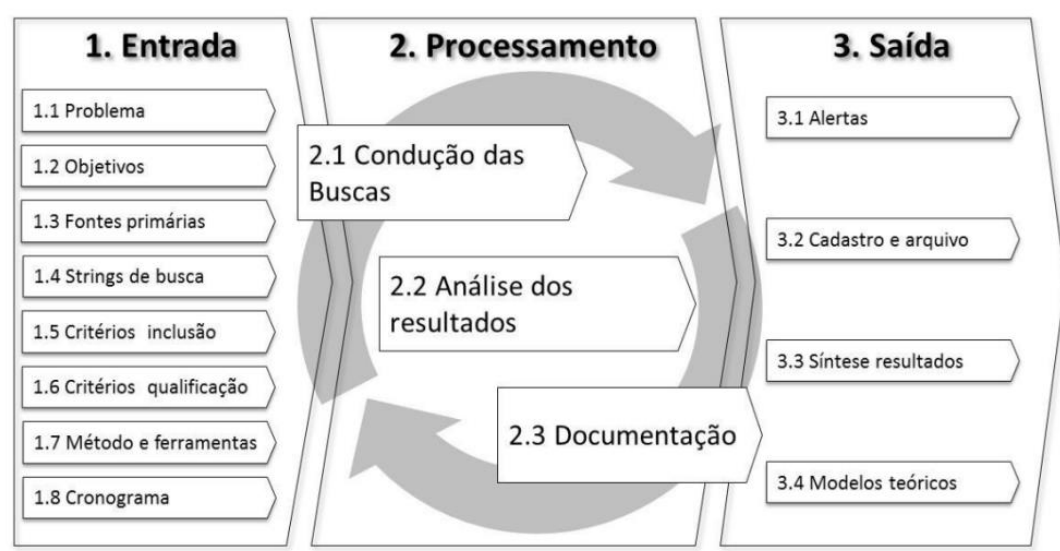

Figura 2: Modelo para a condução da revisão bibliográfica sistemática.

Fonte: Conforto et al. (2011)

- Fase 1: Entrada

○ Etapa 1.1 - Problema

A questão central da pesquisa deve ser definida levando-se em consideração o tipo de evidência que deve ser incluída na revisão. Nesta revisão o problema investigado foi: Quais os modelos de avaliação dos impactos do uso da terra existentes para estudos de ACV?

○ Etapa 1.2 - Objetivos

Os objetivos da revisão devem ser alinhados aos objetivos do projeto de pesquisa e é a partir deles que é possível definir critérios para inclusão dos artigos no estudo. O objetivo definido foi: Identificar os modelos de caracterização de impactos do uso da terra na ACV existentes na literatura e suas principais características. 
○ $\quad$ Etapa 1.3 - Fontes Primárias

Constituem-se de artigos, periódicos ou bases de dados úteis para a identificação dos principais autores e artigos relevantes. Para implementar as estratégias de busca para seleção de estudos primários foi elegida a base de dados Web of Science devido a sua abrangência, o caráter internacional e também por reunir trabalhos que apresentam maior fator de impacto.

- Etapa $1.4-$ Strings de busca

Segundo Conforto et al. (2011) é preciso testar a combinação das palavras e termos, bem como a forma de utilização dos operadores lógicos. Algumas palavras-chave relevantes foram identificadas para a revisão sendo posteriormente empregadas na formulação dos strings. São elas: Biodiversity, Land Use, Indicators, Life Cycle Assessment (LCA), Life Cycle Impact Assessment (LCIA), Methodology, Erosion, Occupation and Transformation of land, Land use change e impact assessment. O Quadro 1 apresenta os strings de busca resultantes da combinação destas expressões.

\begin{tabular}{|c|c|}
\hline \multicolumn{2}{|c|}{ Strings de busca utilizados } \\
\hline LCA AND Biodiversity & LCIA AND Biodiversity \\
\hline LCA AND Land Use & LCIA AND Land Use \\
\hline LCA AND Land Use Change & LCA AND Indicators AND Land Use \\
\hline LCA AND Land Use AND Characterization & LCIA AND Occupation AND Transformation \\
\hline LCA AND Land Use AND Methodology & LCA AND Impact indicator AND Erosion \\
\hline
\end{tabular}

Quadro 1: Strings de pesquisa.

○ Etapa 1.5 - Critérios de inclusão

Foram considerados os objetivos da pesquisa para a definição dos filtros de leitura. Para realizar as análises foi adotado como critério de inclusão tanto estudos de aplicação e estudos de caso, ou seja, aqueles que descrevem a avaliação dos impactos do uso da terra, quanto propostas de novas metodologias de avaliação. 
○ Etapa 1.6 - Critérios de qualificação

Foram empregados critérios referentes à disponibilidade online do trabalho completo além da seleção de materiais na língua inglesa.

○ Etapa 1.7 - Método e ferramentas

A definição do método de busca envolve definir as etapas para a condução das buscas, definir os filtros de busca, como os resultados serão armazenados, etc. Foi adotado o software EndNote $\mathrm{Web}^{\circledR}$ como gerenciador de referências bibliográficas uma vez que permite a importação direta das referências a partir de pesquisas elaboradas na base de dados utilizada.

- Etapa 1.8 - Cronograma

Segundo Conforto et al. (2011) é necessário definir um cronograma para a realização da revisão com uma estimativa de prazo. A realização desta revisão se deu em dez meses.

\section{- Fase 2: Processamento}

○ Etapa 2.1 - Busca

Esta etapa consistiu nas buscas realizadas na base de dados e a imediata exportação dos resultados.

- Etapa 2.2 - Análise dos resultados

Nesta etapa os dados são avaliados de acordo com os critérios anteriormente estabelecidos através dos seguintes filtros de leitura (Figura 3):

- Filtro 1 - Leitura do título, palavras-chave e abstract.

- Filtro 2 - Leitura da introdução e conclusão

- Filtro 3 - Leitura completa 


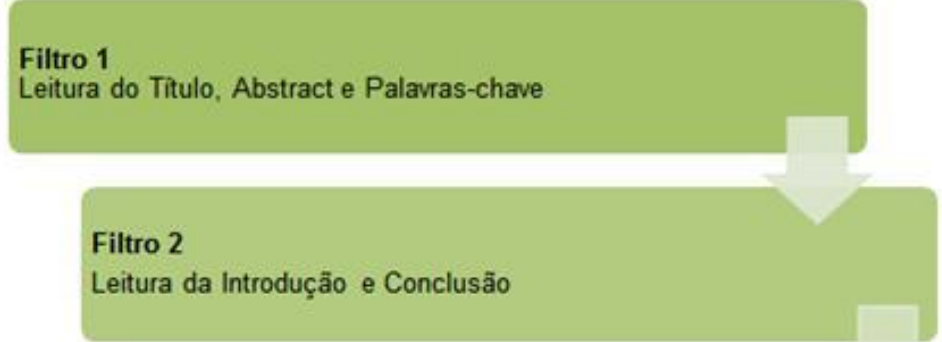

\section{Filtro 3}

Leitura completa dos estudos

\section{Artigos catalogados}

Figura 3: Filtros do procedimento de análise da Revisão Bibliográfica Sistemática.

\section{○ Etapa 2.3 - Documentação}

As informações foram armazenadas com a ajuda da ferramenta Excel, sendo cadastradas de acordo com os campos: $N^{o}$ de identificação do artigo, Autor(es), Título, Fonte, Ano e Abstract.

Cabe salientar uma das vantagens do modelo de Conforto et al. (2011) refere-se aos ciclos na fase de processamento enfatizando a evolução gradual da revisão e proporcionando a inserção de novos estudos na revisão.

- Fase 3: Saída

○ Etapa 3.1 - Alertas

Consistiu na inserção de "alertas" nos principais periódicos identificados durante a condução da revisão, de maneira que é possível receber avisos sobre artigos publicados em futuras edições. Tal ferramenta é útil para rastrear novos artigos e atualizar o repositório de artigos da pesquisa. 
- Etapa 3.2 - Cadastro e arquivo

Os trabalhos selecionados e analisados foram incluídos no repositório de artigos da pesquisa e armazenados no EndNote $\mathrm{Web}^{\circledR}$.

○ Etapa 3.3 - Síntese e Resultados

Nesta etapa foi elaborada a síntese da bibliografia estudada, sendo descritos dezesseis modelos de caracterização.

\subsection{Análise dos modelos de caracterização para avaliação de impactos do uso da} terra e recomendações para aplicação no Brasil.

Esta segunda etapa tem como objetivo descrever as características dos principais modelos de caracterização identificados na revisão bibliográfica, a fim de promover uma análise da aplicabilidade e regionalização destes modelos.

Esta descrição foi realizada com base na revisão bibliográfica sistemática e na leitura dos materiais indicados anteriormente, de modo a abordar as características técnicas indicadas a seguir. A partir disto elaboraram-se três quadros de maneira a comparar os modelos de caracterização.

Em um primeiro momento foram indicados quais impactos ambientais são avaliados em cada modelo bem como através de qual mecanismo ambiental esta avaliação é feita. Além disso, foi verificada a abordagem do modelo de caracterização, podendo ser: abordagem endpoint, quando vários passos são considerados entre as alterações do meio ambiente e o impacto final; ou abordagem midpoint, quando se refere a pontos intermediários de medição ao longo da cadeia causal do impacto. Foram também indicadas as intervenções avaliadas pelos modelos, a saber: ocupação da terra (utilização de uma área, por uma atividade, em um determinado tempo) e transformação da terra (mudanças na qualidade da terra, decorrentes da alteração do tipo de ocupação). Foi verificado também se o modelo de caracterização faz parte de algum dos métodos de AICV reconhecido internacionalmente e amplamente utilizados segundo o Programa Iniciativa do Ciclo de Vida (UNEP, 2010). Por fim, foi averiguada a abrangência do escopo de aplicação de cada um dos modelos, classificando-a em global, 
continental (neste caso o nome do continente abordado é indicado) ou nacional (neste caso o nome do país abordado é indicado).

Posteriormente, foi realizada a síntese desses itens em um quadro de acordo com a Figura 4.

\begin{tabular}{|l|c|c|c|c|c|c|}
\hline Modelo & $\begin{array}{c}\text { Impacto ambiental } \\
\text { avaliado }\end{array}$ & $\begin{array}{c}\text { Mecanismo } \\
\text { ambiental utilizado }\end{array}$ & $\mathbf{M} / \mathbf{E}^{1}$ & $\mathbf{O} / \mathbf{T}^{2}$ & $\begin{array}{c}\text { Implementado } \\
\text { em }\end{array}$ & $\begin{array}{c}\text { Abrangência } \\
\text { de aplicação }\end{array}$ \\
\hline & & & & & & \\
\hline
\end{tabular}

Figura 4: Modelo de quadro síntese das características analisadas.

${ }^{1}$ Abordagem midpoint/ endpoint

2 Ocupação/ Transformação

Em seguida, foram avaliadas características como a área utilizada para a coleta dos dados e a diferenciação bio-geográfica empregada em cada modelo de caracterização. Esta última se refere ao nível de detalhamento das áreas consideradas para os fatores de caracterização, podendo ser: biomas, ecorregiões, ecozonas, regiões climáticas e países. Outro fator considerado nesta etapa foi o tempo de recuperação da terra após ocupação por determinada atividade para atingir um nível de qualidade específico, considerado em cada modelo. Por fim, foram indicadas as escolhas para a situação de referência de cada modelo, ou seja, a situação definida para a comparação de impactos de transformação e ocupação, em termos de qualidade da terra. Ressalta-se que as definições e exemplificações destes itens citados acima se encontram no Capítulo 4. A síntese desta análise foi elaborada na forma de um quadro, como visto na Figura 5.

\begin{tabular}{|l|l|l|l|l|}
\hline Modelo & Área de coleta & $\begin{array}{c}\text { Diferenciação bio- } \\
\text { geográfica }\end{array}$ & $\begin{array}{c}\text { Tempo de } \\
\text { recuperação }\end{array}$ & Situação de referência \\
\hline & & & & \\
\hline
\end{tabular}

Figura 5: Modelo de quadro usado na síntese dos parâmetros dos modelos de caracterização.

Por fim, a partir da revisão bibliográfica foram identificados artigos científicos, trabalhos e manuais que apresentam na pesquisa critérios e orientações para a avaliação específica de impactos do uso da terra. Assim, as recomendações encontradas em Bare 
(2011), EC-JRC (2010b) e EC-JRC (2011) foram definidas como requisitos para a análise dos pontos fortes e fracos dos modelos de caracterização durante a análise da robustez científica e relevância ambiental.

Cada um destes requisitos foi verificado de maneira a apontar sua conformidade ou não; como por exemplo, se os autores apresentam um modelo de caracterização específico e de base científica, ou seja, se seus pressupostos e dados usados possuem um respaldo científico. Também são considerados requisitos referentes à dependência do local onde ocorre o impacto e a inclusão de parâmetros relacionados à duração da transformação/ocupação da terra. Ainda pensando sobre a dependência do local e representatividade do mesmo, um requisito foi delimitado de maneira a distinguir modelos de abrangência de aplicação global daqueles que se limitam à áreas específicas. Outros requisitos como estar disponível para implementação e considerar intervenções de ocupação e transformações também foram incluídos nesta etapa. Ademais, são listados requisitos referentes à impactos específicos do uso da terra como: considerar efeitos nas alterações climáticas, considerar efeitos na produção primária líquida, considerar a perda de biodiversidade devido à alteração na composição de espécies, considerar mudanças quantitativas na fauna e flora e considerar mudanças físicas no solo.

A etapa seguinte, de elaboração das recomendações para subsidiar a aplicação no Brasil, consistiu da análise das informações obtidas na etapa anterior. Assim, os modelos de caracterização foram analisados de acordo com cada via de impacto ambiental, segundo sua representatividade do local do uso da terra. Além disso, seus pontos fortes e fracos foram confrontados na análise de robustez científica e relevância ambiental, de maneira a indicar aqueles que apresentem em sua maioria pontos fortes.

Já na etapa final deste trabalho, tendo em vista a necessidade de adaptações de modelos de caracterização para o contexto brasileiro, o conjunto de requisitos apresentados anteriormente foi examinado de modo a identificar oportunidades de regionalização nos modelos, através da identificação de parâmetros que possibilitam a inserção de dados regionalizados. Esta etapa, somada à extensa revisão bibliográfica conduzida anteriormente, subsidiou também a adaptação de um guia metodológico que sintetiza elementos chave para a avaliação dos impactos do uso da terra e possíveis fontes de dados para os parâmetros que dependem das condições específicas do local de aplicação. 


\begin{tabular}{|c|c|c|}
\hline \multirow{2}{*}{ Requisitos } & \multicolumn{2}{|c|}{ Critérios } \\
\hline & Pontos fortes & Pontos fracos \\
\hline Uso de um modelo específico e com base científica. & $\begin{array}{l}\text { Usa um modelo específico e se respalda em } \\
\text { publicações científicas }\end{array}$ & $\begin{array}{l}\text { Não apresenta um modelo específico e/ou referências } \\
\text { científicas }\end{array}$ \\
\hline $\begin{array}{c}\text { O modelo deve ser o mais reprodutível e mais transparente } \\
\text { possível. }\end{array}$ & $\begin{array}{c}\text { Não apresentar obstáculos quanto à sua reprodução } \\
\text { ou acesso às informações. }\end{array}$ & $\begin{array}{c}\text { Apresentar obstáculos quanto à sua reprodução ou } \\
\text { acesso às informações. }\end{array}$ \\
\hline $\begin{array}{l}\text { O modelo deve ser loco-específico, pois a modelagem é } \\
\text { altamente depende de parâmetros de entrada que são } \\
\text { característicos do local. }\end{array}$ & Ser loco-específico & Não ser loco-específico \\
\hline $\begin{array}{l}\text { O modelo deve ser temporalmente específico. A duração da } \\
\text { transformação, os tempos de ocupação e o tempo de recuperação } \\
\text { devem ser incluídos. }\end{array}$ & Ser temporalmente específico. & Não ser temporalmente específico. \\
\hline $\begin{array}{l}\text { O modelo deve cobrir de preferência o país, ou ter escopo de } \\
\text { aplicação global. }\end{array}$ & Ter escopo de aplicação global. & Ser limitado à uma região ou país específico. \\
\hline Estar pronto para implementação nos próximos anos. & Estar disponível para utilização. & $\begin{array}{l}\text { Não estar disponível para uso, necessitando de } \\
\text { melhorias. }\end{array}$ \\
\hline Considerar a transformação e a ocupação da terra. & Considerar os dois tipos de intervenção. & Considerar apenas um tipo de intervenção. \\
\hline Considerar as mudanças quantitativas na fauna e flora. & $\begin{array}{l}\text { Considera os efeitos das mudanças quantitativas tanto } \\
\text { na fauna quanto na flora. }\end{array}$ & Considerar apenas um dos impactos. \\
\hline Considerar as mudanças físicas no solo. & Considerar as mudanças físicas no solo. & Não considerar as mudanças físicas no solo. \\
\hline $\begin{array}{l}\text { Considerar os efeitos nas alterações climáticas devido a } \\
\text { mudanças nos teores de } \mathrm{CO}_{2}, \mathrm{~N}_{2} \mathrm{O} \text { e } \mathrm{CH}_{4} \text {. }\end{array}$ & Considerar os efeitos nas alterações climáticas. & Não considerar os efeitos nas alterações climáticas. \\
\hline $\begin{array}{l}\text { Considerar os efeitos na produção primária líquida devido a } \\
\text { alterações nas funções do solo ou composição de espécies. }\end{array}$ & $\begin{array}{l}\text { Considera os efeitos na produção primária líquida } \\
\text { devido a alterações nas funções do solo ou } \\
\text { composição de espécies. }\end{array}$ & $\begin{array}{l}\text { Não considera os efeitos na produção primária líquida } \\
\text { devido a alterações nas funções do solo ou } \\
\text { composição de espécies. }\end{array}$ \\
\hline $\begin{array}{l}\text { Considerar a perda de biodiversidade devido à alteração da } \\
\text { composição de espécies. }\end{array}$ & $\begin{array}{l}\text { Considera o efeito da perda de biodiversidade devido } \\
\text { à alteração da composição de espécies. }\end{array}$ & $\begin{array}{l}\text { Não considera o efeito da perda de biodiversidade } \\
\text { devido à alteração da composição de espécies. }\end{array}$ \\
\hline
\end{tabular}

Quadro 2: Conjunto de critérios utilizados para a avaliação da robustez científica e relevância ambiental dos modelos de caracterização. Adaptado de Bare (2011), EC-JRC (2010b) e EC-JRC (2011). 


\section{REVISÃO BIBLIOGRÁFICA}

\subsection{Avaliação do Ciclo de Vida}

Ao longo dos últimos anos tem aumentado consideravelmente o interesse da maioria das empresas mundiais em avaliar os impactos que suas atividades exercem no meio ambiente bem como preveni-las. Com o avanço dos estudos relacionados ao meio ambiente alinhado ao surgimento do modelo de desenvolvimento sustentável fica evidente a maior preocupação com tal questão e a conscientização pela utilização dos recursos naturais de forma ambientalmente consciente.

Além destes esforços, novas tecnologias de produção mais "limpas" vêm sendo desenvolvidas, porém, tomadas de decisão pontuais são insuficientes para minimizar de maneira substancial os impactos adversos gerados pelas atividades humanas.

Assim, a ACV é uma importante metodologia para avaliar os possíveis impactos associados aos produtos, não somente na fase de fabricação, mas sim, com foco onde os impactos realmente prevalecem, tendo em vista todo o ciclo de vida do produto, desde a extração de matérias-primas, passando pelas etapas de produção, distribuição e utilização, até sua destinação final (ABNT, 2009a).

Os estudos de ACV tiveram início na década de 60, com a crise do petróleo, que levou a sociedade a se questionar sobre o limite da extração dos recursos naturais, especialmente combustíveis fósseis e recursos minerais. Os primeiros estudos tinham por objetivo calcular o consumo de energia e, por isso, eram conhecidos como "análise de energia" (energy analysis). Tais estudos envolviam a elaboração de um fluxograma de processo com balanço de massa e de energia. Assim, eram contabilizados automaticamente tanto dados sobre consumo de matérias-primas e de combustíveis, quanto os resíduos sólidos gerados. Por esta razão, alguns analistas se referiam a estes estudos como "análise de recursos" (resources analysis) ou “análise do perfil ambiental” (environmental profile analysis) (COLTRO, 2007).

O interesse pela ACV cresceu a partir de 1985, quando a ACV foi escolhida pela Comunidade Europeia para o auto monitoramento de consumos de matéria e energia nas empresas (RIBEIRO, 2003). Esta expansão nos estudos de ACV também foi impulsionada pela normalização implementada pela série de normas ISO 14040, sendo que no Brasil essas normas foram editadas pela Associação Brasileira de Normas Técnicas (ABNT).

Um dos princípios fundamentais da técnica refere-se exatamente à perspectiva de ciclo de vida e sua abordagem sistemática, o que possibilita que transferências de cargas ambientais 
potenciais entre os estágios do ciclo de vida possam ser identificados e até mesmo evitados (ABNT, 2009a). Além disso, o emprego da ACV possibilita melhorias ou alternativas para produtos, processos ou serviços.

A estrutura metodológica da ACV, padronizada pela International Organization for Standardization (ISO) através das normas ISO 14.040 e ISO 14.044, consiste em quatro fases e o relacionamento entre essas fases é ilustrado na Figura 6. No Brasil, as normas correspondentes são: ABNT NBR ISO 14.040:2009 e ABNT NBR ISO 14.044:2009.

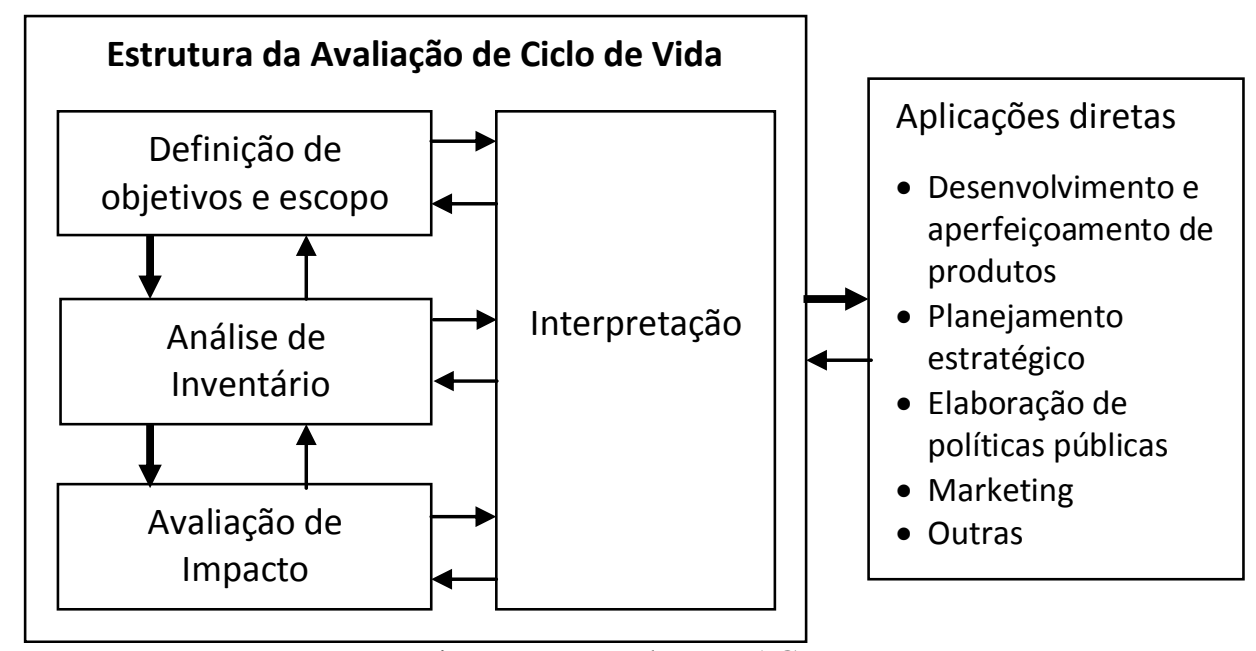

Figura 6: Fases de uma ACV.

Fonte: ABNT (2009a).

A primeira fase da ACV especifica os procedimentos necessários para a definição do objetivo e do escopo do estudo, de forma clara e consistente, de acordo com a aplicação almejada. O objetivo do estudo deve retratar as razões da execução do mesmo e buscar a identificação dos pontos críticos e a aplicação destinada a determinado público alvo.

A fase de análise de Inventário do Ciclo de Vida (ICV) é a segunda fase de uma ACV. Trata-se de um inventário dos dados de entrada e saída associados ao sistema em estudo. $\mathrm{O}$ ICV envolve os procedimentos de coleta de dados e de cálculo. As informações adquiridas, referentes aos fluxos de entrada e saída, devem estar relacionadas à unidade funcional, estabelecida na fase anterior.

A Avaliação de Impacto do Ciclo de Vida (AICV), terceira fase da ACV, corresponde ao processo quantitativo e/ou qualitativo aplicado na caracterização dos impactos associados ao inventário do ciclo de vida. De acordo com a norma NBR ISO 14040 (2009a) compreende elementos obrigatórios e opcionais (Figura 7). 


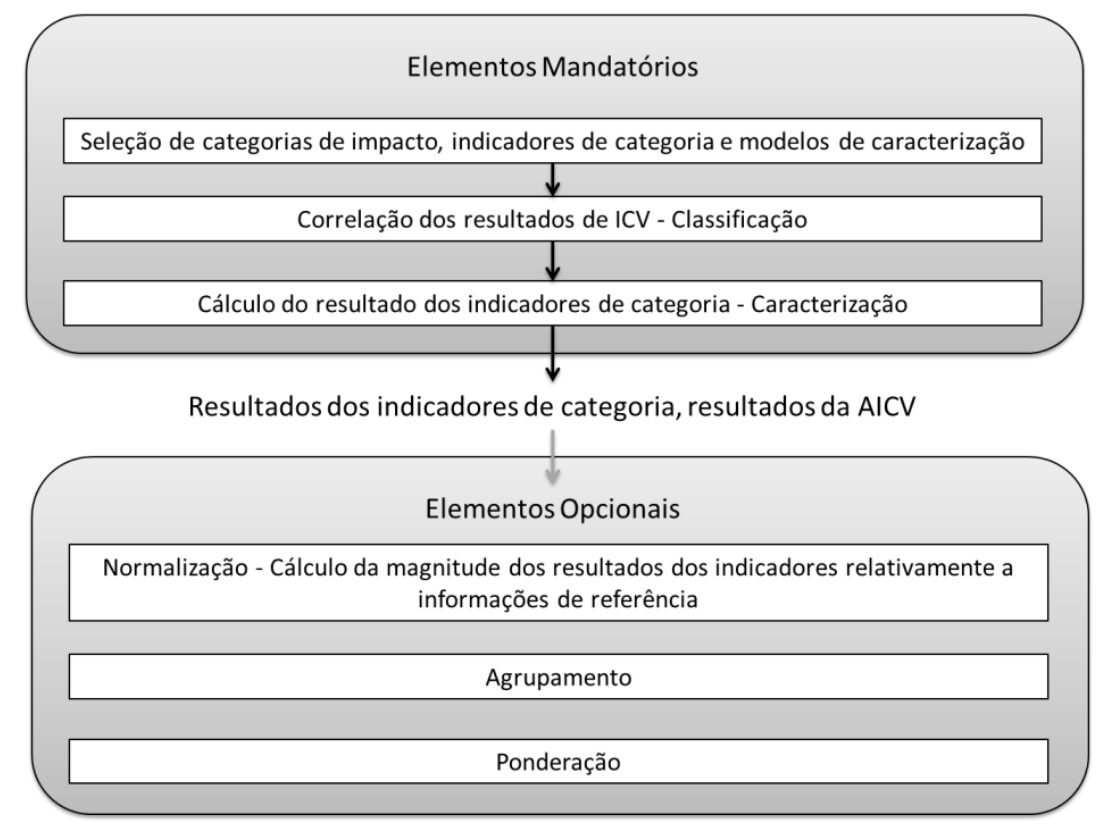

Figura 7: Elementos da AICV.

Fonte: ABNT, 2009a.

De acordo com a norma NBR ISO 14.040 (ABNT, 2009a), os elementos opcionais consistem na normalização, agrupamento e ponderação. A primeira corresponde ao cálculo da magnitude dos resultados dos indicadores de categoria relativamente a informações de referência. O segundo elemento de realização facultativa, o agrupamento, envolve a ordenação dos resultados caracterizados, e normalizados, em um ou mais conjuntos. Estes conjuntos podem, por exemplo, fazer referência à escala espacial das categorias (global, regional ou local) ou à hierarquia seguida (prioridade alta, média ou baixa). Já a ponderação consiste na atribuição de pesos (fatores de ponderação) a cada categoria de impacto ou conjunto, destacando sua importância com relação aos demais.

Por fim, a última fase do estudo de ACV refere-se à Interpretação dos dados e resultados, na qual é feita a combinação dos resultados da avaliação de impactos e os dados do inventário, a fim de obter conclusões e recomendações. 


\subsection{Avaliação de Impacto do Ciclo de Vida}

Este estudo tem como foco a terceira fase da $\mathrm{ACV}$, portanto, para se compreender a estrutura dos modelos de caracterização de impactos é importante conhecer os termos utilizados em AICV.

Os impactos podem ser avaliados de acordo com inúmeras categorias de problemas ambientais estabelecidas em escalas geográficas distintas. Algumas das categorias de impacto são aceitas internacionalmente, bem como seus modelos de caracterização, como é o caso do Potencial de Aquecimento Global, indicador da categoria "mudança climática" sugerido pelo International Panel on Climate Change (IPCC) (SOUZA, 2008).

A norma NBR ISO 14.044 (ABNT, 2009b) não especifica as categorias de impacto a serem incluídas em métodos de AICV. Segundo Klöpffer (1998) esta abertura é dada principalmente porque novos conceitos acerca de riscos ambientais surgem com o avanço do conhecimento científico.

Devido à complexidade da cadeia causal, vários passos são considerados entre as alterações do meio ambiente e o impacto final (também chamado de endpoint). Tais pontos intermediários de medição ao longo da cadeia causal são chamados de pontos médios (ou midpoint). O ponto final faz referência a uma Área de Proteção que designa entidades de interesse para a sociedade, como a saúde humana, recursos naturais ou a qualidade do ambiente natural. As categorias midpoint podem receber diferentes classificações, sendo a mais utilizada àquela que distingue categorias globais, regionais e/ou locais.

De acordo com Udo de Haes et al., (2002) as categorias globais são aquelas em que o impacto é gerado por poluentes que se dispersam globalmente e para as quais nenhuma relação pode ser estabelecida entre a localização geográfica da emissão e o impacto resultante. Já no caso de categorias regionais / locais os impactos estão diretamente associados às condições ambientais do local de ocorrência, como por exemplo: oxidação fotoquímica, acidificação, eutrofização, toxicidade humana, ecotoxicidade e uso da terra.

Como mostrado anteriormente, a AICV é constituída de três etapas obrigatórias, as quais serão descritas a seguir. 


\subsubsection{Seleção de categorias de impacto}

Esta etapa constitui a escolha e definição de categorias de impacto e seus indicadores, além dos modelos de caracterização. Isto deve ser fundamentado no conhecimento científico dos mecanismos ambientais e processos analisados. Dentre as categorias de impacto presentes em métodos existentes, pode-se citar: mudança climática, eutrofização, ecotoxicidade e acidificação.

\subsubsection{Classificação de dados de dados do inventário do ciclo de vida}

Nesta etapa é feita a correlação dos resultados do ICV às categorias de impacto selecionadas. A classificação é, portanto, qualitativa, baseada na análise científica dos aspectos ambientais. Para Steen (1999) esta etapa não só reconhece a existência de um mecanismo ambiental que conecta entradas e saídas de uma dada atividade com as categorias de impacto, como também indica que tal mecanismo causa ou poderá causar impactos ao meio ambiente em uma extensão reconhecida.

\subsubsection{Caracterização dos impactos}

A representação quantificável do impacto de uma categoria é dada pelo indicador de cada uma destas. $\mathrm{O}$ indicador representa o potencial de impacto ou dano que pode ser causado durante o ciclo de vida de um produto.

O cálculo dos resultados dos indicadores (caracterização) se dá pela conversão dos resultados do ICV para unidades comuns e agregação dos resultados convertidos em uma mesma categoria de impacto (ABNT, 2009b). Ao contrário da classificação, que é qualitativa, este é um processo quantitativo. Nesta etapa, portanto, as contribuições das diferentes substâncias para cada categoria de impacto são quantificadas por meio de modelos e fatores de caracterização.

A simplificação da realidade e a previsão dos impactos potenciais em ecossistemas se dão por modelos matemáticos, denominados modelos de caracterização. A caracterização do impacto gerado por dado fluxo elementar ao meio ambiente deve levar em consideração suas características físicas, químicas e biológicas. 
Segundo a ABNT (2009b) os modelos de caracterização devem ser internacionalmente aceitos e científica e tecnicamente válidos. Estes são necessários para o cálculo dos fatores de caracterização: valores que possibilitam avaliar a magnitude dos impactos potenciais de cada uma das substâncias em uma dada categoria (CURRAN, 1996 apud SOUZA, 2010).

\subsubsection{Métodos de AICV e Regionalização}

As normas ISO 14.040 e ISO 14.044 definem os procedimentos gerais para conduzir uma $\mathrm{ACV}$, mas não indicam o método que deve ser utilizado para cada caso. Assim, diversos métodos foram desenvolvidos em diferentes países. A região europeia se destaca contendo várias proposições de métodos de avaliação, muitos deles considerando especificidades geográficas regionais ou mesmo locais em algumas das categorias de impacto selecionadas. Dentre estes se destacam os holandeses ReCiPe (DE SCHRYVER; GOEDKOOP, 2009), CML (GUINÉE et al., 2002) e Ecoindicator 99 (GOEDKOOP; SPRIENSMA, 2001); o dinamarquês EDIP 2003 (HAUSCHILD; POTTING, 2005); o suíço IMPACT 2002+ (JOLLIET et al., 2003); e o sueco EPS (STEEN, 1999).

Há também o método denominado TRACI (BARE, 2003), desenvolvido a fim de possibilitar uma diferenciação geográfica para os Estados Unidos da América. Além destes, o Japão conta com o chamado método LIME (ITSUBO; INABA, 2003).

Devido à especificidade regional desses métodos, restrita à Europa, Estados Unidos e Japão, esforços crescentes vem surgindo visando o desenvolvimento de novos métodos ou aperfeiçoamento daqueles já existentes. Como exemplo tem-se o método canadense LUCAS (TOFFOLETTO et al., 2007).

O problema da falta de diferenciação espacial na modelagem de impactos é especialmente grave no caso de categorias de impacto que não são globais, como acidificação, eutrofização, uso da terra, oxidação fotoquímica e toxicidade. Isto porque a AICV geralmente utiliza condições locais incompletas para a avaliação de efeitos potenciais para categorias de impacto regionais e locais (OWENS, 1998). Além disso, para Udo de Haes et al. (2002), a ausência e/ou deficiência de dados de inventário é uma das maiores causas da deficiência na distinção espacial.

O termo regionalização, no contexto da AICV refere-se à especificidade espacial de um dado impacto e suas características, ou seja, à consideração de variações expressivas nos impactos, entre diferentes regiões geográficas (ROSENBAUM et al., 2008). 
A maioria dos métodos de AICV desenvolvidos atualmente visa à modelagem locodependente, que realiza a distinção entre categorias de fontes poluentes e seu impacto ao meio ambiente. Neste tipo de modelagem a caracterização envolve a influência de variações causadas em diferentes regiões, de acordo com a categoria de fonte poluente, por meio de análises de exposição e tolerância do meio atingido (HAUSCHILD; POTTING, 2005).

Ainda segundo os mesmos autores, existem também modelagens que consideram que todas as fontes poluentes contribuam para o mesmo ambiente receptor. Em outras palavras, não é realizada a diferenciação espacial em relação às fontes emissoras e ao ambiente receptor.

Já um terceiro tipo de modelagem, loco-específica, inclui informações precisas com relação às fontes emissoras situadas ou próximas ao local impactado. Todavia, tal precisão requer informações detalhadas em relação a todas as emissões que atingem o local em estudo e geralmente esta modelagem não é aplicada. 


\section{O USO DA TERRA NA AVALIAÇÃO DE IMPACTO DO CICLO DE VIDA}

A partir da revisão bibliográfica conduzida neste trabalho foi possível não só sintetizar as informações disponíveis na literatura sobre a avaliação dos impactos do uso da terra como também apontar orientações sobre os principais tópicos relacionados ao tema aos praticantes da ACV.

O termo "uso da terra", segundo Choudhury e Jansen (1999) consiste principalmente nas intervenções humanas em um determinado tipo de cobertura terrestre para nele realizar modificações, produzir ou manter seu estado.

Já para Bie; Leeuwen; Zuidema (1996), o termo, está associado às atividades realizadas pelo homem numa dada extensão de terra ou um ecossistema, com o objetivo de obter através do uso dos recursos da terra, benefícios e produtos.

É possível compreender que as nomenclaturas "uso do solo" e "uso da terra", são utilizadas para designar uma mesma ação - a da apropriação do espaço pelo homem para um determinado fim - sendo que nesta pesquisa o termo adotado conceitualmente é uso da terra.

No campo da ACV, o termo refere-se a "um tipo específico de intervenção ambiental, definido nos resultados do inventário do ciclo de vida, o qual ocasionará modificações na habilidade do solo em realizar suas funções” (MILÀ i CANALS, 2003).

Goedkoop et al. (2013) ressaltam a importância em se distinguir: i) impactos do uso da terra quando se trata dos impactos ambientais potenciais, e ii) uso da terra nas formas de ocupação e transformação de maneira análoga a uma emissão ou a extração de recursos naturais, ou seja, quando são itens que aparecem na análise de inventário.

Ao lidar com o uso da terra no ICV, as intervenções são relacionadas ao uso de uma área de terra para determinados fins, como:

- Extração de matérias-primas (mineração);

- Processos de produção (terras agrícolas, área do território industrial);

- Transporte (estradas);

- Processos de uso (área residencial, área de lazer);

- Processos de tratamento de resíduos (aterros sanitários, área de incineração).

Já as consequências do uso da terra estão relacionadas a diferentes tipos de impactos ambientais visto que influencia a biodiversidade e a estrutura e funções dos ecossistemas, o que será discutido ao longo deste trabalho. 
A Figura 8 apresenta um esquema das mudanças na qualidade da terra. $\mathrm{O}$ eixo vertical representa a qualidade da terra, podendo ser expressa por meio de diferentes indicadores (como apresentado adiante). Passada a ocupação, não estando mais sujeita a intervenções humanas, a área tem a possibilidade de se recuperar (t3 a t4 na Figura 8) e uma nova forma de uso passa a ocorrer. Este processo de aumento natural da qualidade é denominado recuperação da terra (SOUZA, 2010).

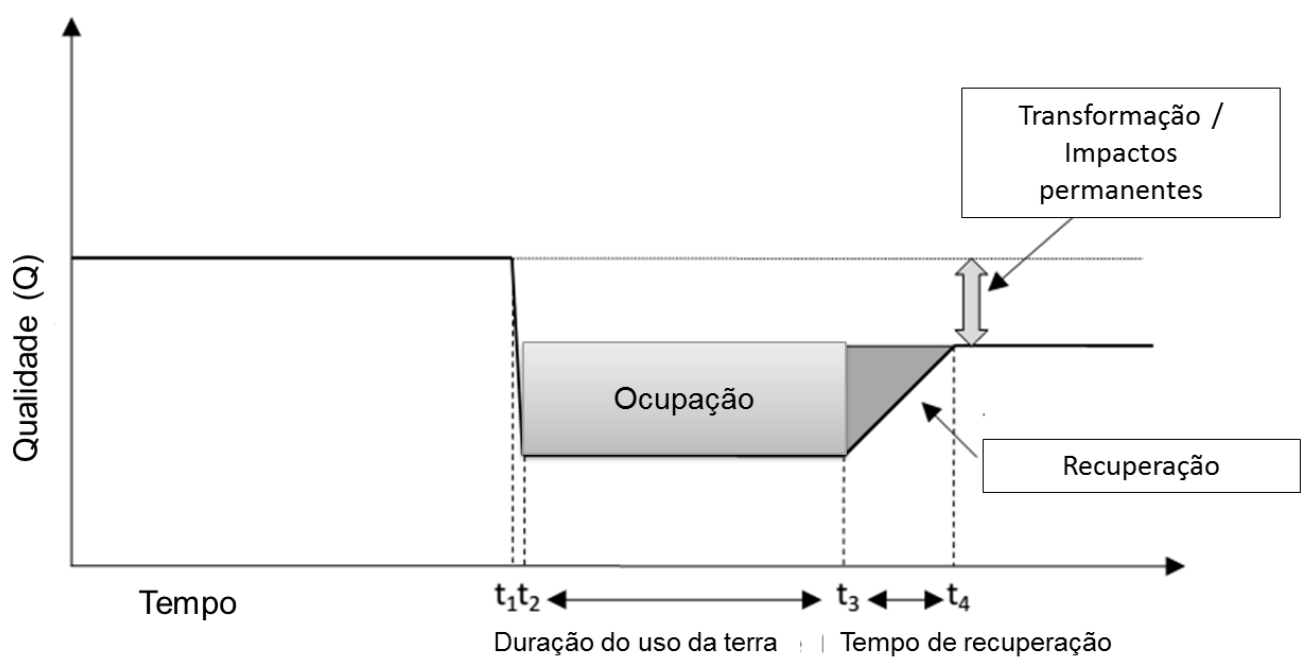

Figura 8: Representação dos impactos decorrentes da ocupação e transformação da terra.

\subsection{O uso da terra no Inventário do Ciclo de Vida}

$\mathrm{Na} A C V$, a ocupação e transformação da terra podem ser distinguidas como dois tipos básicos de fluxos elementares de uso da terra (MILÀ I CANALS et al., 2007) sendo que resultam em danos ou benefícios para a qualidade do ecossistema. Assim, a transformação da terra provoca uma mudança na qualidade do ecossistema e a ocupação provoca o atraso na recuperação de tal qualidade.

A fim de avaliar estes impactos na ACV, é necessário registrar no ICV o tipo de uso da terra, a extensão espacial, a extensão temporal e a localização geográfica (MILÀ I CANALS et al., 2007). No inventário, o fluxo elementar do uso da terra é especificado da seguinte forma:

- Para ocupação da terra: $\mathrm{m}^{2} \times$ anos, tipo de uso da terra $i$, e região $k$.

- Para transformação da terra: $\mathrm{m}^{2}$, tipo inicial de uso da terra $i \rightarrow$ tipo de uso da terra final $j$, e região $k$. 
Para o desenvolvimento prático da ACV, é fundamental definir como classificar o uso da terra e como registrar o local do uso. A fim de permitir a troca de dados entre inventários é, portanto, desejável a padronização da classificação e regionalização do uso da terra (KOELLNER et al., 2013b).

Além disso, para uma avaliação com abrangência global é importante utilizar uma classificação abrangente dos usos da terra e coberturas terrestres resultantes. Este sistema tem de ser aplicável a uma escala global permitindo a comparação de produtos e serviços similares provenientes de diferentes partes do mundo.

Os conceitos de uso e cobertura da terra (sistemas naturais e/ou antrópicos) possuem grande relação entre si. Di Gregorio e Jansen (2005) definem a cobertura da terra como a cobertura (bio)física observada, incluindo a vegetação (natural ou plantada) e construções humanas (edifícios, estradas, etc), que cobrem a superfície da terra. Já o uso da terra é caracterizado pelo regime, atividades e insumos que as pessoas realizam em um determinado tipo de cobertura da terra para produzir, alterar ou mantê-lo. O uso da terra estabelece, então, uma ligação direta entre cobertura vegetal e as ações humanas no seu ambiente.

Assim, os sistemas de classificação de cobertura da terra não só se caracterizam como um instrumento útil para a definição de tipos de transformação e ocupação do solo, como também um ponto importante para a condução da ACV. Segundo Koellner et al. (2013a), a classificação de uso da terra na ACV deve preferencialmente (i) ser derivada de um sistema de classificação da cobertura terrestre amplamente aceito, (ii) distinguir os tipos da cobertura da terra em classes ambientalmente relevantes (indicando também informações sobre a intensidade do uso da terra), e (iii) classificar casos individuais de uso da terra de tal forma que os impactos ambientais causados sejam semelhantes sob determinadas condições biogeográficas.

Existem diferentes projetos que descrevem e classificam a superfície da terra fora do contexto da ACV. Entre os sistemas mais conhecidos destacam-se o sistema Land Cover Classification System (LCCS) (DI GREGORIO \& JANSEN, 2000), vinculado à Food and Agriculture Organization of the United Nations (FAO). Ao mesmo tempo em que é um método de classificação uniforme, ainda oferece flexibilidade para a descrição da cobertura do solo nos níveis nacional e regional. O LCCS foi usado para desenvolver a classificação para dois importantes mapas globais de cobertura terrestre: Global Land Cover 2000 e GlobCover.

O Global Land Cover 2000 (GLC 2000) desenvolveu uma nova classificação global de cobertura da terra, útil para o apoio à decisão para indústrias, governo e organizações não governamentais (BARTHOLOMÉ \& BELWARD, 2005). Tal classificação divide a superfície 
da Terra em 18 regiões. Já o GlobCover tem uma resolução cerca de dez vezes maior (especialmente na Amazônia, onde os padrões de desmatamento podem ser vistos de maneira mais eficaz). Além disso, o GlobCover usa uma classificação totalmente automatizada e reprodutível. Algumas classes de legenda no GlobCover contêm um elevado número de classes de mosaico, o que é uma desvantagem em termos de estudos de ACV. Outra clara desvantagem é a falta de atualizações regulares e frequentes de ambos os mapas globais de ocupação do solo.

Já os modelos europeus desenvolvidos em AICV, frequentemente utilizam a base europeia CORINE para a classificação de diferentes tipos de uso da terra (SOUZA, 2010). O Projeto CORINE Land Cover (EUROPEAN ENVIRONMENTAL AGENCY, 2000) oferece uma classificação detalhada da cobertura terrestre da Europa.

Por fim, o GLOBIO3 é um Modelo da Biodiversidade Global (ALKEMADE et al., 2009), que visa avaliar os impactos das mudanças no uso da terra sobre a biodiversidade terrestre. A classificação da cobertura da terra é baseada no GLC 2000, agregado em sete amplas classes de uso da terra. Para um estudo de ACV, esta classificação pode ser muito ampla para algumas aplicações, mas, por outro lado, pode ajudar a simplificar as classes.

Existem também classificações do uso e cobertura da terra criadas no contexto da ACV. Por exemplo, nos estudos de Koellner (2003), Koellner \& Scholz (2008a) e Koellner \& Scholz (2008b) foi elaborada uma classificação mais detalhada: CORINE Plus, a qual atende melhor os requisitos da $\mathrm{ACV}$. Uma desvantagem, porém, se refere à sua complexidade.

Já a base de dados para ICV Ecoinvent 2.0 contém dados extensos sobre o uso da terra de processos industriais (FRISCHKNECHT \& JUNGBLUTH, 2007). Ele usa uma classificação de terras, que é baseada no CORINE Plus, mas tem um número muito menor de classes de uso do solo. Portanto, sua desvantagem está na omissão de classes. Já a terceira versão desta base de dados se fundamenta na classificação apresentada por Koellner et al. (2013a).

Recentemente foi lançada a nova versão desta base de dados: Ecoinvent $3.0^{2}$, na qual foram adicionadas centenas de conjuntos de dados não europeus. Além disso, a nossa capacidade de regionalização de dados foi aperfeiçoada no banco de dados, de maneira a dar suporte a uma avaliação de impacto regionalizada.

Olson et al. (2001) propuseram uma classificação dos biomas e ecorregiões terrestres e de água doce visando a regionalização dos fluxos elementares de uso da terra. O sistema de

\footnotetext{
${ }^{2}$ http://www.ecoinvent.org/database/ecoinvent-version-3/introduction/
} 
ecorregiões é baseado em um esquema de oito regiões biogeográficas e 14 biomas que são posteriormente divididos em mais de 867 ecorregiões terrestres e de água doce. Cada uma das ecorregiões é descrita e avaliada de acordo com suas propriedades: biodiversidade, condição climática e diversidade de habitats. Além disso, são definidas cerca de 238 ecorregiões, tanto terrestres como de água doce, com maior relevância mundial para a conservação da biodiversidade (OLSON \& DINERSTEIN, 1998).

Já Spalding et al. (2007) desenvolveram uma classificação coerente para os biomas e ecorregiões costeiras e de plataforma. A classificação é baseada em informações como descontinuidades, habitats dominantes, características geomorfológicas, correntes e temperaturas. Como resultado, a classificação distingue 12 regiões e 232 ecorregiões em uma escala global.

Ressalta-se que no Brasil, um mapeamento sistemático do uso da terra foi desenvolvido pelo Instituto Brasileiro de Geografia e Estatística (IBGE), com referência à base europeia CORINE (IBGE, 2006).

Por fim, uma questão crucial referente à regionalização dos fluxos elementares do uso da terra na ACV é o nível de detalhe necessário sobre a localização geográfica. Os níveis de regionalização podem ser muito diferentes dependendo dos objetivos e escopo específicos do estudo. Segundo Koellner et al. (2013a), para fins práticos, as fronteiras políticas dos países podem ser usadas como base para a regionalização uma vez que dados de inventário, na sua maioria, são mais facilmente disponíveis ao nível de países do que ecorregiões ou biomas. No entanto, para grandes países como o Brasil, esta escala pode ser muito ampla para refletir as diferenças regionais. Estes autores elaboraram uma primeira proposta de classificação do uso e cobertura da terra para a ACV em escala global que consiste em quatro níveis de detalhe:

- Nível 1: classes de cobertura e uso da terra a partir do GLC 2000. São diferenciados neste nível: biomas terrestres, biomas de água doce, águas costeiras e oceanos.

- Nível 2: refinamento das categorias do nível 1, utilizando principalmente a classificação do Ecoinvent v2.0 e GLOBIO3. Neste nível a divisão se dá em regiões climáticas: tropical / subtropical, temperada, boreal e polar.

- Nível 3: classificação em dezesseis biomas terrestres e de água doce por Olson et al. (2001) e três biomas marinhos com base em Spalding et al. (2007).

- Nível 4: classificação em 867 ecorregiões terrestres e de água doce por Olson et al. (2001) e 232 ecorregiões costeiras de Spalding et al. (2007). 
Tal estrutura em diferentes níveis permite elaborar a análise de acordo com o grau de detalhe necessário ou disponível. Portanto, os usuários, no momento de realizar o ICV tem a opção de indicar o tipo de uso da terra, bem como a sua localização geográfica, em qualquer um dos níveis de diferenciação propostos, dependendo das informações disponíveis. Contudo, a falta de dados ou informações pode reduzir a precisão.

Além disso, os próprios autores ressaltam que, para algumas vias de impacto (como o potencial de erosão), a abordagem proposta de regionalização pode não ser ideal. O conceito de bioma e ecorregião delimitam áreas biologicamente semelhantes, mas para a erosão, por exemplo, a indicação da bacia hidrográfica e declividade da área em um tipo de uso da terra poderiam ser mais relevantes. Neste caso, a regionalização das ecorregiões de água doce, como proposto por Abell et al. (2008) pode ser uma alternativa útil, pois considera a delimitação das bacias hidrográficas. Tal classificação leva em conta também as características dos ecossistemas, como por exemplo, a distribuição e composição das espécies de peixes e os principais padrões ecológicos e evolutivos, enquanto as ecorregiões de água doce definida por Olson et al. (2001) apenas classificam o corpos d'água .

Quanto à questão da alocação dos impactos de ocupação e transformação na AICV, não é possível identificar um consenso. Porém, sabe-se que a alocação dos impactos da transformação para as saídas (output) decorrente do novo uso da terra fica sob escolha do praticante da ACV (De Baan; Alkemade; Koellner, 2013; Souza et al., 2013). Essa alocação da transformação da terra pertence ao inventário, ao passo que o cálculo da magnitude dos impactos de transformação da terra pertence à fase de AICV.

Uma opção é tomar um período fixo de alocação para todos os tipos de uso da terra. Koellner et al. (2013b) indicam que 20 anos seria consistente com o que sugere o IPCC para as emissões de carbono orgânico do solo.

Outra opção é assumir diferentes prazos de alocação, dependendo do tipo de uso da terra. Isso foi proposto no Ecoinvent v2.0 (FRISCHKNECHT \& JUNGBLUTH, 2007) com base em períodos de uso padrão, indicados para uma gama de tipos de uso da terra. Segundo estes autores, a transformação da terra para novos fins é atribuída a esse novo uso e nenhuma transformação da terra é registrada para um uso da terra que provavelmente não mudará no futuro, bem como para terrenos abandonados e sujeitos a sucessão natural.

No entanto, o número real de anos é arbitrário em qualquer caso, o que evidencia a necessidade de mais estudos sobre esta questão. Na ausência de uma alternativa clara e cientificamente válida, Koellner et al. (2013b) sugerem adotar o período de 20 anos, pois está 
em consonância com as normas e regulamentos de alocação de emissões de gases de efeito estufa devido ao uso da terra.

\subsection{Situação de referência}

De maneira geral, os impactos do uso da terra são avaliados na ACV proporcionalmente à diferença de qualidade entre o sistema estudado e uma situação de referência (Koellner et al. 2013b). O estado de referência da qualidade da terra é alvo de inúmeras discussões e segundo Koellner \& Geyer (2013), a decisão sobre qual a situação de referência mais apropriada é uma das questões mais relevantes para pesquisas futuras no campo do desenvolvimento de metodologias de avaliação de impactos do uso da terra na $\mathrm{ACV}$.

Ao longo dos anos foram propostas opções de referência como: o estado natural da terra antes da atividade humana; o estado da terra imediatamente antes da ocupação; o estado da terra imediatamente após a ocupação; ou ainda o estado da terra após recuperação (clímax ou estado de equilíbrio do ecossistema) (KOELLNER, 2013b).

As mais recentes publicações acerca da avaliação do uso da terra na AICV apontam três opções principais para descrever a situação de referência na ACV (KOELLNER et al., 2013b):

1. Adotar o conceito de Vegetação Natural Potencial (VNP), o qual descreve a vegetação que se desenvolveria se acabasse toda a influência humana no local e em seu entorno (WESTHOFF \& VAN DER MAAREL, 1973; CHIARUCCI et al., 2010; SAAD et al., 2011).

2. Tomar como referência o estado (semi) natural da terra em cada bioma/ região, como por exemplo, um mosaico de florestas, zonas húmidas, lagos e rios. Este termo é utilizado pois esta situação não representa, necessariamente, habitats naturais e isentas de intervenções humanas, mas sim habitats em estágio de fim de sucessão (de BAAN, ALKEMADE, KOELLNER, 2013)

3. Adotar o uso atual do solo como referência, ou seja, o uso anterior à modificação, utilizando um mosaico de tipos de usa da terra, como já proposto para a Europa (Koellner; Scholz, 2008a). 
Alguns autores sugerem o uso da VNP. O uso desta situação adota uma abordagem mais conservadora levando a resultados de impactos mais altos independente do local. Nesta situação é dado peso similar para impactos de atividades atuais e impactos do uso da terra que se deu há muito tempo. Já o uso de mix resulta em maiores impactos de ocupação em países tropicais com grande cobertura florestal em comparação com países europeus que apresentam pouca cobertura florestal.

Ressalta-se mais uma vez a dependência desta escolha ao objetivo e escopo do estudo, sendo ainda aconselhável comparar o efeito de cada escolha.

\subsection{Reversibilidade dos impactos do uso da terra e tempo de recuperação}

Segundo Koellner et al. (2013b), assume-se que depois de um certo tempo de recuperação, a qualidade de um ecossistema pode ter sua situação de referência restabelecida. Porém, é claro que um ecossistema que tenha sido alterado por atividades humanas ou naturais nunca será exatamente o mesmo.

No contexto da utilização do solo, estes autores propõem considerar os impactos geralmente como reversíveis em um sentido amplo. Isto significa que a terra abandonada espontaneamente e sem ação humana contínua se desenvolverá rumo a uma vegetação natural potencial dependente do local (VNP) durante certo tempo (tempo de recuperação, também chamado tempo de relaxamento).

Este tempo de recuperação, depende não só da intensidade do tipo de uso do solo durante a fase de transformação (MÜLLER-WENK, 1998) e do tamanho da área (MILÀ I CANALS et al., 2007) como também da dinâmica da cobertura vegetal nas condições específicas da unidade biogeográfica em questão (SAAD, KOELLNER, MARGNI, 2013).

Ao final, uma área abandonada pode ser considerada como equivalente, embora não idêntica, ao seu estado antes do impacto. No entanto, de acordo com o conhecimento atual, há situações em que o tempo de recuperação ultrapassa os horizontes de modelagem dos estudos de ACV, ou ainda, ultrapassa um número finito de anos (KOELLNER et al., 2013b). Segundo tais autores, estes impactos, chamados permanentes, podem ser expressos pela multiplicação da diferença da qualidade do ecossistema entre a situação de referência inicial $\left(Q_{\text {ref }}\right)$ e um novo estado de equilíbrio estabelecido $\left(\mathrm{Q}_{\mathrm{ref} 2}\right)$. 


\subsection{Uso da terra e seus impactos na qualidade do ecossistema}

De modo geral, a avaliação dos impactos do uso da terra na ACV passou por diversas mudanças desde os primeiros esforços da SETAC (LINDEIJER et al. 2002) e a primeira fase do projeto Life Cycle Initiative da UNEP/SETAC (MILÀ I CANALS et al., 2007), evidenciando a necessidade de mais consistência entre as abordagens propostas para a modelagem dos diferentes mecanismos ambientais dos impactos.

A Figura 8 apresenta a cadeia de causa e efeito dos impactos do uso da terra e suas relações com estas áreas. A fim de aprimorar a relevância global da pesquisa em AICV, é essencial que esta acompanhe as pesquisas em andamento sobre avaliação de impactos ambientais. Assim, a estrutura proposta por Koellner et al. (2013b) está de acordo com a tipologia mundialmente reconhecida dos serviços ecossistêmicos ${ }^{3}$ do Millennium Ecosystem Assessment (MA, 2005).

${ }^{3}$ Os serviços ecossistêmicos são os benefícios que as pessoas obtêm dos ecossistemas. Estes incluem serviços de produção como alimentos e água; serviços de regulação como regulação de cheias, secas e de doenças; serviços de suporte como a formação dos solos e os ciclos de nutrientes e serviços culturais como o recreio, o valor religioso e outros benefícios não materiais. 


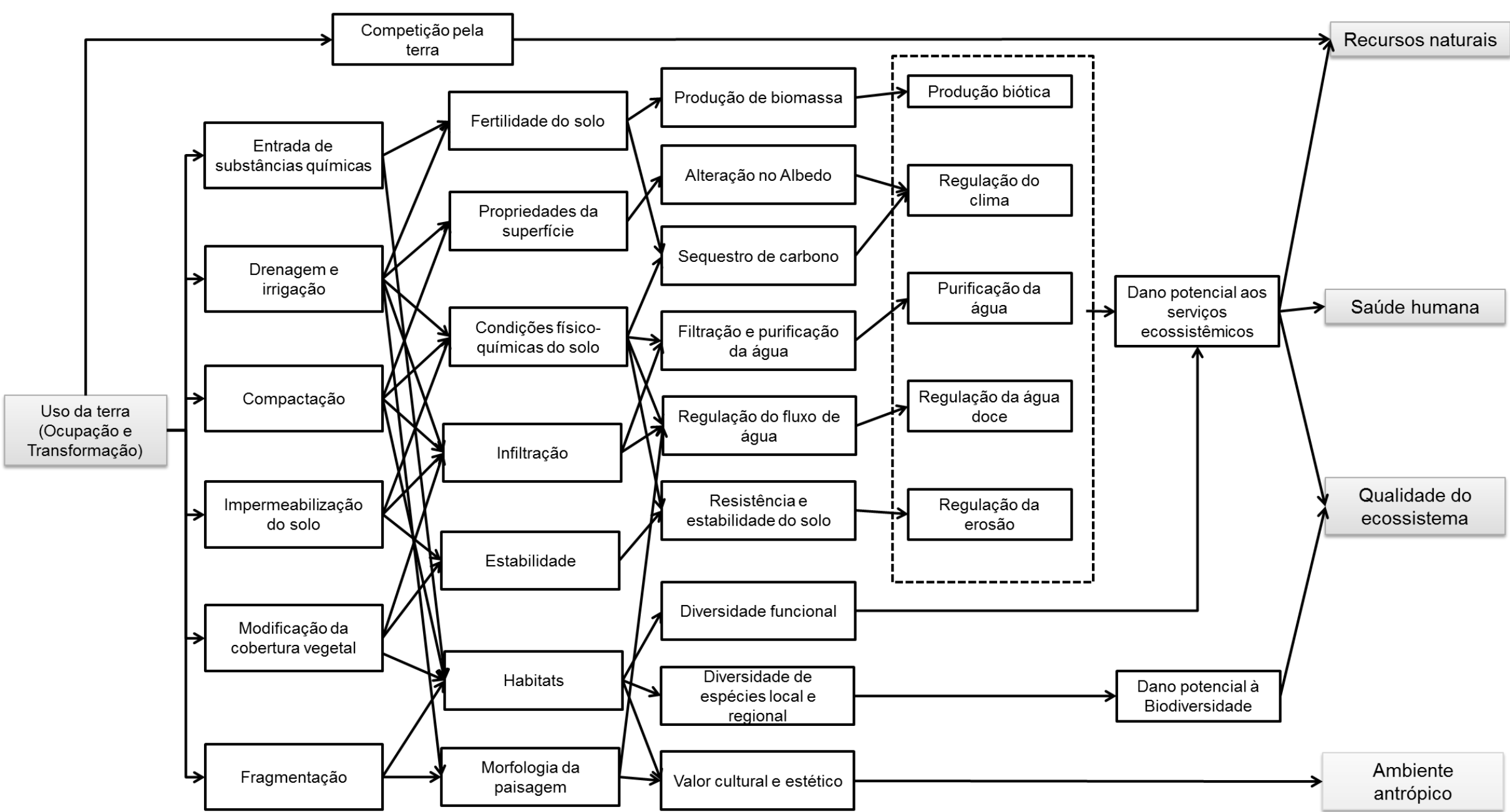

Figura 9: Cadeia de causa e efeito para os impactos do uso da terra.

Fonte: adaptado de Koellner et al. (2013b). 
Desta forma, publicações recentes de diretrizes da avaliação dos impactos do uso da terra distinguem duas vias de impacto ambientais: o potencial de dano à biodiversidade $\mathrm{e} o$ potencial de dano aos serviços ecossistêmicos.

O uso da terra, como uma intervenção, também afeta muitas categorias de impacto na ACV, como a eutrofização e acidificação (por exemplo, por meio da remoção de biomassa), toxicidade (através da aplicação de pesticidas), esgotamento de recursos bióticos (por exemplo, extração de madeira de florestas naturais), etc. Esses impactos convencionalmente devem ser abordados nas respectivas categorias de impacto e não são objeto de discussão neste trabalho.

Os impactos do uso da terra e danos à qualidade do ecossistema devido à transformação e ocupação do solo podem ser medidos com diferentes indicadores que expressam o valor intrínseco da biodiversidade e paisagens naturais ou o valor funcional dos ecossistemas em termos de seus bens (ou seja, os recursos naturais, como madeira ou alimentos) e serviços (ou seja, funções de suporte à vida como regulação do clima ou regulamento erosão) (Koellner et al., 2013b).

Ainda segundo os autores, de maneira geral o impacto da transformação da terra (IT) é calculado com base na diferença de qualidade do ecossistema entre uma situação de uso da terra e uma situação de referência apropriada $(\Delta Q)$ ao longo do tempo, multiplicada pela área transformada $(A)$. Como a dinâmica temporal da qualidade do ecossistema são na sua-maioria desconhecidas, uma trajetória linear de recuperação do ecossistema é assumida. Assim, os impactos da transformação são calculados segundo Koellner et al. (2013b) usando a Equação 1 , sendo $t_{\text {reg }}$ o tempo necessário para a recuperação total da qualidade do ecossistema.

$$
I T=0.5 \times \Delta Q \times t_{r e g} \times A
$$

Segundo estes autores, o fluxo de inventário registra a área $A$ transformada e o fator de caracterização da transformação $F C_{\text {trans }}$ é dada pela Equação 2:

$$
F C_{\text {trans }}=0.5 \times \Delta Q \times t_{\text {reg }}
$$

Já o impacto da ocupação da terra $(I O)$ é calculado com base na diferença de qualidade $(\triangle Q)$ em um período de tempo, multiplicada pela área $(A)$ ocupada. (Eq. 3). Assume-se que $\Delta \mathrm{Q}$ é constante durante a fase se ocupação, assim o impacto é calculado pela Equação 3 (Koellner et al. 2013b): 


$$
I O=\Delta Q \times T \times A
$$

Assim, de acordo com Koellner et al. (2013b) o fluxo de inventário é dado como $A_{o c} x$ $T_{o c}$ e o fator de caracterização $F C_{o c}$ é dado pela Equação 4:

$$
F C_{o c}=\Delta Q
$$

Assim, existem hoje na literatura diversas propostas metodológicas para o cálculo dos impactos resultantes de processos de ocupação e transformação da terra, de acordo com diferentes aspectos do ecossistema. A seguir uma revisão de alguns dos principais modelos de avaliação destes impactos em ACV será apresentada. 


\section{MODELOS DE CARACTERIZAÇÃO DOS IMPACTOS DO USO DA TERRA}

\subsection{Introdução}

Com a revisão bibliográfica sistemática obtiveram-se, entre artigos e outros tipos de publicações (relatórios técnicos, relatos, etc), mais de 500 trabalhos. Assim como descrito no Capítulo 2, aplicou-se uma sequência de filtros, descartando-se os trabalhos que não eram focados à área de interesse. Ao final, foram efetivamente analisados 36 trabalhos (Figura 6).

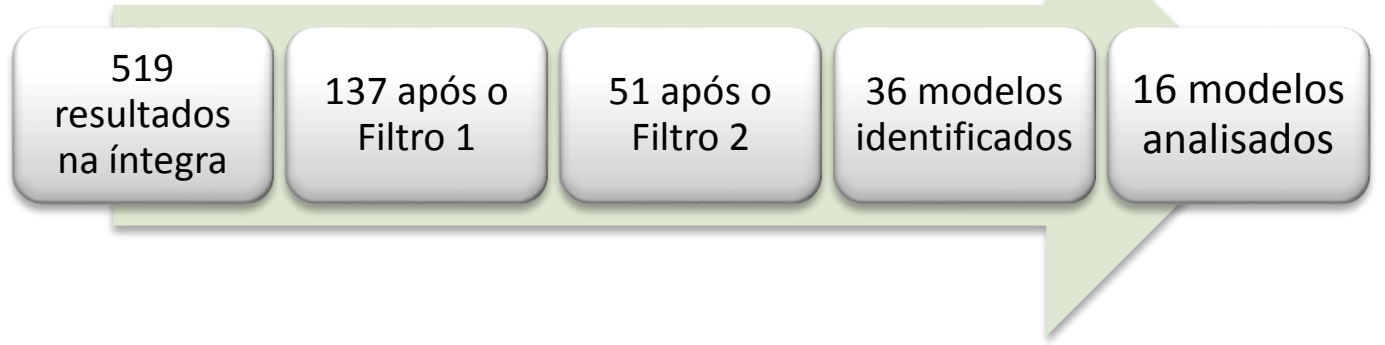

Figura 10: Resultado da Revisão Bibliográfica Sistemática.

A seguir, os modelos de caracterização são descritos e analisados de acordo com os objetivos deste trabalho. Alguns destes modelos pertencem a métodos de AICV internacionalmente reconhecidos e amplamente utilizados segundo a Iniciativa do Ciclo de Vida (UNEP, 2010).

\subsection{O Modelo de Goedkoop e Spriensma (2001) - Ecoindicator 99}

O método Ecoindicator 99 é uma versão atualizada do Ecoindicator 95 desenvolvido como parte da Política de Produto Integrada do Ministério Holandês de Moradia, Planejamento Espacial e Ambiental (VROM).

Este método introduz uma abordagem em função dos danos, apresentando uma relação entre o impacto e os danos para a saúde humana ou para o ecossistema. Assim, trata-se de 
uma metodologia endpoint, desenvolvida na Holanda, com o objetivo de simplificar a interpretação e ponderação dos resultados. São abordadas três áreas de danos:

- Saúde humana: quantidade e duração das doenças e a perda de anos de vida pela morte prematura devido aos impactos ambientais. Inclui mudanças climáticas, depleção de ozônio, radiação ionizante, efeitos respiratórios e efeitos carcinogênicos;

- Qualidade do ecossistema: efeito na diversidade de espécies, especialmente para plantas e organismos menores. Inclui ecotoxicidade, acidificação, eutrofização e uso da terra;

- Recursos: necessidade de geração de energia no futuro para extrair recursos minerais e fósseis de menor qualidade. As perdas na agricultura são consideradas na avaliação dos impactos de uso da terra.

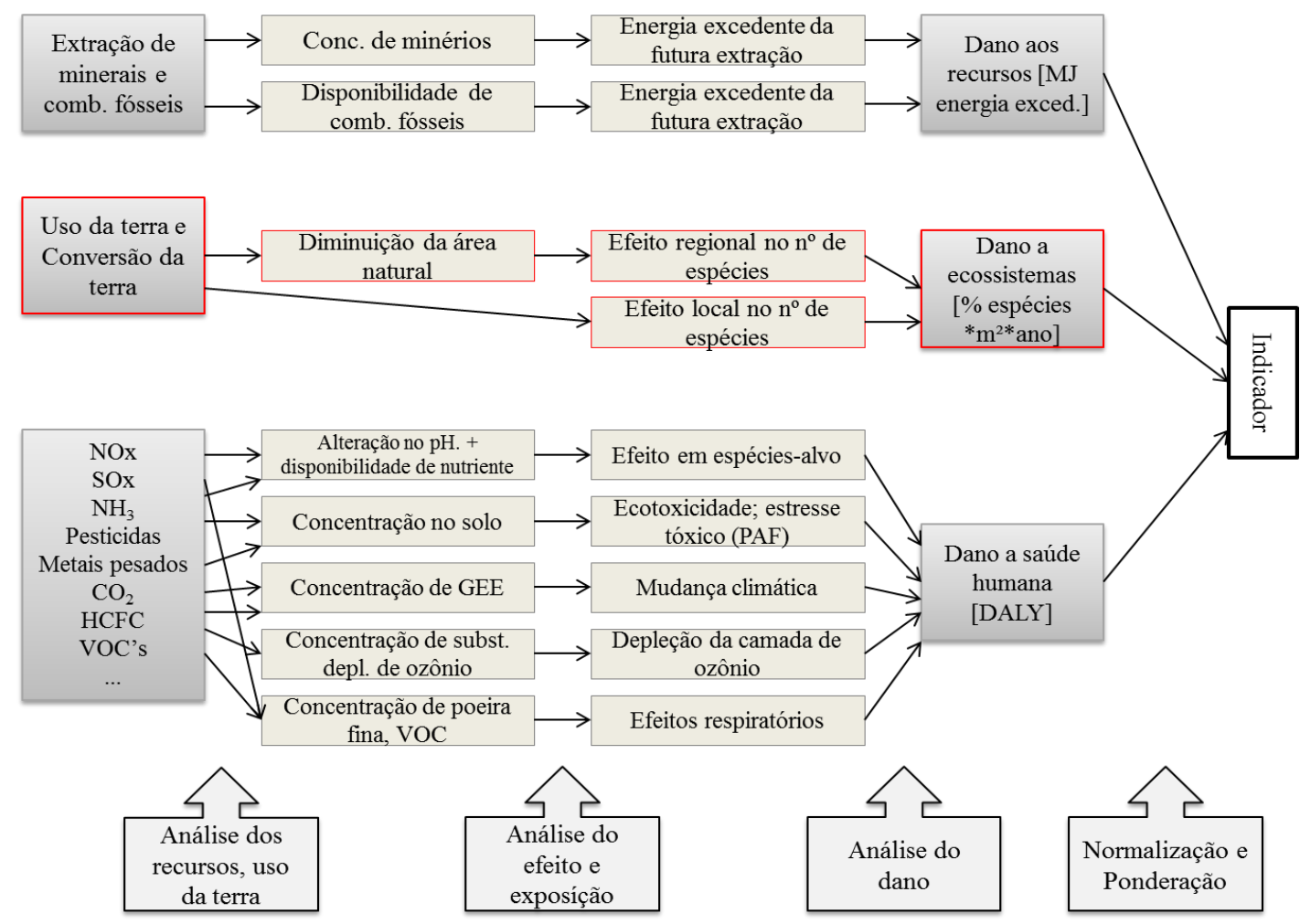

Figura 11: Mecanismo ambiental do método Ecoindicator 99.

Fonte: EC-JRC (2010c).

Essa metodologia apresenta validade global para algumas categorias de impacto, como mudança climática e depleção do ozônio, mas não no caso da avaliação dos impactos do uso da terra, sendo utilizado um modelo europeu. 
Os impactos do uso da terra e transformação da terra são baseados em dados empíricos da ocorrência de plantas vasculares, como uma função do tipo de uso do solo e do tamanho da área. Tanto o dano local na área ocupada ou transformada quanto danos nos ecossistemas regionais são considerados na metodologia.

Goedkoop e Spriensma (2001) ressaltam que ao se utilizar o método deve ser levado em conta o pressuposto que todas emissões e todas formas de uso da terra ocorrem na Europa.

Para tanto, o método faz uso de dados de tipos de cobertura do solo de acordo com a classificação CORINE, um banco de dados que engloba a maior parte dos países da Europa. Além disso, dados para os números de espécies por tipo de uso do solo e alguns dos conceitos para o efeito local são baseados em Köllner (2000).

\subsubsection{A categoria endpoint Qualidade do Ecossistema}

Ecossistemas são muito complexos, sendo muito difícil determinar todos os danos infligidos sobre eles. A diversidade de espécies é adotada como indicador, sendo então os danos à Qualidade do Ecossistema expressos em porcentagem de espécies ameaçadas ou que desapareceram de determinada área durante certo tempo.

A unidade para Qualidade do Ecossistema denomina-se Fração de Espécies Potencialmente Desaparecidas (PDF - Potentially Disappeared Fraction) multiplicado pela área e ano $\left[\mathrm{m}^{2} . \mathrm{a}\right]$. Para uso da terra essa unidade é facilmente explicada: o dano aumenta com o aumento no tamanho de área, tempo de ocupação ou um aumento no tempo de recuperação para uma área convertida (GOEDKOOP; SPRIENSMA, 2001).

O PDF é usado para expressar efeitos nas populações de plantas vasculares de dada área e pode ser interpretado como a fração de espécies que tem alta probabilidade de não ocorrer em uma região devido a condições não favoráveis. É baseado na Probabilidade de Ocorrência usada por Alkemade et al. (1996) apud Goedkoop e Spriensma (2001) para modelar os efeitos da acidificação e eutrofização.

A categoria de danos Qualidade do Ecossistema é a mais problemática por não ser completamente homogênea. O Quadro 3 apresenta os detalhes e considerações sobre a avaliação da categoria Qualidade do Ecossistema e sua heterogeneidade. 


\begin{tabular}{|c|c|c|c|c|}
\hline Categoria & $\begin{array}{c}\text { Grupo taxonômico } \\
\text { abordado }\end{array}$ & Unidade & $\begin{array}{c}\text { Definição de } \\
\text { "ameaçada" }\end{array}$ & $\begin{array}{c}\text { Pressuposto sobre as } \\
\text { espécies }\end{array}$ \\
\hline Ecotoxicidade & Diversas espécies & $\mathrm{PAF}^{*} \mathrm{~m}^{2 *}$ ano & Estresse tóxico & $\begin{array}{c}\text { Todos organismos } \\
\text { iguais }\end{array}$ \\
\hline Acidificação & Plantas vasculares & $\mathrm{PDF}^{*} \mathrm{~m}^{2 *}$ ano & $\begin{array}{c}\text { Probabilidade de } \\
\text { desaparecer }\end{array}$ & $\begin{array}{c}\text { Somente espécies- } \\
\text { alvo inclusas }\end{array}$ \\
\hline Eutrofização & Plantas vasculares & $\mathrm{PDF}^{*} \mathrm{~m}^{2 *}$ ano & $\begin{array}{c}\text { Probabilidade de } \\
\text { desaparecer }\end{array}$ & $\begin{array}{c}\text { Somente espécies- } \\
\text { alvo inclusas }\end{array}$ \\
\hline Uso da terra & Plantas vasculares & $\mathrm{PDF}^{*} \mathrm{~m}^{2 *}$ ano & $\begin{array}{c}\text { Probabilidade de } \\
\text { desaparecer }\end{array}$ & $\begin{array}{c}\text { Todas plantas } \\
\text { vasculares iguais }\end{array}$ \\
\hline
\end{tabular}

Quadro 3: Diferenças entre as categorias de impacto no método Ecoindicator 99. Fonte: Adaptado de Goedkoop e Spriensma (2001).

A combinação destas unidades significa que não existe uma unidade de danos uniforme para a categoria Qualidade do Ecossistema, como há na categoria Saúde Humana por exemplo.

5.2.2 Danos à Qualidade do Ecossistema causados por uso da terra

O modelo de caracterização para os danos devido ao uso da terra é complexo devido à existência de dois tipos de área (local e regional) e dois tipos de processos (transformação e ocupação) tornando-se necessária a divisão em quatro modelos diferentes:

1. Efeito local da ocupação da terra;

2. Efeito local da conversão da terra;

3. Efeito regional da ocupação da terra;

4. Efeito regional de conversão da terra.

O efeito local refere-se à alteração no número de espécies que ocorrem na terra ocupada ou convertida, enquanto que o efeito regional refere-se às alterações nas áreas naturais fora da área ocupada ou convertida.

Vale ressaltar ainda que a transformação da terra e a qualidade original e posterior devem ser especificadas. Uma limitação existente no modelo refere-se à lista limitada de 10 diferentes tipos de uso da terra disponível até sua publicação.

Segundo os autores, um fator que aumenta a complexidade do modelo de avaliação de impactos do uso da terra é a relação espécie-área. A relação entre o tamanho da área e a diversidade de espécies foi descrita por Arrhenius em 1921 e é geralmente expressa da seguinte maneira: 


$$
S=a \times A^{b}
$$

Onde:

$\mathrm{S}=$ diversidade de espécies.

$\mathrm{a}=$ fator de riqueza de espécies, usualmente entre 20 e 2000.

$\mathrm{A}=$ área (em hectares).

$\mathrm{b}=$ fator de acumulação de espécies, usualmente entre 0.2 e 0.5 .

5.2.3 O princípio geral do modelo

O conceito de PDF pode ser facilmente aplicado ao modelo de dano, tanto regional quanto local, causado pela ocupação ou transformação da terra. A fração de espécies de plantas vasculares potencialmente desaparecidas é expressa como a diferença relativa entre o número de espécies $\mathrm{S}$ na situação de referência e as condições criadas pela conversão ou mantidas pela ocupação. Assim, o PDF pode ser expresso como:

$$
P D F=\frac{s_{r e f}-S_{u s o}}{S_{\text {ref }}}
$$

Onde:

$S_{\text {ref }}=$ Diversidade de espécies no tipo de área referência.

$\mathrm{S}_{\mathrm{uso}}=$ Diversidade de espécies na área convertida ou ocupada.

O dano à Qualidade do Ecossistema pode ser calculado então, quando o PDF é multiplicado pela área e intervalo de tempo (Eq. 7).

$$
E Q=P D F \times \text { área } \times \text { tempo }=\frac{s_{r e f}-s_{u s o}}{s_{r e f}} \times A \times t
$$

Esta fórmula pode ser usada tanto para ocupação quanto para transformação e também para efeitos regionais e locais. O Quadro 4 especifica como os fatores devem ser aplicados. 


\begin{tabular}{|c|c|c|c|c|}
\hline Tipo & $\mathbf{S}_{\text {ref }}$ & $\mathbf{S}_{\text {uso }}$ & Área & Período de tempo \\
\hline Transformação Local & $\begin{array}{c}\text { Estado } \\
\text { original }\end{array}$ & $\begin{array}{c}\text { 'S' no novo tipo de uso } \\
\text { da terra }\end{array}$ & $\begin{array}{c}\text { Área } \\
\text { convertida }\end{array}$ & $\begin{array}{c}\text { Tempo de } \\
\text { restauração }\end{array}$ \\
\hline Ocupação Local & $\begin{array}{c}\text { Estado } \\
\text { natural }\end{array}$ & $\begin{array}{c}\text { 'S' no novo tipo de uso } \\
\text { da terra }\end{array}$ & Área ocupada & $\begin{array}{c}\text { Tempo de } \\
\text { ocupação }\end{array}$ \\
\hline $\begin{array}{c}\text { Transformação } \\
\text { Regional }\end{array}$ & $\begin{array}{c}\text { Estado } \\
\text { original }\end{array}$ & Área natural reduzida & Área natural* & $\begin{array}{c}\text { Tempo de } \\
\text { restauração }\end{array}$ \\
\hline Ocupação Regional & $\begin{array}{c}\text { Estado } \\
\text { natural }\end{array}$ & Área natural reduzida & Área natural* & $\begin{array}{c}\text { Tempo de } \\
\text { ocupação }\end{array}$ \\
\hline
\end{tabular}

Quadro 4: Visão geral dos parâmetros determinantes dos quatro tipos de uso da terra.

*A redução de espécies acontece na área natural fora da área convertida ou ocupada.

O tempo de restauração deve ser estimado dependendo das características da área antes e depois da intervenção. Contudo, na maioria dos casos não ocorre a restauração à exata condição original. O critério para selecionar o tempo de recuperação, portanto, deve ser o tempo estimado para atingir uma qualidade comparável à anterior, porém não a mesma. $\mathrm{Na}$ ausência de informações, o método propõe o uso de 5 anos para transformações de área agrícola para urbana (e vice-versa); e 30 anos para conversões de áreas naturais para urbana ou agrícola.

Goedkoop e Spriensma (2001) adotam o fator de riqueza de espécies para caracterizar as diferenças entre tipos de uso do solo levando em consideração que se trata de uma propriedade inerente do tipo de cobertura do solo. Isto significa que o parâmetro S pode ser substituído pelo fator de riqueza de espécies.

Para solucionar o problema de falta de dados disponíveis, Goedkoop e Spriensma (2001) utilizam o fator de riqueza de espécies “a” de Koellner (2000) como referência, apesar de contestarem o grau de incerteza presente nos dados. Por conseguinte o cáculo do PDF emprega dados específicos para a Suíça para os valores de referência, sendo um problema para a aplicação do Ecoindicator 99 no Brasil. 


\subsection{O modelo de Jolliet et al. 2003 - Impact 2002+}

O Impact Assessment of Chemical Toxics (IMPACT 2002+) é um método suíço que propõe uma implementação viável de abordagem combinada midpoint/endpoint, ligando todos os tipos de resultados de ICV (fluxos elementares e outras intervenções), através de 14 categorias midpoint, dentre elas a ocupação da terra (Figura 11) e 4 áreas de proteção (saúde humana, qualidade do ecossistema, mudança climática e recursos) (JOLLIET et al., 2003).

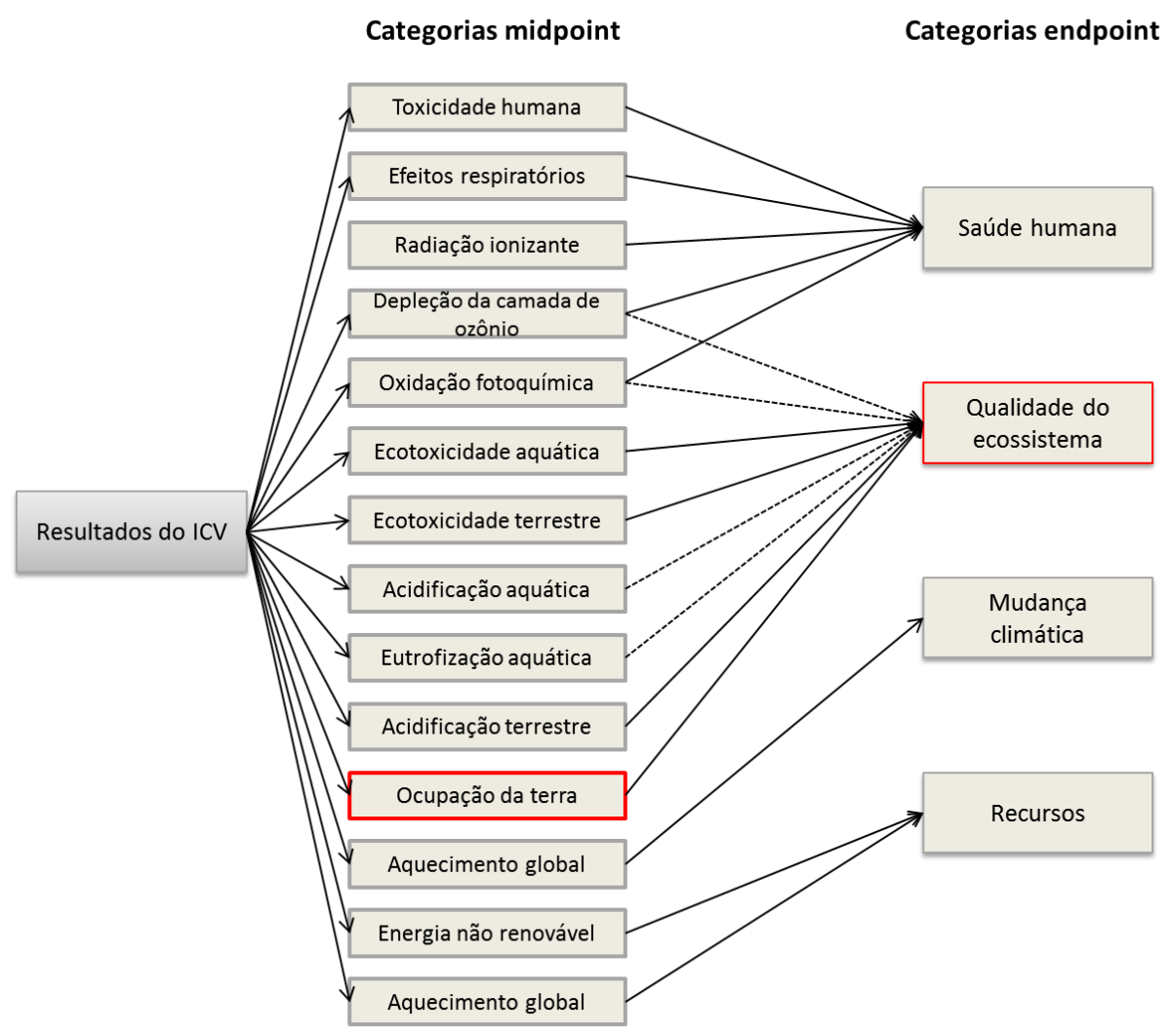

Figura 12: Esquema geral do método IMPACT 2002+.

Fonte: Adaptado de JOLLIET et al. (2003).

Trata-se de uma metodologia com validade regional para a Europa (EC-JRC, 2010c) sendo os fatores de caracterização para a avaliação dos impactos de ocupação da terra obtidos do método Ecoindicator 99 (Goedkoop \& Spriensma 2001) já detalhado anteriormente.

Embora este último avalie os impactos por meio de dois diferentes processos (ocupação e transformação da terra), no caso do IMPACT 2002+ somente a ocupação é contemplada. 
Os fatores de caracterização para a categoria midpoint são expressos em $\mathrm{m}^{2}$ de terra arável orgânica $a_{\mathrm{eq}} \cdot \mathrm{ano} / \mathrm{m}^{2}$.ano. Além disso, o impacto da ocupação da terra é ligado à categoria endpoint Qualidade do Ecossistema expressa em PDF.m².ano.

O modelo endpoint é fundamentado em Goedkoop \& Spriensma (2001), sendo que os fatores são baseados em observações empíricas do $\mathrm{n}^{\circ}$ de espécies de plantas por tipo de área. Nestas observações, os efeitos do tipo da área são inclusos. Isto significa que, assim como efeitos de ocupação, os efeitos de emissões (pesticidas e fertilizantes) estão também incluídos.

Por conseguinte, para evitar a dupla contagem com categorias como Ecotoxicidade, Acidificação e Eutrofização, apenas emissões que "deixam" o campo (por meio de erosão pela água e colheita) e as emissões que são "acima do normal" devem ser levadas em conta no ICV.

Ao longo das atualizações do método foram identificadas algumas necessidades de aprimoramento, como por exemplo, a avaliação dos impactos de perda de biodiversidade devido a desmatamentos. Assim, foram adicionados três fatores de caracterização para os seguintes fluxos elementares: Ocupação (culturas permanentes); Ocupação (culturas permanentes irrigadas); e Perda de biodiversidade devido desmatamento com horizonte de 100 anos.

\subsection{O modelos de Itsubo et al., 2004 - LIME}

Em 2003 foi lançado o LIME (Life-cycle Impact Assessment Method based on Endpoint Modeling), método desenvolvido para quantificar os impactos ambientais associados às cargas ambientais no Japão, com a maior precisão possível (ITSUBO et al., 2004).

As categorias midpoint (entre elas uso da terra) são sumarizadas em quatro tipos de danos: saúde humana, bem estar social, biodiversidade e produção primária.

O indicador de dano para a biodiversidade é relacionado ao aumento do risco de extinção de espécies de plantas e para a produção primária, à quantidade perdida na produtividade primária líquida (PPL).

O método LIME é totalmente desenvolvido para as condições naturais e humanas japonesas e aborda danos associados ao ambiente artificial (MENDES, 2013). Logo, os efeitos primários de produção são calculados para o Japão de acordo com o sistema de 
classificação de uso da terra e aplicação do modelo Chikugo (UCHIJIMA; SEINO, 1985 apud ITSUBO et al., 2004).

\subsubsection{Avaliação do dano para produção primária}

São considerados tanto o processo de ocupação da terra quanto o de transformação. O dano de ocupação do solo é calculado supondo que a PPL potencial não é plenamente alcançada enquanto a terra está ocupada. $\mathrm{O}$ dano devido à transformação da terra é calculado pela perda de PPL durante o período necessário para a recuperação da vegetação alterada para o seu estado potencial.

O fator de dano para a ocupação é expresso em " $\mathrm{kg} / \mathrm{m}^{2} / \mathrm{ano"}$ " a partir da Eq. (8)

$$
D F_{P P L}^{o c}(a)=P P L_{p}-P P L_{a}
$$

Já o fator de dano de transformação da terra é expresso em $\mathrm{kg} / \mathrm{m}^{2}$ :

$$
D F_{P P L}^{\text {trans }}(b, a)=\alpha_{a \rightarrow p} D F_{P P L}^{o c}(a) \times\left(T_{a \rightarrow p}\right)-\alpha_{b \rightarrow p} D F_{P P L}^{o c}(b) \times\left(T_{b \rightarrow p}\right)
$$

b, a: Categoria da vegetação ou uso da terra (antes e depois).

T: tempo requerido para a recuperação da produtividade da terra.

$\alpha: 0.5$ (A recuperação da PPL é considerada como de progressão linear).

\subsubsection{Avaliação dos danos para a biodiversidade}

O indicador é a soma dos aumentos no número inverso do tempo esperado para extinção de plantas vasculares ameaçadas $(\mathrm{T})$ devido à transformação da terra para uma unidade de terra. Tal indicador é chamado de EINES (Expected Increase in Number of Extinct Species), sendo calculado da seguinte maneira:

$$
\text { EINES }=\sum_{s} \Delta\left(\frac{1}{T_{s}}\right)=\sum_{s}\left(\left(\frac{1}{\left.T_{b, s}\right)}-\left(\frac{1}{T_{a, s}}\right)\right)\right.
$$


O cálculo é baseado no método desenvolvido por Matsuda et al. (2003). Os fatores para os danos são desenvolvidos para 30 tipos de vegetação e nove categorias de uso do solo e as fontes principais de dados são: Red Data Book (RDB) e Environmental Impact Statements (EIS's).

\subsubsection{Análise de incerteza}

No desenvolvimento do método foram conduzidas análises de incerteza, bem como a adição e atualização de dados de parametrização (YAMAGUCHI et al., 2006; Ii et al., 2006).

Os resultados mostram que a incerteza é maior nos fatores de danos sobre a biodiversidade do que para PPL, provavelmente devido à variabilidade geográfica, bem como por refletir as diferenças no risco de extinção das espécies, que são influenciadas pelas variações de espécies de plantas que crescem na área a ser transformada.

\subsection{O modelo de Guinée (2001) - CML 2002}

O CML 2002 LCA Handbook (Guinée et al., 2002) é um seguimento do CML 1992 LCA Guide \& Backgrounds (HEIJUNGS et al., 1992), de abordagem midpoint e validade global.

A versão revisada deste método, intitulada "Handbook on Life Cycle Assessment: Operational Guide to the ISO Standards" foi publicada em 2002, fornece orientações para dois níveis de sofisticação da ACV: uma versão simplificada e um nível detalhado, além disso, extensões opcionais para o nível detalhado são fornecidas (GUINÉE, 2001).

Quanto aos impactos relacionados ao uso da terra os autores reconhecem os diversos efeitos ao homem, e, portanto, uma distinção é feita em três subcategorias de impacto:

- Competição pela terra: relacionada à perda de terra como um recurso, no sentido desta estar temporariamente indisponível. As áreas de proteção são 'recursos naturais' e 'ambiente antrópico'.

- Perda de biodiversidade: efeitos na biodiversidade resultante de intervenções como a colheita de recursos bióticos, a destruição ou alteração da terra. 
- Perda nas funções de suporte a vida: efeitos nas funções de suporte a vida resultante de intervenções como a colheita de recursos bióticos, a destruição ou alteração da terra.

A primeira subcategoria é indicada pelos autores como categoria de impacto obrigatória com método de caracterização disponível enquanto as duas últimas são consideradas adicionais e não possuem métodos disponíveis, apenas métodos alternativos recomendados.

Além disso, Guinée et al. 2001 adotaram os conceitos apresentados pelo grupo de trabalho da SETAC - WI-2 (Lindeijer, 2000), diferenciando processos de ocupação e transformação da terra. A ocupação (em $\mathrm{m}^{2}$. ano) leva a um aumento na competição por um determinado período de tempo, devido a uma atividade ou processo. Já a transformação (em $\mathrm{m}^{2}$ ) altera a qualidade da terra em si, bem como da região.

\subsubsection{Competição pela terra}

Dada a falta de um indicador mais sofisticado para a competição da terra, os autores recomendam a simples agregação da área usada ( $\mathrm{em} \mathrm{m}^{2}$.ano) como modelo de caracterização. Os fatores de caracterização disponíveis são adimensionais, sendo igual a 1 para todos os tipos de uso da terra.

O resultado do indicador total é, portanto, uma agregação não ponderada expressa em [m².ano] não tendo relevância ambiental.

5.5.2 Perda de biodiversidade e Perda de funções de suporte a vida

O autor ressalta que no momento da publicação não era possível selecionar um método satisfatório para a perda de biodiversidade e as funções de suporte à vida. Segundo ele, existem muitas falhas inerentes a todos os métodos atualmente disponíveis. Portanto, não é recomendado qualquer método de referência. 


\subsection{O modelo de Goedkoop et al. (2013) - ReCiPe}

O método ReCiPe é baseado nos métodos Ecoindicador 99 e CML 2002 integrando abordagens midpoint e endpoint (Figura 12).

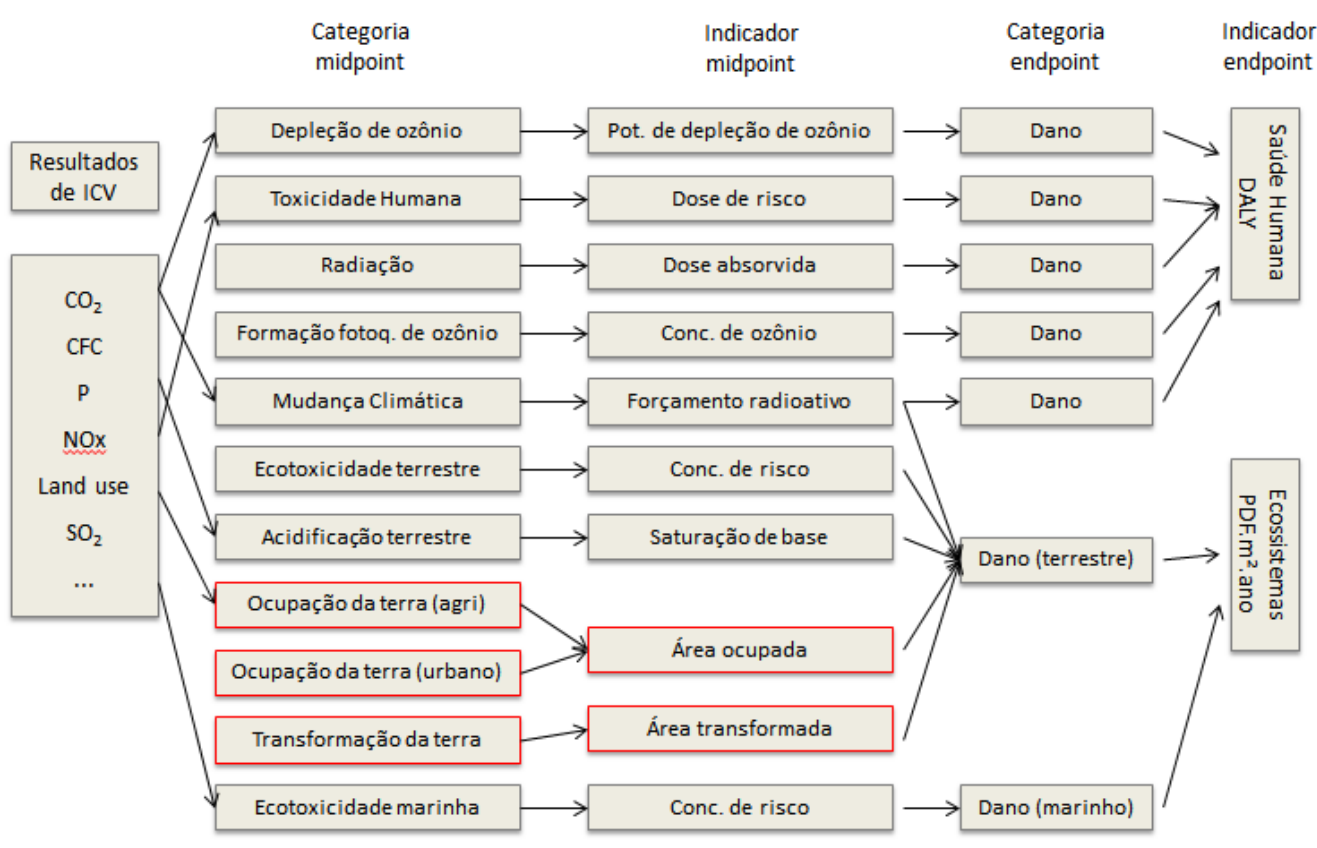

Figura 13: Relação entre os parâmetros do ICV, indicadores midpoint e endpoint no método ReCiPe.

Fonte: Adaptado de Goedkoop et al. (2013).

A categoria de impacto uso da terra reflete os danos ao ecossistema devido aos efeitos da ocupação de determinada área durante dado período de tempo e transformação da terra.

Os dois mecanismos podem ser combinados, sendo que frequentemente a ocupação segue a transformação, mas também é comum que a ocupação ocorra em uma área já transformada. Nestes casos, não é alocado nenhum impacto da transformação ao sistema de produção que ocupa a área.

O dano aos ecossistemas pode ser calculado tendo em conta o tempo necessário para a zona transformada para restaurar a um tipo de uso do solo com uma diversidade semelhante. Como os tempos de restauração de áreas naturais podem ser muito longos e algumas estimativas são de que as áreas naturais podem levar milhares de anos para se recuperar, os autores desenvolveram um conjunto de tempos de restauração que diferem dependendo dos tipos de uso da terra antes e depois da transformação. 
Além disso, foi desenvolvido um conjunto de casos de conversão do uso da terra considerados pelos autores como mais relevantes para processos de produção.

\subsubsection{Caracterização midpoint}

Nesta abordagem, os modelos de caracterização para efeitos de competição pela terra são baseados na metodologia CML (GUINÉE et al., 2002), porém, com três categorias midpoint.

Tabela 1: Fatores de caracterização midpoint para os três impactos do uso da terra.

\begin{tabular}{|c|c|c|c|}
\hline $\begin{array}{c}\text { Categoria de impacto } \\
\text { midpoint }\end{array}$ & $\begin{array}{c}\text { Fator de } \\
\text { Caracterização }\end{array}$ & ICV & Sendo: \\
\hline $\begin{array}{l}\text { Ocupação da terra - } \\
\text { agricultura (ALO) }\end{array}$ & $\mathrm{FC}_{\mathrm{agr}}=1$ & $\mathrm{~A}_{\mathrm{o}(\mathrm{agr})} \cdot \mathrm{t}$ & $\begin{array}{c}\mathrm{A}_{\mathrm{o}(\mathrm{agr}),} \text { a área ocupada para } \\
\text { agricultura }\left(\mathrm{em} \mathrm{m} \mathrm{m}^{2}\right) \text { e } \mathrm{t}, \text { tempo } \\
\text { de ocupação (em anos) }\end{array}$ \\
\hline $\begin{array}{c}\text { Ocupação da terra - urbana } \\
\text { (ULO) }\end{array}$ & $\mathrm{FC}_{\mathrm{urb}}=1$ & $\mathrm{~A}_{\mathrm{o}(\text { urb })} \cdot \mathrm{t}$ & $\begin{array}{c}\mathrm{A}_{\mathrm{o}(\mathrm{urb}),} \text { a área urbana ocupada } \\
\left(\mathrm{em} \mathrm{m}^{2}\right) \text { e } \mathrm{t} \text {, tempo de ocupação } \\
\text { (em anos) }\end{array}$ \\
\hline $\begin{array}{l}\text { Transformação da terra } \\
\text { natural (NLT) }\end{array}$ & $\mathrm{FC}_{\text {trans }}=1$ & $\mathrm{~A}_{\mathrm{o}(\text { trans })} \cdot \mathrm{t}$ & $\begin{array}{l}\mathrm{A}_{\mathrm{o}(\text { trans), }} \text { a área transformada (em } \\
\mathrm{m}^{2} \text { ) e } \mathrm{t} \text {, tempo de ocupação (em } \\
\text { anos) }\end{array}$ \\
\hline
\end{tabular}

Fonte: Adaptado de Goedkoop et al. (2013)

Para o cálculo, apenas a quantidade de área ocupada ou transformada ( $\mathrm{m}^{2}$.ano) é necessária. Nenhuma diferenciação de tipos de uso da terra é feita a nível midpoint devido às incertezas. Enquanto que a nível endpoint, as incertezas são aceitas, sendo, portanto, feita a diferenciação entre diversos tipos de uso da terra.

\subsubsection{Caracterização endpoint}

O indicador endpoint para a ocupação da terra é a Fração de Espécies Potencialmente Desaparecidas (PDF). O dano referente à ocupação é calculado multiplicando-se o PDF, o parâmetro do ICV (expresso $\mathrm{em}^{2}$.ano) e a densidade de espécies. Já o indicador para a transformação da terra é o PDF multiplicado pelo tempo de restauração e a densidade de espécies.

Segundo os autores, a fração de espécies potencialmente desaparecidas é influenciada pela relação espécie-área, já apresentada na seção 5.2.2. 


\subsubsection{Impactos da ocupação da terra}

No que se refere aos efeitos de processos de ocupação, a avaliação é feita sobre a diferença entre duas situações: i) área ocupada e ii) área ocupada em seu estado de referência.

Durante o período em que a área é ocupada, existem dois efeitos (Figura 13):

1) Efeito regional, subdividido em:

a. A ocupação restringe o tamanho do tipo de uso da terra de referência (natural), mas não aumenta o tamanho do tipo de uso do solo. $\mathrm{O}$ número de espécies na área de referência diminui ligeiramente.

b. O número de espécies em outras áreas com o mesmo tipo de uso da terra é influenciado pela ocupação devido à ligação da área ocupada com as outras regiões com o mesmo tipo de uso da terra.

2) Efeito local, ou seja, o efeito na própria área ocupada. O número de espécies na área ocupada depende apenas do tamanho da área e os valores dos fatores de riqueza de espécies e de acumulação de espécies para esse tipo de uso da terra.

\begin{tabular}{|c|c|c|c|c|c|c|}
\hline & \multicolumn{3}{|c|}{$\begin{array}{l}\text { A) Área ocupada é isolada do outro tipo de uso } \\
\text { da terra }\end{array}$} & \multicolumn{3}{|c|}{$\begin{array}{l}\text { B) Área ocupada é conectada a outras áreas } \\
\text { com o mesmo tipo de uso da terra }\end{array}$} \\
\hline $\begin{array}{l}\text { Situação } \\
\text { sem } \\
\text { ocupação }\end{array}$ & $\begin{array}{l}\text { Tipo de } \\
\text { terra i }\end{array}$ & & $\begin{array}{r}\text { Tipo } \\
\text { referência }\end{array}$ & $\begin{array}{l}\text { Tipo de } \\
\text { terra i }\end{array}$ & & $\begin{array}{r}\text { Tipo } \\
\text { referência }\end{array}$ \\
\hline $\begin{array}{l}\text { Situação } \\
\text { com }\end{array}$ & $\begin{array}{l}\text { Tipo de } \\
\text { terra i }\end{array}$ & ocupação & $\begin{array}{r}\text { Tipo } \\
\text { referência }\end{array}$ & $\begin{array}{c}\text { Tipo de } \\
\text { terra i }\end{array}$ & ocupação & $\begin{array}{r}\text { Tipo } \\
\text { referência }\end{array}$ \\
\hline
\end{tabular}

Figura 14: Ilustração da área conectada e não conectada da transformação de um tipo referência de uso da terra para um tipo i.

Fonte: Adaptado de Goedkoop et al. (2013). 
Assim, para o cálculo dos impactos da ocupação da terra é importante definir com cuidado alguns parâmetros:

- Tamanho da área de referência sem ocupação $\left(A_{r}\right)$;

- Tamanho da área do tipo de uso da terra i sem ocupação $\left(A_{i}\right)$;

- Tamanho da área ocupada $\left(A_{o}\right)$;

- Número de espécies na área de referência sem ocupação $\left(S_{i}\right)$;

- Número de espécies a menos na área de referência quando se dá a ocupação $\left(\Delta S_{r}\right)$;

- Diferença no número de espécies $\left(\Delta S_{i}\right)$;

- Tempo de ocupação $(t)$

\section{Dano regional da ocupação}

O dano regional descreve a perda marginal de espécies na área adjacente devido ao fato de que a ocupação reduz o tamanho de tal área e consequentemente o número de espécies encontrado nela.

Sob as condições descritas em $\boldsymbol{A}$, a área ocupada não é ligada com a área sob o mesmo tipo de uso da terra. A perda de espécies marginais é multiplicada pela área e o tempo a fim de se obter o dano causado pela ocupação:

$$
E D_{o c}=t \times A_{r} \frac{\Delta s_{r}}{s_{r}}
$$

Sendo que $\mathrm{ED}_{\mathrm{oc}}$ representa o impacto ambiental devido a ocupação; $\mathrm{A}_{\mathrm{r}}$, o tamanha da área de referência; $S_{\mathrm{r}}$, o número de espécies na região; e $\Delta \mathrm{S}_{\mathrm{r}}$ a diferença entre o número de espécies em um estado natural e durante a ocupação.

Aparentemente, sob a hipótese $\boldsymbol{A}$ o dano regional é independente do tamanho da região. Segundo os autores, é possível também interpretar o fator de acumulação de espécies (b) como o fator de caracterização para danos regionais:

$$
C F_{\text {oc-A }}\left(\text { regional }_{\text {hipótese'A' }}\right)=b_{r} \times E D
$$


Já sob a hipótese $\boldsymbol{B}$, o fator de dano ambiental é a soma do ganho marginal da área ocupada.

$$
C F_{\text {oc-B }}\left(\text { regional }_{\text {hipótese'B' }}\right)=\left(b_{r}-b_{i}\right) \times S D
$$

Dano local da ocupação

O número de espécies em uma área não ocupada pode ser calculado pela relação espécies-área (ver seção 5.2.2). O número de espécies encontrados na área $\mathrm{A}_{\mathrm{o}}$ antes da ocupação é dada na Equação 14 e após a ocupação pode ser caracterizada pela Equação 15.

$$
\begin{gathered}
S_{o c}(\text { local })=a_{r} A_{0}^{b_{r}} \\
S_{i_{\_} \text {local }}=a_{i} A_{0}^{b_{i}}
\end{gathered}
$$

Sendo $S$ o número de espécies de plantas, $A$ o tamanho da área $\left(\mathrm{m}^{2}\right), a$ o fator de riqueza de espécies e $b$ o fator de acumulação de espécies.

Os fatores $a$ e $b$ são específicos para cada tipo de uso da terra, mas o fator $b$ é também dependente do tamanho da área. Esta relação adiciona certa complexidade ao modelo uma vez que não é possível ligar certo tipo de uso da terra a um número de espécies, já que o número depende do tamanho da área.

Os autores adotaram a Equação 16 para a determinação da perda de espécies na área $\mathrm{A}_{0}$ :

$$
\Delta S_{\text {local }}=a_{r} A_{0}^{b_{R}}-a_{i} A_{0}^{b_{i}}
$$

O impacto ambiental local em uma área $A_{o}$ pode então ser calculado pela Equação 17 e por consequência, o fator de caracterização pela Equação 18.

$$
E D_{o c}(\text { local })=t \times A_{0} \frac{a_{r}-a_{i} A_{0}^{b_{i}-b_{r}}}{a_{r}}
$$




$$
C F_{o c}(\text { local })=\frac{a_{r}-a_{i} A_{0}^{b_{i-b_{r}}}}{a_{r}} \times S D
$$

\subsubsection{Impactos de transformação da terra}

Segundo Goedkoop et al. (2013) o parâmetro do ICV para transformação da terra é dado em $\mathrm{m}^{2}$ e o fator de caracterização é a combinação da perda de espécies integrada ao tempo que ocorre. Isto indica que o fator de caracterização descreve a combinação de dois processos: conversão e restauração.

O processo de transformação também ocorre em determinado tempo, mas na prática este tempo é curto comparado com o tempo necessário para restauração da terra ao estado original (ou próximo ao original). A restauração pode ser um processo completamente natural ou pode ser 'ajudado' através de medidas apropriadas que aceleram o processo.

Ao se realizar o ICV devem-se especificar os parâmetros de transformação e ocupação separadamente.

O dano gerado pela conversão de uma área é determinado pela diferença entre a riqueza de espécies da área antes e depois da transformação, e pelo tempo de restauração $\left(\mathrm{t}_{\text {rest }}\right)$. Para a transformação também existem efeitos locais e regionais, assim como hipóteses $\boldsymbol{A}$ e $\boldsymbol{B}$.

O fator de caracterização para a transformação pode ser computado de maneira semelhante ao anteriormente detalhado para a ocupação com algumas poucas modificações:

- O índice $r$ (referência) é substituído pelo $o$ (original);

- A área $\mathrm{A}_{\mathrm{o}}$ representando a área ocupada é substituída por $\mathrm{A}_{\text {trans }}$, representando a área transformada (parâmetro do ICV);

- O tempo t é substituído por $\mathrm{t}_{\text {rest. }}$

Para a hipótese $\boldsymbol{A}$, o impacto ambiental da transformação é expresso da seguinte maneira:

$$
E D_{\text {trans }}\left(\text { hipótese }^{\prime} A^{\prime}\right)=\left(b_{o}+\frac{a_{o}-a_{i} A_{0}^{b_{i}-b_{0}}}{b_{o}}\right) \times A_{\text {trans }} \times t_{\text {rest }}
$$


No caso da hipótese $\boldsymbol{B}$, o cálculo do impacto ambiental da transformação é dado pela Equação 20:

$$
E D_{\text {trans }}\left(\text { hipótese }^{\prime} B^{\prime}\right)=\left(b_{o}-b_{i}+\frac{a_{o}-a A_{0}^{b_{i}-b_{o}}}{a_{o}}\right) \times A_{\text {trans }} \times t_{\text {rest }}
$$

Utilizando o parâmetro $A_{\text {trans }}$ é possível expressar o fator de caracterização nas Equações 21 e 22.

$$
\begin{gathered}
C F_{\text {trans }}\left(\text { hipótese }^{\prime} A^{\prime}\right)=\left(b_{o}+\frac{a_{o}-a_{i} A_{0}^{b_{i-b_{o}}}}{c_{o}}\right) \times t_{\text {rest }} \times S D \\
C F_{\text {trans }}\left(\text { hipótese }^{\prime} B^{\prime}\right)=\left(b_{o}-b_{i}+\frac{a_{o}-a_{i} A_{0}^{b_{i}-b_{o}}}{c_{o}}\right) \times t_{\text {rest }} \times S D
\end{gathered}
$$

5.6.5 Dados para a determinação dos fatores de caracterização

Como visto na descrição da metodologia, são necessários valores para os fatores $a$ e $b$ por tipo de uso da terra. Além disso, no caso de impactos da transformação, são necessários também os tempos de restauração.

Três fontes foram usadas para coletar os dados de riqueza de espécies para os fatores $a$ e $b$ :

- Crawley \& Harral (2001), o qual fornece uma análise da variabilidade dos fatores de acumulação de espécies em diferentes tamanhos de área de terra no Reino Unido. Dados para os dois fatores são fornecidos, contudo, o número de tipos de uso da terra é limitado.

- CS2000, o qual traz dados de espécies para os tipos de uso da terra no Reino Unido para diferentes tamanhos de área com uma boa separação dos principais tipos de uso da terra e limites.

- Köllner (2001), o estudo fornece valores de $c$ para uma gama de tipos de uso da terra para a Suíça, porém, assume um valor uniforme de $b(0.21)$ independentemente do tipo de uso da terra. 
Em suma, no método ReCiPe, os fatores $b$ são obtidos de Crawley \& Harral, considerando uma área de $10.000 \mathrm{~m}^{2}$. Em alguns poucos casos em que não havia dados disponíveis os autores usaram o estudo de Köllner (2001) e as informações sobre os tempos de restauração, obtidas do trabalho de Bastian \& Schreiber (1999 apud GOEDKOOP et al., 2013) para seis diferentes tipos de uso da terra. Nota-se que os dados utilizados para os cálculos dos fatores de caracterização são predominantemente europeus, o que traz muito incerteza ao uso deste modelo em estudos voltados para o contexto brasileiro.

\subsection{O modelo de Toffoletto (2007) - LUCAS}

LUCAS (LCIA method Used for a CAnadian-Specific context) foi desenvolvido em 2005 com o objetivo de fornecer uma metodologia adaptada ao contexto canadense. Para isso, baseia-se em modelos de caracterização de metodologias de AICV existentes (e.g. TRACI e IMPACT 2002+) cujos parâmetros foram reajustados e adaptados para uma avaliação mais precisa no Canadá (EC-JRC, 2010a).

Tal adaptação implica em uma seleção inicial dos modelos de caracterização, seguido da coleta de dados e em alguns casos alterações no modelo (TOFFOLETTO et al., 2007). Dentre as categorias de impacto abordadas está o uso da terra, cuja validade é específica para o Canadá (Figura 14). 


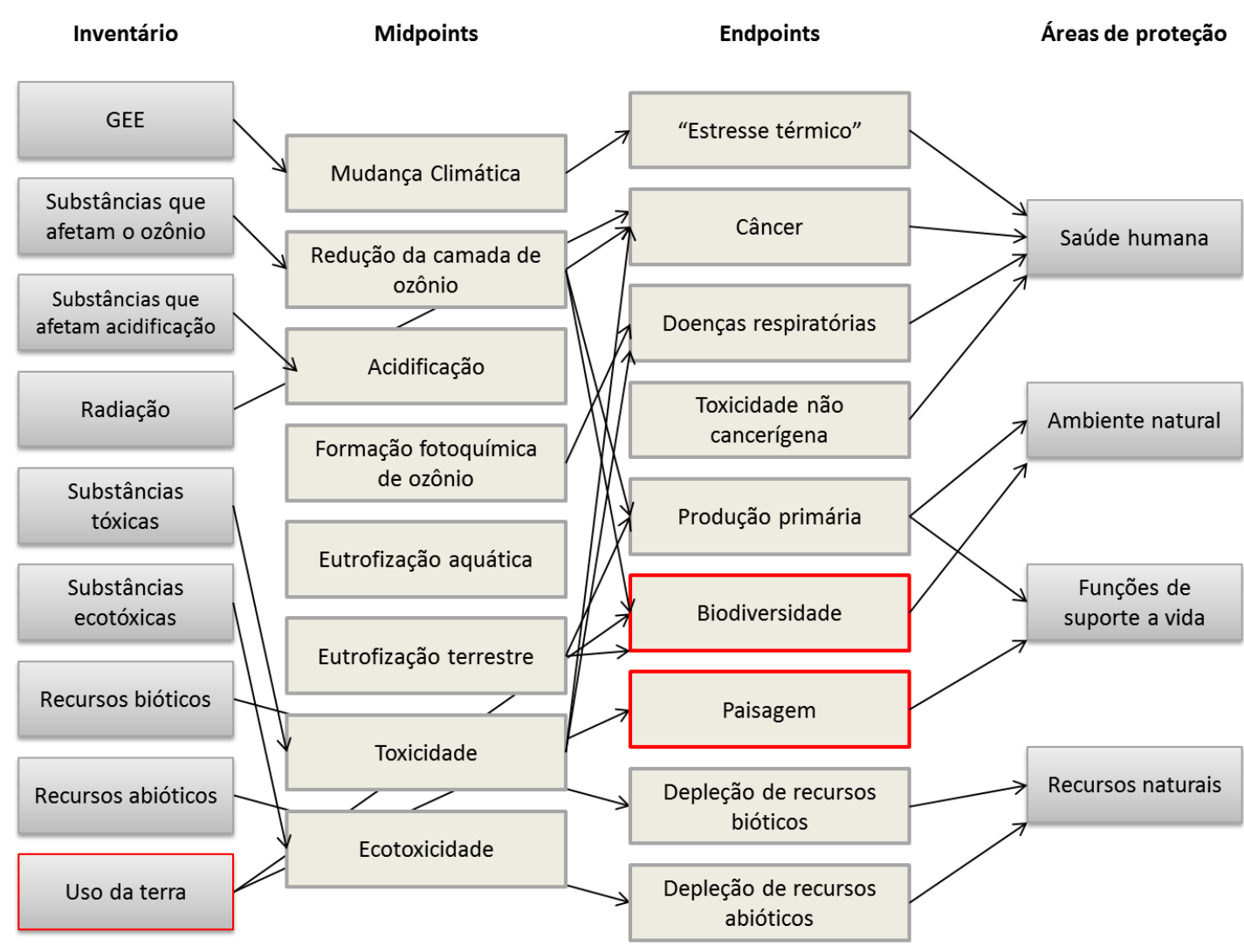

Figura 15: Framework do método LUCAS.

Fonte: Adaptado de Toffoletto et al. (2007).

A diferenciação espacial tem sido reconhecida como importante fator na melhoria de métodos de AICV e seus modelos de caracterização de impactos locais e regionais. Assim, o método assume a importância da utilização de fatores de caracterização específicos de uma região e tempo, principalmente no caso de categorias de impacto como acidificação, eutrofização (aquática e terrestre), toxicidade, ecotoxicidade, e uso da terra.

Toffoletto et al. (2007), ao desenvolver os modelos de caracterização locodependentes, selecionou como unidade de resolução espacial as chamadas ecozonas. Esta divisão cartográfica ecológica em 15 zonas terrestres foi estabelecida sob a iniciativa do governo canadense (WIKEN, 1986 apud TOFFOLETTO et al., 2007) e cada uma possui seu próprio clima, relevo, tipo de solo, fauna, flora e respectivas atividades humanas.

As razões para esta escolha de unidade de resolução espacial são:

- Relevância em termos de ecossistema;

- Os dados necessários para os modelos estão disponíveis para cada ecozona: o Environment Canada forneceu um banco de dados completo sobre várias características geográficas utilizados nos modelos de avaliação de impacto 
(MARECHAL \& SCHUT 1999 apud TOFFOLETTO et al., 2007). A transformação de dados com base em proporções de área de superfície foi realizada apenas quando os dados da ecozona não estavam disponíveis.

- Sua grande área facilita a acessibilidade aos dados loco-dependentes de inventário. As áreas de superfície variam de $168.000 \mathrm{~km}^{2}$ a $1.940 .000 \mathrm{~km}^{2}$. A preocupação com a compatibilidade do inventário com a resolução espacial selecionada levou a escolha desta unidade de resolução grande. Outra preocupação associada com o uso de um fator de caracterização genérico para a ecozona inteira é que ele pode ter grandes variações na sensibilidade ao impacto de uma categoria particular. No entanto, alguns dados de inventário são muito difíceis de obter, assim uma resolução de área de terra mais precisa para o fator de caracterização não seria útil.

Este nível de hierarquia geográfica já foi amplamente usado e, portanto, facilita a comunicação em níveis industriais e governamentais. Por conseguinte, as especificidades do método LUCAS frente a outros modelos se referem ao uso de dados das ecozonas ao invés de dados por bioma. De acordo com os autores, estes dados utilizados no cálculo dos modelos foram obtidos de organizações nacionais como Statistics Canada e Environment Canada.

Para impactos regionais e locais, o método LUCAS realizou alterações de alguns modelos existentes utilizando dados canadenses. O modelo selecionado para uso da terra é baseado no trabalho de Weidema e Lindeijer (2001) o qual indica fatores de caracterização para biomas mundiais. $\mathrm{O}$ autor justifica sua escolha pelo fato do modelo avaliar os impactos relacionados à biodiversidade e às funções de suporte à vida, sendo usado o mesmo processo de cálculo para os fatores de caracterização de cada uma das 15 ecozonas terrestres canadenses.

Portanto, o autor apresenta dois fatores de caracterização loco-dependentes para cada ecozona tanto para perda de biodiversidade quanto para funções de suporte à vida. 
5.7.1 Avaliação da perda de biodiversidade

O indicador para a biodiversidade é dado pela equação:

$$
Q_{\text {biodiversidade }}=n S R \times n E S \times n E V
$$

Onde:

SR: riqueza de espécies do ecossistema (ou número de espécies por área)

ES: Escassez inerente do ecossistema

EV: Vulnerabilidade do ecosssitema

n: Fator de normalização

As plantas vasculares são utilizadas como representantes para a riqueza de espécies. Já a escassez inerente do ecossistema é expressa como o inverso da área potencial que pode ser ocupada pelo ecossistema se deixado em repouso (i.e. sem atividades humanas).

Por fim, a vulnerabilidade do ecossistema está ligada ao nível de estresse a qual este se encontra, indicando o número relativo de espécies afetadas por uma alteração na área, tal como expresso pela relação espécie-área.

5.7.2 Avaliação dos impactos sobre as funções de suporte a vida

Quanto aos impactos sobre as funções de suporte à vida é utilizada como indicador a Produção Primária Líquida (PPL), a qual é definida como a assimilação líquida de carbono do ecossistema (fixação através da fotossíntese menos perdas através respiração) ao longo do tempo.

No entanto, é possível criticar esta escolha de indicador por não incluir adequadamente os efeitos de atividades de colheita por exemplo. Nestes casos, onde o ecossistema manejado passa repetidamente pela remoção da maior parte da biomassa acima do solo, a PPL pode ser mantida elevada, embora muitas funções de suporte a vida importantes podem estar em perigo logo após a colheita ou até que uma cobertura vegetal adequada seja restabelecida. Seria apropriado, portanto, a combinação com outros indicadores que reflitam melhor a cobertura e estrutura vegetal. Outra opção seria tornar a medida mais dinâmica e atribuir mais importância aos níveis particularmente baixos de PPL. 


\subsection{O modelo de Beck et al. (2010) - LANCA}

O Fraunhofer Institute for Building Physics desenvolveu esta metodologia que permite a quantificação de diversas possibilidades de utilização do solo dentro do contexto da ACV, ou em outras palavras, capaz de avaliar as mudanças nos solos e compará-las com valores que indicam a intensidade dos impactos presentes ou futuros.

A ferramenta de cálculo operacional (Land Use Indicador Calculation Tool, LANCA®) foi elaborada para tornar o método desenvolvido por Baitz (2002) amplamente aplicável bem como adaptá-lo ao modelo conceitual indicado por Milà i Canals et al. (2007).

Segundo os autores, para calcular a qualidade da terra em diferentes intervalos de tempo, são necessários parâmetros de entrada que representam condições específicas do local antes, durante e depois do uso da terra. Os cálculos neste modelo seguem a estrutura mostrada na Figura 14.

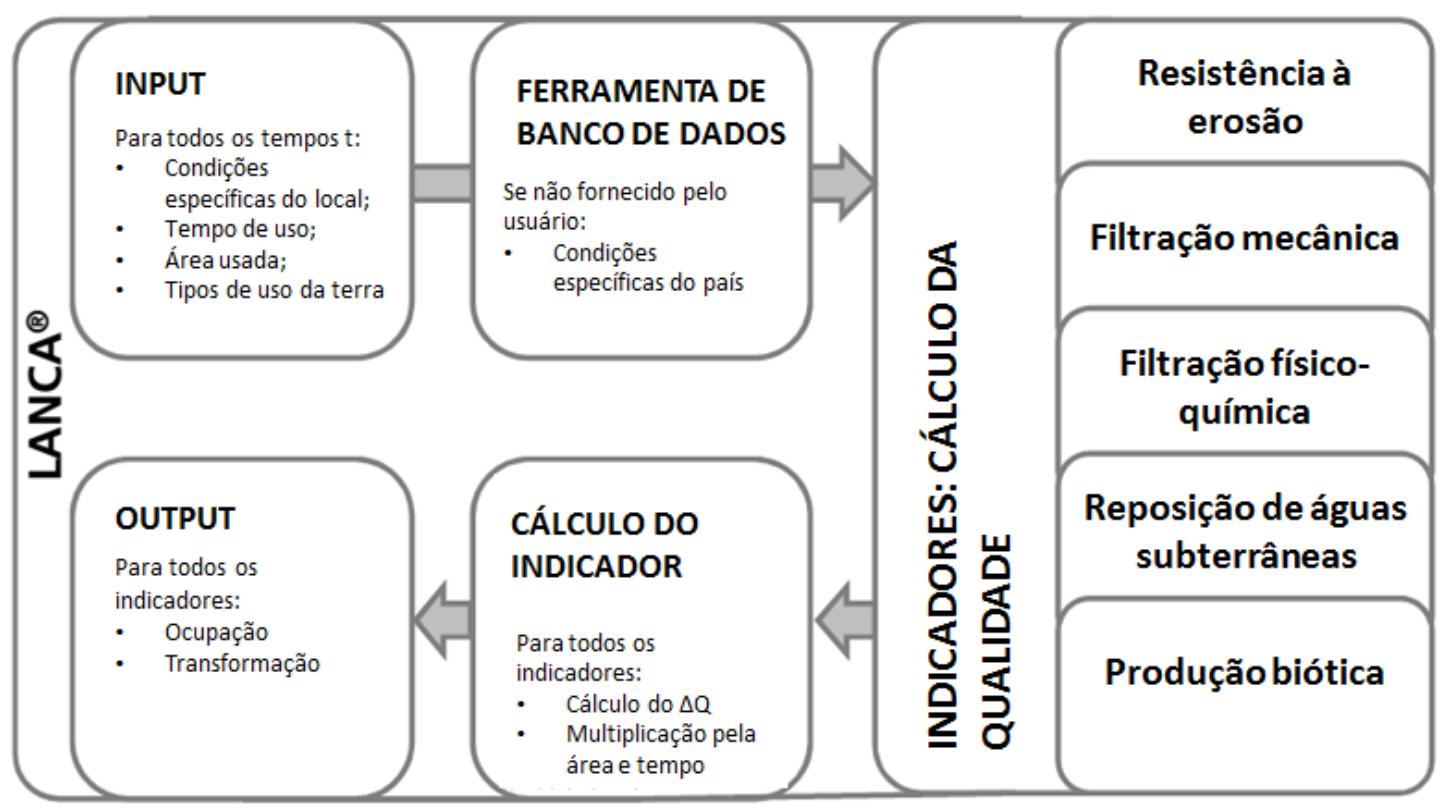

Figura 16: Estrutura metodológica do LANCA.

Adaptado de Beck et al. (2010).

Assim, a partir de uma qualidade [q $\left(\mathrm{t}_{1}\right)$ ], a qual representa a situação antes do início do uso do solo, um uso hipotético da terra leva a um rápido declínio da qualidade, representada pela situação $\left[\mathrm{q}\left(\mathrm{t}_{2}\right)\right]$. 
Ao usuário são solicitados dados de entrada relativos às condições específicas do solo e clima do local, para os diferentes intervalos de tempo considerados. Além disso, devem ser fornecidos os tipos de uso da terra que ocorrem nos diferentes intervalos de tempo, o tempo de uso e a área necessária relacionada à unidade funcional. Se estes dados de entrada específicos do local não puderem ser fornecidos pelo usuário, há a possibilidade de utilizar informações de banco de dados (em nível de país).

Os valores dos indicadores calculados podem ser interpretados como midpoints. Eles podem ser incluídos em softwares de $\mathrm{ACV}$, como o $\mathrm{GaBi}$, na forma de fluxos de inventário, permitindo uma agregação de dados na exibição do balanço, porém, até então sem outras possibilidades de caracterização.

Os efeitos potenciais do uso da terra são contabilizados como a mudança da qualidade da terra durante o tempo da ocupação. Além disso, o estado após a recuperação é a situação referência para o cálculo dos impactos.

Por fim, os parâmetros para representar a qualidade dos solos no cálculo de acordo com Baitz (2002) e suas unidades são apresentados no quadro abaixo.

\begin{tabular}{|c|c|c|c|}
\hline Indicador & Unidade & $\begin{array}{c}\text { Unidade do indicador de } \\
\text { ocupação }\end{array}$ & $\begin{array}{c}\text { Unidade do indicador de } \\
\text { transformação }\end{array}$ \\
\hline Resistência à erosão & {$[\mathrm{t} /(\mathrm{ha} * \mathrm{a})]$} & {$[\mathrm{t}]$} & {$[\mathrm{t} / \mathrm{a}]$} \\
\hline Filtração mecânica & {$[\mathrm{cm} / \mathrm{d}]$} & {$\left[\mathrm{cm}^{*} \mathrm{~m}^{2}\right]$} & {$\left[\mathrm{m}^{2} / \mathrm{d}\right]$} \\
\hline Filtração físico-química & {$\left[\mathrm{cmol} / \mathrm{kg}_{\text {solo }}\right]$} & {$\left[\mathrm{cmol}^{*} \mathrm{~m}^{2 *} \mathrm{a} / \mathrm{kg}_{\text {solo }}\right]$} & {$\left[\left(\mathrm{mm}^{2} / \mathrm{kg}_{\text {solo }}\right]\right.$} \\
\hline $\begin{array}{c}\text { Reposição de águas } \\
\text { subterrâneas }\end{array}$ & {$[\mathrm{mm} / \mathrm{a}]$} & {$\left[\mathrm{mm}^{*} \mathrm{~m}^{2}\right]$} & {$[\mathrm{g} / \mathrm{a}]$} \\
\hline Produção biótica & $\left.\left[\mathrm{g} / \mathrm{m}^{2 *} \mathrm{a}\right)\right]$ & {$[\mathrm{g}]$} & \\
\hline \multicolumn{2}{|c|}{ Quadro 5: Indicadores da metodologia LANCA. } \\
\hline
\end{tabular}

Fonte: Adaptado de Beck et al. (2010)

\subsubsection{Resistência à erosão}

A resistência à erosão, que se refere à capacidade de resistir à erosão que excede o que ocorre naturalmente no solo, é dependente principalmente da declinação, da textura e do tipo de uso do solo (BASTIAN \& SCHREIBER 1994) e em parte do teor de matéria orgância e o balança hídrico.

O modelo utilizado pelos autores é baseado na Equação Universal de Perdas de Solo (WISCHMEIER, 1978) e respectivas especificações (SCHWERTMANN, 1987). Esta calcula 
a erosão hídrica média anual multiplicando diferentes fatores que representam a precipitação, o escoamento, o solo, declive, cobertura de superfície, uso do solo e proteção contra a erosão.

Os autores usam no modelo classes de resistência à erosão específicas para tipos de solo, com base em Baitz (2002) e Arbeitsgruppe Bodenkunde (1982 apud BECK et al., 2010). Além disso, como a erosão é fortemente dependente do tipo de uso do solo, a erosão natural do solo é corrigida por um fator de correção correspondente: $\mathrm{k}_{\mathrm{uso}}$.

A figura a seguir sintetiza os dados necessários bem como as etapas da construção do modelo de avaliação.

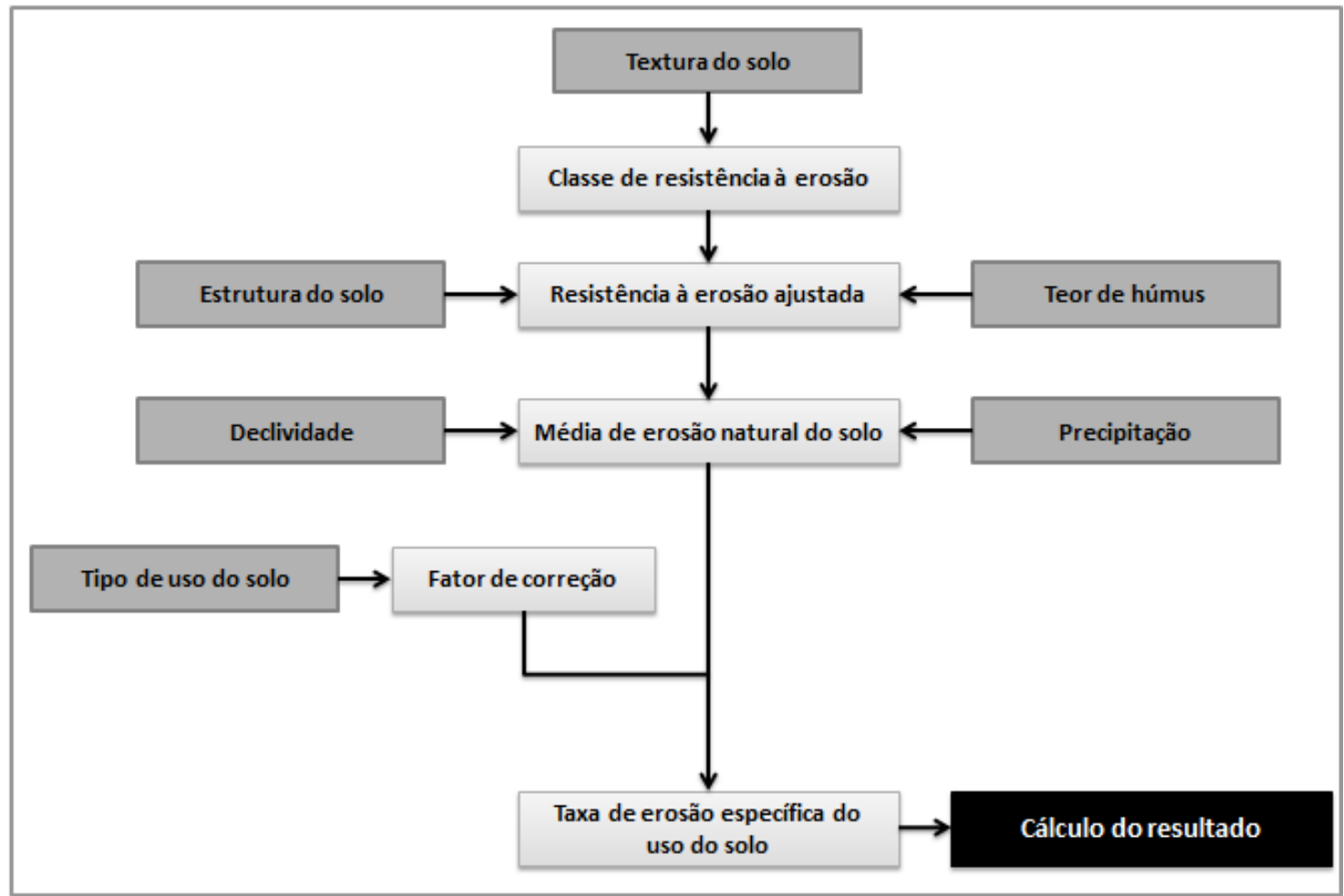

Figura 17: Etapas de cálculo da resistência à erosão.

Fonte: Adaptado de Beck et al. (2010).

\subsubsection{Filtração mecânica}

O termo capacidade de filtração mecânica se refere à capacidade do solo filttrar mecanicamente uma suspensão (MARKS, 1989). No processo de filtração, os poluentes e partículas suspensas são mecanicamente fixados ao solo. Para esse indicador, a capacidade de filtração de um solo é caracterizada pela quantidade de água capaz de passar no solo em uma determinada unidade de tempo. 
Desta maneira, a capacidade de filtração mecânica é medida pelo valor de $\mathrm{k}_{\mathrm{f}}$, que por sua vez é dependente da textura do solo e teor de argila do solo (Figura 17). Solos com uma elevada porcentagem de areia e cascalho geralmente têm uma alta capacidade de filtração, enquanto solos com uma elevada porcentagem de argila e silte tem uma baixa capacidade de filtração.

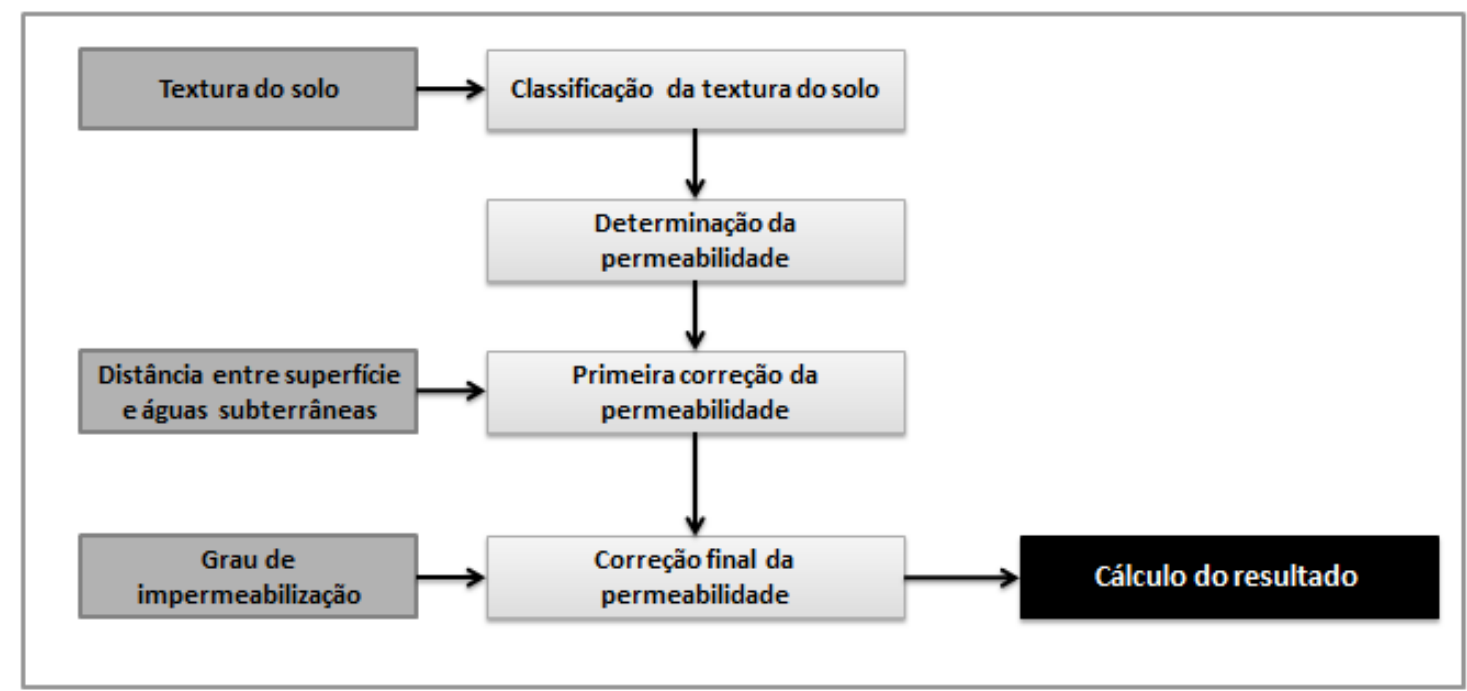

Figura 18: Etapas de cálculo para filtração mecânica.

Adaptado de Beck et al. (2010).

\subsubsection{Filtração físico-química}

A capacidade de filtração físico-química especifica a capacidade do solo de absorver substâncias diluídas e trocar íons adsorvidos.

É medida pela capacidade efetiva de troca catiônica [mmolc/ $\mathrm{kg}_{\text {solo }}$ ], a qual é dependente da textura do solo (BASTIAN \& SCHREIBER 1994), valor de pH do solo, teor de argila e conteúdo de húmus. Baitz (2002) sugere que seja calculada a capacidade de troca catiônica efetiva $\left(\mathrm{CEC}_{\mathrm{ef}}\right)$, sendo este o parâmetro de desempenho que especifica a função de filtração físico-química e pode ser determinado de acordo com o uso local e as condições dos solos.

O cálculo pode ser esquematizado em duas etapas (Figura 18), primeiramente com a entrada dos dados de capacidade de troca catiônica específica do local. Se esses dados não estiverem disponíveis para o usuário, dados extraídos do banco de dados ISRIC (BATJES, 
2002) são fornecidos ao nível de países. Em seguida, o cálculo considera um fator de correção, baseado no grau de impermeabilização da área estudada.

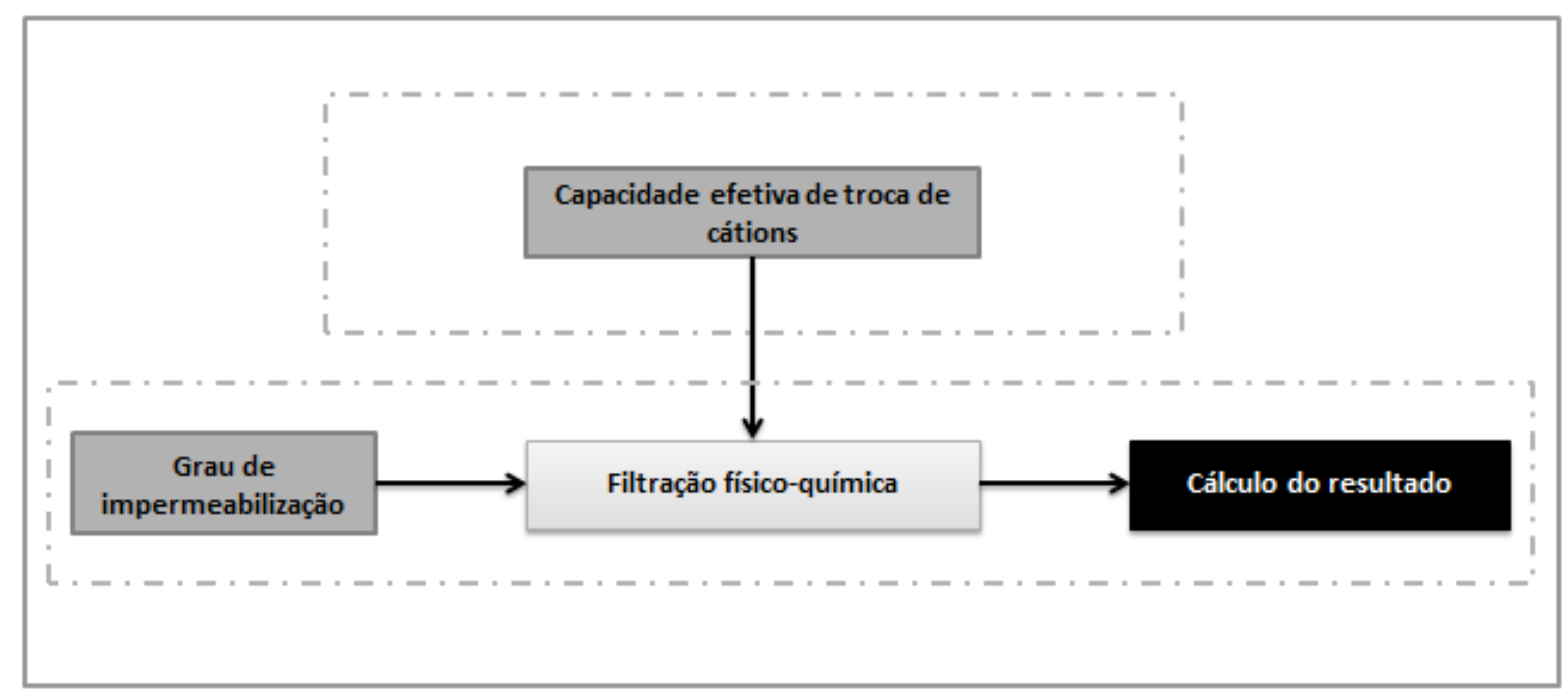

Figura 19: Etapas de cálculo para filtração físico-química.

Adaptado de Beck et al. (2010).

\subsubsection{Reposição de águas subterrâneas}

Esta função do ecossistema descreve a capacidade da terra de reabastecer recursos hídricos subterrâneos, devido à estrutura da vegetação, condições climáticas e camadas permeáveis. Para a qualidade das águas subterrâneas são considerados os potenciais de filtração, tampão e de transformação, a distância entre a superfície e as águas subterrâneas, bem como o intervalo de tempo entre a descarga de poluentes e a entrada em águas subterrâneas (MARKS, 1989). Os efeitos sobre esta função são principalmente importantes para os processos industriais associados à impermeabilização, a degradação de superfície e exposição de camadas subterrâneas.

A abordagem apresentada pelos autores tem base na precipitação anual [mm/a], a capacidade disponível de campo [mm] e a evaporação, calculado de acordo com Renger (1980 apud BECK et al., 2010) e Marks (1989).

A taxa de escoamento resultante corrigida $\left(\mathrm{GWN}_{\mathrm{ab}}[\mathrm{mm} / \mathrm{a}]\right)$ é o parâmetro de desempenho especificado para a função de reposição de águas subterrâneas. 


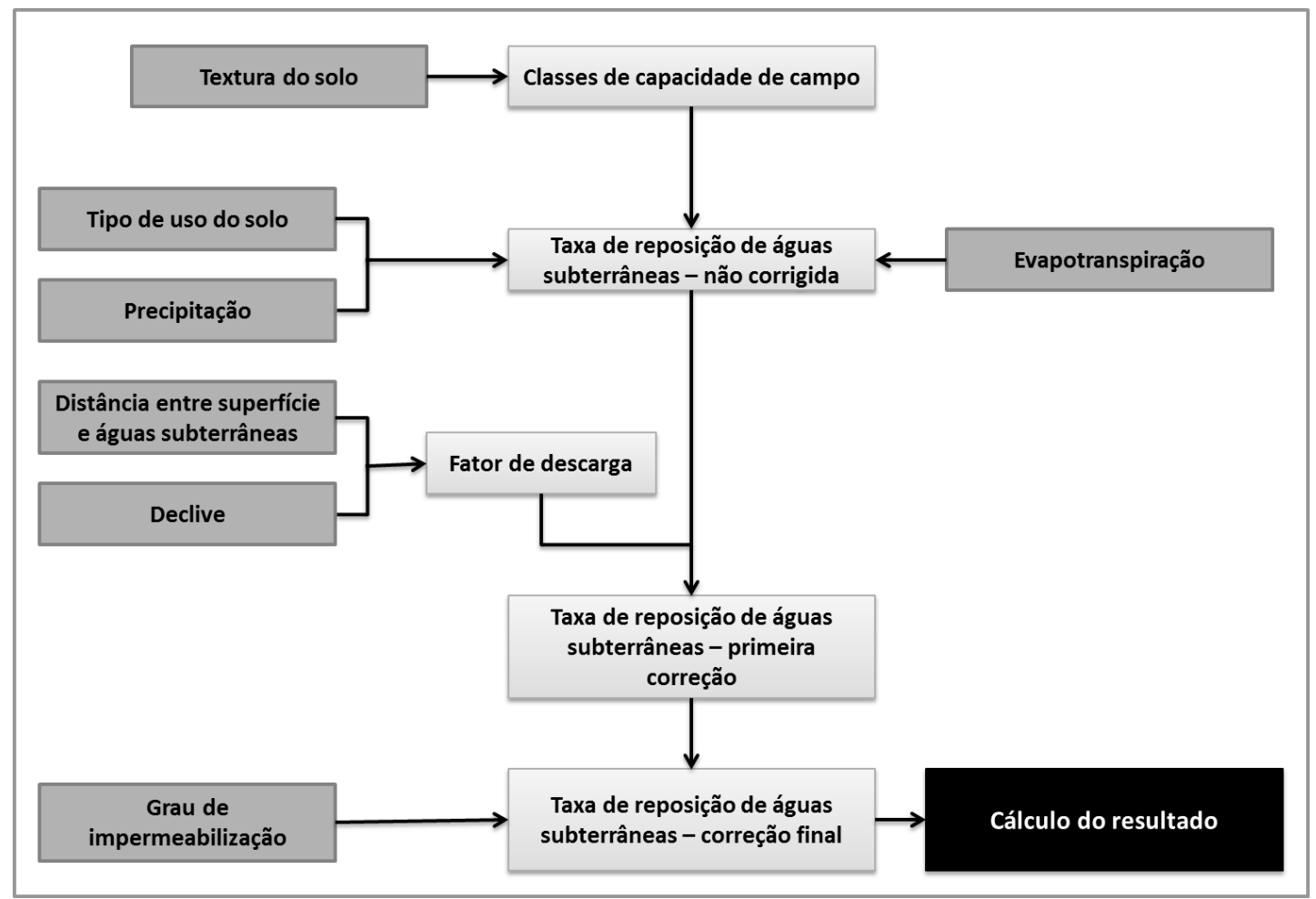

Figura 20: Etapas de cálculo para reposição de águas subterrâneas.

Adaptado de Beck et al. (2010).

\subsubsection{Produção biótica}

Segundo os autores a principal função ecológica do potencial de produção biótica de um ecossistema é o fornecimento de biomassa para o primeiro nível heterotrófico do ecossistema.

Esta função pode ser descrita pela produção primária líquida, ou seja, o total da produtividade primária do ecossistema menos a respiração autotrófica. Pode ser expresso em unidades de energia $(\mathrm{J} / \mathrm{m})$, carbono $\left(\mathrm{gC} / \mathrm{m}^{2}\right)$ ou matéria orgânica seca (por exemplo, $\mathrm{t} / \mathrm{ha}$ ).

Baitz (2002) sugere o cálculo da produção biótica com base em diferentes faixas do ecossistema, dependendo do declive, textura do solo, fornecimento de nutrientes, abastecimento de água, temperatura média anual ou sensibilidade à erosão. 


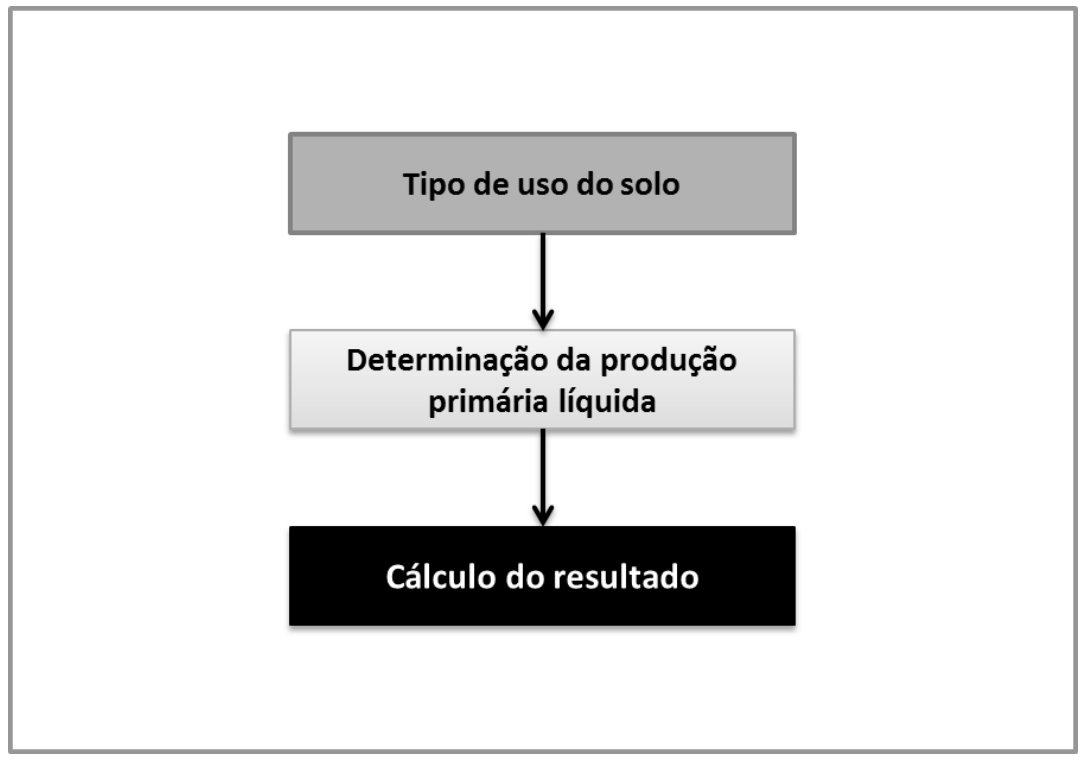

Figura 21: Etapas de cálculo para produção biótica.

Adaptado de Beck et al. (2010).

Dados específicos do local podem ser utilizados, bem como dados específicos de cada país. Algumas aplicações, incluindo análises de sensibilidade, mostram que o método é capaz de exibir as diferentes condições do local. Porém, assim como em muitos métodos de AICV, simplificações tiveram que ser feitas para ser capaz de adaptá-lo às exigências da ACV. Algumas diferenciações entre tipos de uso da terra, tais como agricultura convencional e orgânica ainda não é possível.

Os autores enfatizam que melhorias estão sendo estudadas, como por exemplo, o uso de Sistemas de Informações Geográficas (SIG) para obtenção de dados de entrada específicos do local, possibilitando uma escala geográfica mais detalhada.

Logo, tanto a metodologia quanto os indicadores estão sujeitos a processos de melhoria contínua, garantindo a atualidade do método e a acurácia dos resultados. 


\subsection{Impact World+}

Desenvolvido em resposta à necessidade de uma avaliação de impacto regionalizada para todo o mundo, o IMPACT World + parte da atualização conjunta dos métodos IMPACT $2002+$, EDIP e LUCAS.

Estão envolvidos nessa pesquisa, especialistas do grupo de pesquisa CIRAIG, da Politécnica de Montreal (Canadá), Universidade de Michigan (Estados Unidos), Ann Arbor (Estados Unidos), Quantis (Suíça), Universidade Técnica da Dinamarca - DTU (Dinamarca), Escola Politécnica de Lausanne - EPFL (Suíça) e Cycleco (França).

Foram desenvolvidos fatores de caracterização para diferentes resoluções geográficas, cada um com sua incerteza e variabilidade espacial associada (IMPACT WORLD+, 2012). Assim, a escala espacial é um ponto importante desta metodologia, sendo definida em torno dos parâmetros de modelagem mais sensíveis e espacialmente variáveis, tais como bacias hidrográficas ou biomas.

Este método traz melhorias na modelagem dos impactos do uso da terra, por exemplo, com a inclusão dos serviços ecossistêmicos. Assim, cada indicador de impacto midpoint é modelado para três áreas de proteção: saúde humana, qualidade dos ecossistemas e recursos ambientais. A última inclui os impactos sobre a sociedade humana sem consequências diretas sobre a saúde, tais como o uso recursos abióticos e depreciação dos serviços dos ecossistemas (MENDES, 2013).

Ainda não há disponível uma documentação que sintetize os procedimentos metodológicos de desenvolvimento dos modelos de caracterização do Impact World+, mas sim trabalhos individuais para cada categoria de impacto. Dentre eles, dois trabalhos apresentam os avanços obtidos na modelagem dos impactos do uso da terra e subsidiaram a descrição e análise abaixo.

5.9.1 Avaliação dos impactos do uso da terra sobre as funções ecológicas do solo

O trabalho de Saad et al. (2011) objetiva abordar os impactos do uso da terra sobre as funções ecológicas do solo, desenvolver uma abordagem espacial de avaliação de impactos do uso da terra em escala regional e ilustrar a aplicação deste método. Para este último objetivo, os autores desenvolveram fatores de caracterização espacialmente diferenciados para o Canadá em diferentes escalas regionais e avaliaram a extensão de sua variabilidade espacial. 
Medir parâmetros de qualidade da terra requer uma relação explícita entre atributos do solo e suas funções, que podem ser estabelecidos com base em observações, amostragens, e dados de monitoramento de diferentes regiões, a fim de levar em conta variações e parâmetros heterogêneos. Para superar as limitações envolvidas na avaliação loco-dependente, os autores adotaram a abordagem de modelagem proposta por Baitz (2002) desenvolvida no modelo de ferramenta de cálculo, LANCA® (Beck et al., 2010), para avaliar a influência de diferente atividades sobre as funções ecológicas do solo.

Saad et al. (2011) selecionaram quatro indicadores de impacto potencial para descrever os três serviços ambientais definidos no âmbito do uso da terra:

- Resistência à erosão

- Filtração físico-química

- Filtração mecânica

- Recarga de águas subterrâneas

Este método foi escolhido pelos autores por considerar os aspectos multifuncionais do solo e não apenas sua capacidade produtiva, ao contrário de muitos outros métodos de AICV. Além disso, Saad et al. (2011) adotaram este método devido a importância reconhecida na abordagem de diferenciação espacial na ACV, sendo fortemente dependente do uso de informações geográficas e da disponibilidade de dados.

Os autores propõem três etapas principais (Figura 21) no desenvolvimento da abordagem regionalizada para avaliação do impacto do uso da terra e utilizam o contexto canadense para ilustrar o método. 


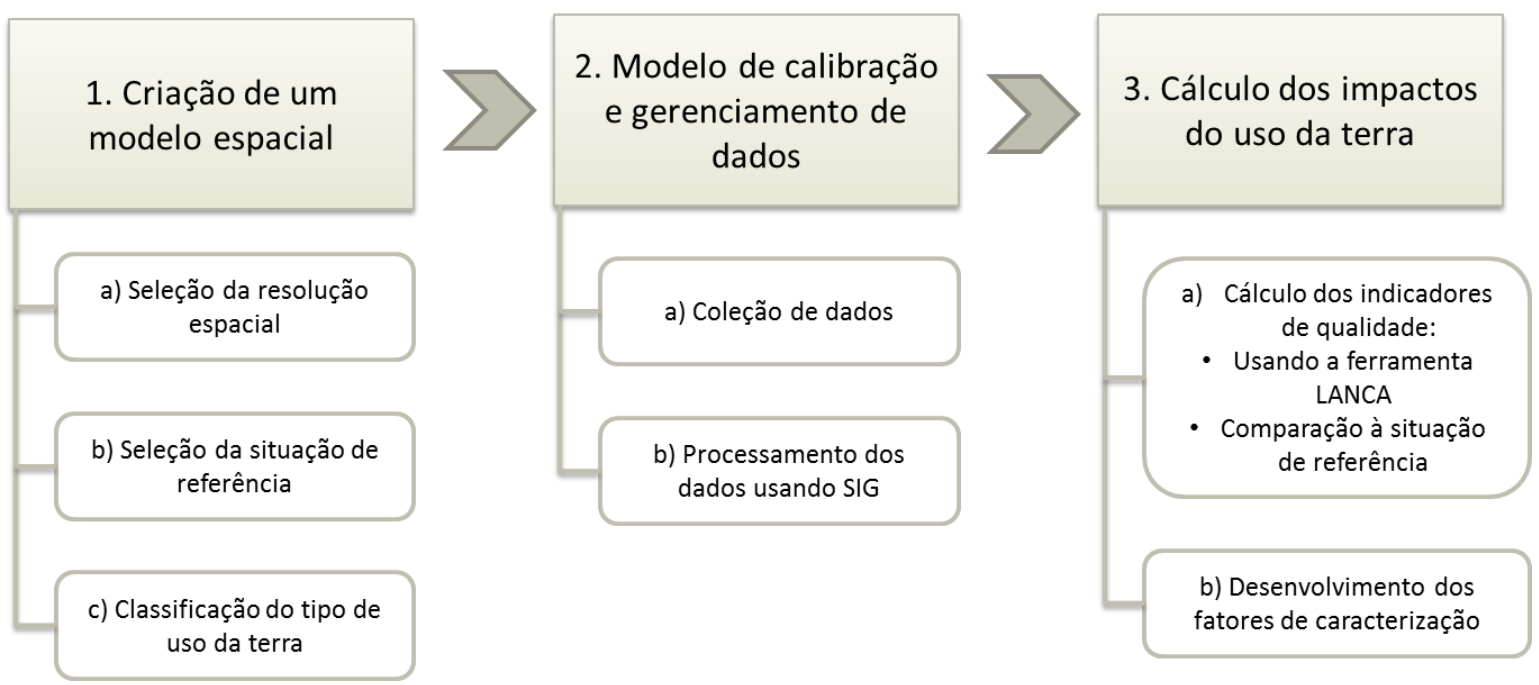

Figura 22: Etapas do desenvolvimento do modelo adotadas por Saad et al. (2011).

Fonte: Adaptado de Saad et al. (2011)

Para o desenvolvimento do modelo espacial e consequente escolha da resolução espacial, os autores partiram do princípio que a delimitação de fronteiras políticas não reflete a natureza dinâmica dos ecossistemas, especialmente para os países com uma grande área territorial. Logo, na $\mathrm{ACV}$, os limites de unidades biogeográficas são considerados mais adequados, pois fornecem informações importantes para a análise ambiental sobre a integridade dos recursos naturais e do seu manejo, por exemplo.

Foram criados dois modelos espacialmente explícitos, com base em uma referência padronizada comumente usada para os ecossistemas canadenses, baseado em:

- 15 “ecozonas” terrestres: unidades ecológicas que descrevem grandes mosaicos de tipos de ecossistemas, fauna, flora e características geológicas.

- 193 ecorregiões: subdivisões de “ecozonas" caracterizadas por fatores distintivos ecológicos, paisagem, macro ou mesoclima e distribuição de plantas em escala regional.

Representando um nível de classificação hierárquica diferente, estas duas divisões em regiões ecológicas específicas se distinguem pelos parâmetros, características biogeográficas e relevo. Assim, tais limites são considerados bem adaptados para a diferenciação espacial das funções ecológicas do solo no Canadá. Os autores também trabalharam com um modelo genérico, considerando o Canadá como uma única unidade ecológica, para fins comparativos. 
Quanto à seleção da situação de referências, os autores adotaram o estado de vegetação natural potencial (VNP) para apresentar o estado de relaxamento $\left(\mathrm{Q}_{\text {relax }}\right)$, após uma atividade de ocupação do solo. Essa opção é considerada a mais adequada no caso da ACV atribucional pelos autores, no entanto, dependendo do objetivo do estudo, é sugerido que um sistema de uso alternativo seja adotado como situação de referência em uma modelagem consequencial. Os autores identificaram um tipo de NVP para cada unidade ecológica da área de estudo canadense usando resultados fornecidos pelo modelo BIOME3 (HAXELTINE \& PRENTICE, 1996) e outro espacialmente refinado, BIOME4 (KAPLAN et al., 2003). Por fim, foi utilizado um sistema de informação geográfica (SIG) de maneira à georreferenciar as imagens e alinha-las aos dados geográficos do país.

Já quanto à classificação dos tipos de uso da terra, o modelo de categorias de uso da terra e a nomenclatura foram adaptados com base na classificação CORINE Land Cover (BOSSARD; FERANEC; OTAHEL, 2000). Um conjunto de sete tipos de uso da terra foi selecionado.

Na fase de gerenciamento dos dados e calibração do modelo os autores utilizaram o modelo LANCA® para calcular os resultados da função ecológica para cada tipo de uso da terra e de todos os quatro indicadores de impacto, o qual requer parâmetros de entrada que consiste em propriedades do solo, paisagem e condições climáticas. Os autores coletaram estas informações por meio de várias bases de dados internacionais acessíveis sendo o tratamento dos dados coletados realizados no ArcGIS 9.3 através da sobreposição de todos os parâmetros ambientais e paisagísticos e, em seguida, cruzando-os com cada escala de resolução.

Por fim, para o cálculo dos impactos do uso da terra e desenvolvimento de fatores de caracterização, Saad et al. (2011) utilizaram o modelo de cálculo LANCA® de maneira que os parâmetros da qualidade ecológica solo absolutos foram calculados para os sete tipos de uso do solo e para cada unidade ecológica das três escalas de resolução (um genérico do Canadá, 15 ecozonas e 193 ecorregiões).

Parâmetros da qualidade ecológica do solo ( $\mathrm{Q}_{\text {uso }}$ e $\left.\mathrm{Q}_{\text {relax }}\right)$ referem-se à qualidade durante o tempo de uso e a VNP. Assim, os fatores de caracterização foram desenvolvidos para cada unidade ecológica e para todos os indicadores de impacto de acordo com as Equações 24 e 25. 


$$
\begin{gathered}
I_{o c}=A \times t_{o c} \times F C_{o c} \text { sendo } F C_{o c}=Q_{\text {relax }}-Q_{\text {uso }} \\
I_{\text {trans }}=A \times F C_{\text {trans }} \text { sendo } F C_{\text {trans }}=\left(Q_{\text {relax }}-Q_{\text {uso }}\right) \times \frac{1}{2} \times t_{\text {relax }}
\end{gathered}
$$

$I_{o c}$ e $I_{\text {trans }}$ são, respectivamente, os valores dos impactos da ocupação e transformação da terra. $\mathrm{O}$ parâmetro $\mathrm{A}\left(\mathrm{m}^{2}\right)$ refere-se à área ocupada ou transformada; $\mathrm{t}_{\mathrm{oc}}$ (anos) é a duração da fase de ocupação; $t_{\text {relax }}$ (anos) é o tempo necessário para a recuperação da área. Já os termos $\mathrm{Q}_{\text {uso }}$ e $\mathrm{Q}_{\text {relax }}$ se referem, respectivamente, à qualidade ecológica do solo na fase de uso e na fase de recuperação. Estes parâmetros são medidos para cada função do solo. Segundo os autores, a avaliação dos impactos permanentes (também chamados impactos irreversíveis)

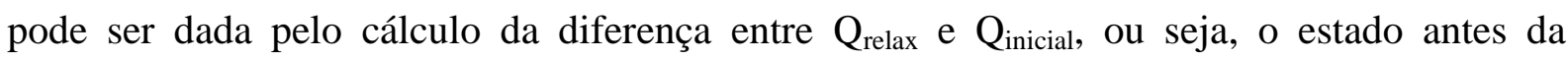
transformação.

Os autores realizaram também uma análise estatística bem como medidas de variabilidade. Além disso, uma análise de variância multidimensional (MANOVA multi-way) do modelo LANCA® foi realizada. Assim, segundo os resultados dos autores, uma resolução mais alta (como a escala baseada em ecorregiões) é tida como mais apropriada.

Por fim, a operacionalização deste método para o contexto brasileiro poderia ser realizada utilizando uma abordagem semelhante, considerando uma possível adaptação para que a avaliação dos impactos do uso da terra atenda às condições específicas do local de aplicação.

5.9.2 Avaliação dos impactos do uso da terra sobre a regulação de água doce, regulação da erosão, e de purificação da água

Saad; Koellner; Margni (2013) apresentam uma abordagem ampliada do método proposto por Saad et al. (2011), de maneira a fornecer um modelo de caracterização global abordando os impactos do uso da terra sobre indicadores de serviços ecossistêmicos. Assim os autores desenvolveram fatores de caracterização espacialmente diferenciados em uma escala mundial e avaliaram a extensão de sua variabilidade espacial utilizando diferentes níveis de regionalização.

Portanto, a mesma abordagem sugerida por Saad et al. (2011) foi aplicada neste estudo. Contudo, como o modelo LANCA® requer a coleta e parametrização de nove parâmetros de entrada para o cálculo dos respectivos indicadores de impacto do uso da terra, o 
que demanda tempo e recursos, o estudo descreve uma solução mais prática para a avaliação de impacto.

O método consiste no desenvolvimento de um conjunto de fatores de caracterização (por tipo de uso do solo) específico para cada região biogeográfica (biomas). Cada conjunto é calculado através do modelo LANCA ${ }^{\circledR}$ de acordo com as condições médias de uma determinada região biogeográfica. A parametrização em nível regional é suportada pelo SIG (ArcGIS 9.3), interpolando bancos de dados espaciais para as propriedades do solo, paisagem e condições climáticas.

Para a diferenciação biogeográfica e coleta de dados, dois modelos de resolução espacial foram criados para abordar o contexto global.

Primeiro, a classificação HOLDRIDGE foi utilizada com base em diferentes características biogeográficas considerando três fatores dominantes: precipitação anual, razão de evapotranspiração potencial e "biotemperatura" (HOLDRIDGE, 1947). Este modelo refere-se a uma combinação de diversas condições climáticas associadas a um determinado tipo de cobertura vegetal. Dois níveis de escala hierárquica diferentes foram estudados com base em (i) nível mais alto de nove regiões globais Holdridge e (2) nível de classificação mais detalhada de 38 "zonas de vida" Holdridge. O sistema foi considerado significativo, uma vez que desempenha um papel-chave em discernir uma distribuição geográfica distinta e fornece uma organização simples e inequívoca da natureza à escala global (RICKLEFS \& MILLER, 2005).

Depois, os resultados dos fatores de caracterização foram agregados em uma classificação mais ampla para biomas terrestres (Olson et al., 2001), definido por um sistema de mapeamento de 14 biomas terrestres com base em regiões biogeográficas delineando grandes unidades de terra de condições ambientais e dinâmica ecológica semelhantes. Além disso, um modelo genérico, não espacial, que considera o mundo como uma única grande região biogeográfica também foi desenvolvido para fins comparativos.

Como estado de referência, foram identificadas a VNP para cada região biogeográfica com base nos mapas do BIOME3 (HAXELTINE \& PRENTICE, 1996) e BIOME4 (KAPLAN et al., 2003).

Os resultados de Saad; Koellner; Margni (2013) mostram que uma escala de resolução mais refinada é menos eficaz que o modelo baseado na classificação Holdridge, uma vez que discrimina ainda mais os resultados, além dos esforços necessários para coletar parâmetros de entrada específicos espacialmente precisos. 
Conforme destacado por Saad et al. (2011), o uso do modelo do LANCA® é um primeiro passo para o desenvolvimento e integração de fatores de caracterização espacialmente diferenciados para os impactos do uso da terra na ACV. Segundo os autores, mais pesquisas devem se concentrar em melhorar este modelo e em torna-lo uma ferramenta mais sofisticada, superando suas limitações.

\subsection{O modelo de Michelsen (2008)}

Uma vez que não é possível avaliar os impactos sob a biodiversidade diretamente, os autores propõem avaliar estes impactos indiretamente por meio de três fatores: (i) a escassez de ecossistemas (EE); (ii) a vulnerabilidade do ecossistema (VE); as condições para a manutenção da biodiversidade (CMB). A qualidade $(\mathrm{Q})$ num determinado local e tempo pode ser avaliada como um produto destes três fatores:

$$
Q=E E \times V E \times C M B
$$

De acordo com o autor, os indicadores sobre escassez e vulnerabilidade dos ecossistemas dão informações sobre o valor intrínseco da biodiversidade de uma área. Por outro lado, o indicador relativo às condições de manutenção da biodiversidade (CMB) fornece informações sobre as condições atuais do ecossistema, avaliadas segundo a condição da biodiversidade da área.

O indicador de escassez dos ecossistemas foi introduzido por Weidema e Lindeijer (2001). Assume-se então que as populações são menores e o risco de extinção maior. Weidema e Lindeijer (2001) expressam o indicador como o valor inverso da estrutura potencial da região $\left(\mathrm{A}_{\text {pot }}\right)$. Este indicador pode ser utilizado em diferentes níveis (bioma, paisagem, tipo de vegetação, etc), dependendo da disponibilidade de dados e da finalidade do estudo.

A vulnerabilidade de ecossistemas (VE) é introduzida como um indicador para dar informações sobre a pressão a um tipo de ecossistema, e relacionar a área existente de um ecossistema com a área potencial. A premissa é que quanto mais de um ecossistema se perde, mais valiosas são as áreas restantes. 
Já a CMB é um índice composto por indicadores, conhecidos por serem importantes para se chegar ao índice para as condições da manutenção da biodiversidade. $\mathrm{O}$ autor sugere a identificação de fatores-chave propostos por Larsson (2001 apud MICHELSEN, 2008). Dentre 17 fatores-chave identificados, três são inicialmente apontados por serem os mais importantes para se avaliar a biodiversidade nas florestas boreais da Europa (a quantidade de madeira em decomposição; a percentagem de áreas abandonadas e a introdução de espécies de árvores exóticas).

A metodologia de Michelsen (2008) prevê a possibilidade de distinguir o impacto do uso da terra a partir de vários tipos de manejo florestal em diferentes ecorregiões.

A grande limitação do estudo se refere ao fato de estar limitado a intervenções de uso da terra em floresta boreal europeia. Além disso, a qualidade intrínseca $(\mathrm{EE} \times \mathrm{VE}) \mathrm{de}$ ecorregiões está disponível globalmente, mas os fatores ligados à CMB devem ser desenvolvidos individualmente.

\subsection{O modelo de Schmidt (2008)}

O método proposto por Schmidt (2008) avalia a diversidade de espécies de plantas vasculares por área ocupada e transformada, sendo o indicador determinado a partir de curvas espécie-área. Assim, o número de espécies afetadas por área padrão (estimada em $100 \mathrm{~m}^{2}$ ) é multiplicado pela duração da ocupação. O cálculo do indicador é realizado por meio da multiplicação dos seguintes fatores: (i) área ocupada; (ii) número de espécies afetadas, em uma área padrão; (iii) vulnerabilidade do ecossistema; e (iv) duração da ocupação e recuperação da terra.

O autor não indica a distinção entre espécies raras e em extinção e entre espécies invasoras ou endêmicas, sendo propostos fatores de caracterização segundo diferentes tipos de uso da terra para a Dinamarca, extrapolando dados para o Norte da Europa, para a Malásia e Indonésia (Sudeste da Ásia). Além disso, para o cálculo do tempo de recuperação, Schmidt (2008) utilizou os valores estimados por Köllner (2003). 
O cálculo dos fatores de caracterização para ocupação e transformação o autor utiliza as Equações 27 e 28 sendo realizado por meio da subtração de valores do estado de referência.

$$
\begin{gathered}
F C_{\text {ocupação }}=\left(S_{100} \times b / L I\right)_{\text {referência }}-\left(S_{100} \times b / L I\right) \\
F C_{\text {transformação }}=\frac{1}{2} \times\left(S_{100} \times b / L I\right) \times t_{\text {recuperação }}
\end{gathered}
$$

Schmidt (2008) considera o tipo de uso da terra "Áreas naturais florestais" como sendo o estado de referência para relaxamento natural do solo, tanto para o norte da Europa (Dinamarca) como para o sudeste da Ásia (Malásia e Indonésia).

\subsection{O modelo de Brandão e Milà i Canals (2013)}

O modelo apresentado neste trabalho aborda o mecanismo de impacto ligando a ocupação e transformação da terra aos efeitos sobre a fertilidade (física, química e biológica) do solo, expressa pelo carbono orgânico do solo (COS).

O modelo visa uma cobertura global de todos os tipos de uso da terra identificados por Koellner et al. (2013a) no primeiro nível de classificação do uso do solo. Para as atividades que envolvem a produção biótica, os autores salientam que um refinamento é desejável, a fim de capturar as diferenças no manejo da terra (por exemplo, culturas permanentes versus culturas anuais).

Neste estudo, os autores sugerem o uso das mudanças no teor de matéria orgânica no solo (MOS) como um indicador para o Potencial de Produção Biótica (PPB). No entanto, de acordo com Reeves (1997) a matéria orgânica do solo é medida de maneira mais eficaz como carbono orgânico do solo (COS), sendo este escolhido como indicador para PPB.

A mudança no teor de matéria orgânica devido a processos de ocupação depende do uso do solo, tipo de solo, localização e manejo. Por sua vez, o COS é influenciado pelo tipo de solo, região climática (ou regime de temperatura), tipo de uso do solo e ordenamento do território. A fim de determinar o valor médio de COS da situação de referência, nos diferentes biomas ou regiões de clima, uma média ponderada é aplicada aos valores associados aos diferentes tipos de solo dentro de cada região climática. Isto é feito com referência a bases de dados SIG e reflete a participação desses tipos de solo em cada região. 
Em suma, neste modelo, o impacto do uso da terra no PPB é dado em função de três parâmetros: alteração no teor de matéria orgânica, área e tempo. Este último refere-se tanto a duração da ocupação como da recuperação.

O impacto é medido como um déficit de carbono (ou crédito, expresso por valores negativos) com a unidade [kg.C.ano], referindo-se a quantidade de carbono adicional temporariamente presente ou ausente do solo devido à ocupação, em relação a um sistema de referência. Segundo os autores, para estimar a mudança no COS, os valores padrão sugeridos pelo IPCC para uma grande variedade de tipos de solo, condições climáticas e opções de manejo podem ser usado em uma primeira instância (IPCC, 2003; 2006).

Quanto ao tempo de recuperação, para determinar os valores de COS em estado estacionário, associados aos diferentes tipos de uso da terra e de manejo, os valores de referência são calculados multiplicando-se o COS de referência com fatores do IPCC (2003; 2006).

Em usos da terra como agricultura e silvicultura, o tempo médio necessário para chegar a novos níveis estáveis de COS é assumido como sendo 20 anos, conforme sugerido pelo IPCC $(2003,2006)$. Para os autores este tempo é claramente muito curto em muitas ocasiões, e, particularmente, para as transformações de usos da terra de baixo COS (por exemplo, terras aráveis) para usos da terra com COS elevado (por exemplo, florestas), sendo que o acúmulo de COS pode levar muito mais tempo (WBGU 1998). Além disso, os solos agrícolas parecem estar quase sempre longe do equilíbrio (Ceschia et al., 2010). No entanto, por enquanto, esta simplificação foi considerada válida. Para os tipos de uso da terra artificiais, onde o solo foi removido ou significativamente prejudicado, os tempos de recuperação são estimados com base em Lindeijer et al. (1998).

O método desenvolvido por Milà i Canals; Romanya; Cowell (2007) foi ligeiramente modificado por Brandão \& Milà i Canals (2013), seguindo as considerações discutidas por Milà i Canals et al. (2007) e Koellner et al. (2013b). A fórmula geral utilizada para calcular os fatores de caracterização para a transformação da terra é mostrada na Eq. 29, e, para a ocupação na Eq. 30.

$$
\begin{aligned}
& \Delta C\left[k g C \text { ano } m^{-2}\right]= \\
& \quad\left(\operatorname{COS}_{\text {pot }}-\operatorname{COS}_{L U 1} \times\left(t_{\text {regen } 1}-t_{\text {ini }}\right)+\frac{1}{2}\left(t_{\text {regen } 1}-t_{i n i}\right) \times\left(\operatorname{COS}_{L U 1}-\operatorname{COS}_{L U 2}\right)\right.
\end{aligned}
$$




$$
\Delta C\left[k g C \text { ano } m^{-2} \text { ano }^{-1}\right]=\frac{\left(\operatorname{Cos}_{\text {pot }}-\operatorname{COS}_{L U 2}\right) \times\left(t_{\text {final }}-t_{\text {ini }}\right)}{\left(t_{\text {final }}-t_{\text {ini }}\right)}
$$

Brandão \& Milà i Canals (2013) ainda discutem sobre a alocação dos impactos de transformação da terra, optando por alocar igualmente os impactos de transformação da terra para os primeiros 20 anos de ocupação do solo, como sugerido por alguns autores, legislação e sistemas de contabilidade de gases de efeito estufa (EU, 2010; Koellner et al., 2013b; Flynn et al., 2011),.

Outras abordagens, não utilizadas neste trabalho, incluem uma abordagem consequencial (e. g. Schmidt, 2008) ou a alocação de toda a transformação da terra para o montante total da terra utilizada (e. g. Pfister et al., 2010; Milà i Canals et al., 2013).

Para Brandão, Milà i Canals, Clift (2011) as estimativas de mudanças no COS são altamente dependente dos dados de entrada para o COS inicial e sobre o sistema de referência usado para comparação, e a evolução do COS depende fortemente das práticas de manejo e localização. Assim, um ponto forte do estudo de Brandão \& Milà i Canals (2013) está na consistência ao derivar fatores de caracterização a partir de uma única fonte de dados, validada cientificamente (IPCC), cobrindo todo o globo.

Uma limitação, porém, é a baixa diferenciação para culturas permanentes; até então, estas recebem o mesmo fator de caracterização que florestas, o que é provavelmente subestimar os impactos de tais culturas.

\subsection{O modelo de Souza et al. (2013)}

Os autores partem do princípio que a modelagem dos impactos do uso da terra sobre a biodiversidade tem se dado principalmente a partir de medidas taxonômicas, como a riqueza de espécies, desconsiderando o papel funcional da espécie no seu habitat, sendo atribuídos pesos iguais às espécies, independentemente das suas características e funções no ecossistema.

Assim, nos últimos anos vários pesquisadores têm enfatizado a diversidade funcional (DF) como um indicador mais apropriado de perda de biodiversidade em comparação com indicadores taxonômicos (DÍAZ \& CABIDO, 2001; FLYNN et al., 2009; MOUCHET et al., 2010; PETCHEY \& GASTON, 2006). 
Segundo Petchey et al. (2009) a diversidade funcional é um reflexo dos aspectos quantificáveis das espécies, mensuráveis ao nível do indivíduo, tais como o comportamento alimentar, a quantidade de recursos consumidos, a absorção de fósforo, etc. Logo, pode ser adotada como indicador das funções das espécies e como elas influenciam a forma como os ecossistemas funcionam (SOUZA et al., 2013).

A base de cálculo da diversidade funcional é um conjunto de características funcionais, ou seja, as características fisiológicas, morfológicas ou comportamentais dos organismos (por exemplo, tamanho da semente, a área foliar ou a densidade da madeira); as quais podem revelar a sua resposta a pressões ambientais ou efeitos que têm sobre os processos do ecossistema (Harrington et al. 2010 apud SOUZA et al., 2013).

O cálculo do índice de diversidade funcional representa, portanto, mais um passo na avaliação de impactos do uso da terra que pode complementar a prática corrente na AICV, focada na riqueza de espécies.

A fim de aumentar a relevância ambiental do indicador de impacto da biodiversidade através de uma melhor contabilização do papel de cada espécie em um ecossistema e sua estabilidade, o estudo de Souza et al. (2013) abrange vários níveis taxonômicos para o cálculo dos fatores de caracterização.

O modelo proposto é baseado em dados compilados por Flynn et al. (2009) e Gibson et al. (2011). Foram incluímos três grupos taxonômicos: mamíferos, aves e plantas, principalmente devido à disponibilidade de dados. O índice de diversidade funcional para cada área de estudo foi usado de acordo com Petchey \& Gaston (2002), utilizando informações de presença ou ausência para cada espécie. A Figura 22 mostra uma visão esquemática dos dados necessários para o cálculo dos fatores de caracterização para avaliação dos impactos do uso da terra sobre a riqueza de espécies e a diversidade funcional. 


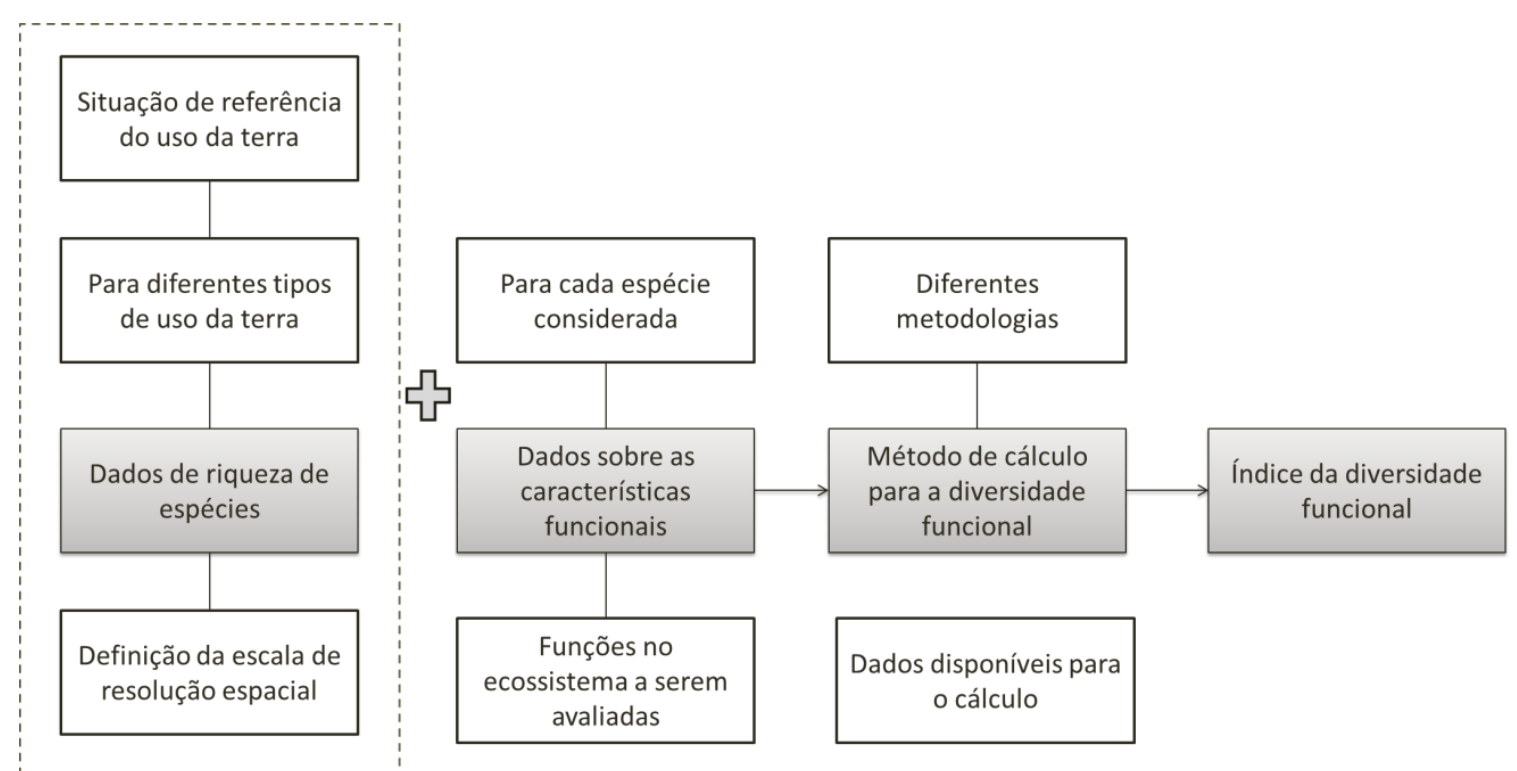

Figura 23: Esquema metodológico aplicado no cálculo dos fatores de caracterização no modelo de Souza et al. (2013).

Fonte: Adaptado de Souza et al. (2013)

Por falta de dados, os autores apenas calcularam fatores de caracterização para impactos de ocupação neste modelo. Além disso, considerou-se que espécies não encontradas em um determinado tipo de uso do solo, em relação à situação de referência, representa a perda de espécies. O mesmo é verdadeiro para a diversidade funcional, no entanto espécies podem ser perdidas sem exibir alterações na diversidade funcional quando uma ou mais espécies desempenham o mesmo papel que as espécies perdidas (SOUZA et al., 2013).

Os dados sobre as características funcionais foram coletados de bases de dados de espécies nacionais, como Instituto Nacional de Biodiversidade da Costa Rica (INBio), o Portal Brasil 500 Pássaros, Animal Diversity Web, e os guias online de aves do Suriname. Bases de dados globais, como BirdLife International, Global Species, NeotropicalBirds e Avian Web foram usadas quando os dados não foram encontrados em bases de dados nacionais.

Para os dados referentes a mamíferos, foram inclusos 12 estudos da Bolívia, Brasil, Peru, Panamá, Costa Rica, México, EUA e Canadá. Já os dados para plantas se estendem desde a Costa Rica até o leste do Canadá. Por fim, os dados de aves foram coletados no Brasil, Costa Rica, México e EUA.

Os diferentes tipos de uso da terra foram alinhados com a classificação proposta pela UNEP e SETAC, seguindo Koellner et al. (2013a). A situação de referência escolhida para 
representar a vegetação natural potencial (VNP) foi o estado natural ou mais próximo ao natural, presente em cada um dos estudos incluídos na análise: a floresta primária.

As principais características funcionais escolhidas para a análise foram: (1) a utilização de recursos e características comportamentais de mamíferos e aves e (2) características morfológicas e anatômicas para as plantas, relacionados com a capacidade de capturar recursos.

Para o cálculo do índice de diversidade funcional, os autores seguiram quatro etapas:

1. Construção de uma matriz contendo valores das características das espécies.

2. Cálculo das distâncias multivariadas entre espécies, utilizando estes valores.

3. Agrupamento hierárquico da matriz de distância em um dendrograma, um diagrama de árvore, usado para descrever o arranjo dos aglomerados.

4. Cálculo do índice com base no dendrograma, para espécies presentes em uma determinada comunidade.

Os fatores de caracterização podem ser utilizados da mesma maneira como os atuais fatores de riqueza de espécies. Outra vantagem importante do indicador de diversidade funcional é a inclusão de mamíferos e aves e, portanto, representa melhor ecossistemas terrestres do que apenas plantas. No entanto, a operacionalização desta abordagem para aplicação global é atualmente limitada pela disponibilidade de dados de entrada.

Supondo-se que a disponibilidade de dados pode crescer com novas pesquisas, a diversidade funcional é um indicador promissor para biodiversidade, não devendo ser negligenciada em pesquisas futuras.

\subsection{O modelo de Souza (2010)}

O trabalho de Souza (2010) propõe um modelo de caracterização de impactos do uso da terra segundo indicadores de biodiversidade. Para tanto, foi estabelecido um esquema de mecanismos ambientais, de causas e efeitos, para a definição de parâmetros para o modelo proposto. Foram observados dois grupos potenciais para a construção de indicadores: espécies e ecossistemas. 
As espécies adotadas no estudo foram: anfíbios, aves, mamíferos e répteis. Desta forma, ao contrário dos outros modelos, o trabalho propôs o emprego de grupos taxonômicos diversos àqueles utilizados nos modelos existentes (plantas vasculares). Com relação aos ecossistemas, empregaram-se como unidade de escala espacial as ecorregiões definidas pelo World Wildlife Fund (WWF). Segundo a autora, apesar de existirem outras propostas de divisão das ecorregiões globais, os dados do WWF se encontram em conformidade com um segundo parâmetro utilizado em seu modelo: o grau de ameaça às espécies, definido na Lista Vermelha de Espécies. Esta escolha também se justifica pelo fato de que nos dias de hoje, informações como (i) o número de espécies presentes e seu grau de endemismo; (ii) o estado de conservação dos ecossistemas; e (iii) o grau de ameaça à espécies estão disponíveis para essas unidades (SOUZA, 2010). Assim, foram identificadas 44 ecorregiões no Brasil.

As ecorregiões foram então avaliadas com relação à sua vulnerabilidade, escassez e as espécies segundo o grau de endemismo e sua classificação na categoria da Lista Vermelha de Espécies da IUCN.

Como situação referência para a comparação dos impactos, emprega-se a situação próxima do natural, definida por cenários de recuperação da terra: a VNP.

A estimativa do tempo de recuperação da terra foi realizada em etapas para cada um dos biomas brasileiros:

1. Organização dos dados de "tipos de uso da terra $\mathrm{x}$ tempo de recuperação da terra”, coletados por Köllner (2003), para a Suíça, para as classes de uso da terra definidas pelo IBGE (2006);

2. Correção dos dados de Köllner (2003), acerca do tempo de recuperação da terra $\left(t_{\text {rec }}\right)$, segundo diferentes tipos de usos, inicial e final, da terra, para os tempos de recuperação da Mata Atlântica;

3. Correção dos valores obtidos na etapa anterior, segundo diferentes latitudes $\left(\sim 5^{\circ} \mathrm{a} \sim 35^{\circ} \mathrm{S}\right)$ e altitudes $(0 \mathrm{a} 3000 \mathrm{~m})$ presentes no Brasil.

Segundo a autora, optou-se pela adaptação de dados coletados em outros países devido à inexistência de um conjunto consistente de estudos que aborde o impacto de diferentes tipos de uso da terra em cada uma das ecorregiões do Brasil.

No trabalho de Souza (2010) os danos são expressos em termos da perda da biodiversidade global, principalmente representada pela perda de espécies endêmicas locais e/ou regionais. 
A autora parte de uma primeira etapa de definição do modelo conceitual, onde fica definido o mecanismo ambiental dos impactos bem como a definição dos parâmetros do modelo. Em uma segunda etapa se dá a definição da estrutura fundamental do modelo, ou seja, a definição da escala de resolução espacial; classificação dos tipos de uso da terra; espécies a serem empregadas no modelo; e diferenciação entre impactos de ocupação e transformação. Em seguida, são definidos os parâmetros para o cálculo dos fatores de caracterização relacionados a espécies (quanto ao endemismo ou grau de ameaça a espécies) e relacionados às ecorregiões (quanto ao grau de escassez e de vulnerabilidade das ecorregiões). Os dados foram então tratados no SIG e posteriormente os fatores de caracterização calculados.

Foi adotada a classificação dos usos da terra no Brasil do IBGE (2006), a qual tem como base, estudos históricos de cobertura e uso da terra no Brasil e a base europeia CORINE.

Para o cálculo dos fatores de caracterização ( $\Delta$ Q, Equação 31$)$, quanto às espécies, foram considerados: o grau de endemismo de cada ecorregião e o grau de ameaça às espécies. No que tange os ecossistemas, foram definidos: o grau de escassez da ecorregião e o grau de vulnerabilidade da ecorregião.

$$
\Delta Q_{j}=Q_{p o t, j}-Q_{o c, j}
$$

O cálculo da qualidade da terra durante a ocupação $\left(\mathrm{Q}_{\mathrm{oc}, \mathrm{j}}\right)$ é obtido através da soma da riqueza das espécies endêmicas ponderada $\left(S_{\text {End,j-W }}\right)$ e não endêmicas ponderada $\left(S_{N E n d, j-W}\right)$ e sua multiplicação com o inverso do grau de escassez $\left(E S_{j}\right)$ e vulnerabilidade $\left(E V_{j}\right)$ de cada ecorregião (j) (Eq. 32).

$$
Q_{o c, j}=\left(S_{E n d, j-W}\right) \times \frac{1}{E S_{j} \times E V_{j}}
$$

A unidade resultante é dada em "espécies-equivalentes", ou seja, a riqueza de espécies ponderada segundo o grau de endemismo e de ameaça à extinção.

Para $\mathrm{EV}_{\text {pot,j }}$ foi utilizado o valor 1,00 para áreas intactas em todas as ecorregiões estudadas, uma vez que se considera que os ecossistemas se encontram em situação próxima ao natural. 
Por fim, os impactos de ocupação e transformação são calculados segundo a Eq. 33 e 34 , respectivamente.

$$
\begin{gathered}
I_{o c}=A_{o c} \times t_{o c} \times\left(Q_{p o t}-Q_{o c}\right) \\
I_{\text {trans }}=A_{o c} \times t_{\text {rec }} \times 1 / 2\left(Q_{p o t}-Q_{o c}\right)
\end{gathered}
$$

Os impactos permanentes, representados pelas espécies extintas (EX) ou extintas na natureza (EW), são calculados por meio da Eq. 38 .

$$
I_{\text {perm }}=A_{o c} \times t_{o c} \times \Delta Q_{p e r m}
$$

Por fim, os fatores de caracterização se dão:

$$
\begin{gathered}
F C_{o c}=\Delta Q=\left(Q_{p o t}-Q_{o c}\right) \\
F C_{\text {trans }}=1 / 2 \times t_{r e c} \times \Delta Q=1 / 2 \times t_{r e c} \times\left(Q_{p o t}-Q_{o c}\right)
\end{gathered}
$$

São considerados no estudo, fatores relacionados ao endemismo (número de espécies endêmicas em relação ao total de espécies de uma ecorregião) e o grau de ameaça a espécies (segundo classificação da IUCN).

O trabalho de Souza (2010) traz grandes contribuições técnico-científicas visto que considera dados regionais e disponíveis em escala global, além de ser a primeira proposta de inclusão de espécies de vertebrados na avaliação de impactos do uso da terra em AICV. Além disso, o modelo proposto sugere a inclusão de aspectos relacionados ao estado de conservação das ecorregiões e diferencia espécies endêmicas e não endêmicas. 


\subsection{O modelo de Nunez et al. (2010)}

Nunez et al. (2010) desenvolveram uma metodologia de ACV para avaliar o impacto ambiental local de desertificação. A abordagem acrescenta uma contribuição inovadora, uma vez que estudos anteriores consideram impactos como erosão e perda de biodiversidade, mas não o impacto da desertificação.

A maioria dos estudos sobre desertificação concentra-se na dimensão biofísica da desertificação, utilizando diversas variáveis na avaliação. Assim, a avaliação através de uma abordagem multi-indicador parece ser um método adequado para avaliar este impacto do uso da terra (NUNEZ et al., 2010).

Os autores selecionaram quatro variáveis físicas para indicar o impacto da desertificação devido às diferentes atividades humanas durante certo período de tempo: índice de aridez, erosão, superexploração de aquíferos e risco de incêndio.

Além dos valores individuais de cada variável ( $\left.\mathrm{V}_{\text {Aridez }}, \mathrm{V}_{\text {Erosão}}, \mathrm{V}_{\text {Aquífero }} \mathrm{e} \mathrm{V}_{\text {Incêncio }}\right)$, para avaliar esse impacto do uso da terra é necessário registrar a localização geográfica e extensão espacial e temporal da atividade no ICV.

$\mathrm{O}$ fator de aridez foi calculado considerando o mapa climático: $\mathrm{P}_{\mathrm{ET}}$, onde $\mathrm{P}$ é a precipitação e $\mathrm{ET}_{0}$ a evapotranspiração potencial. Além disso, para atribuir valores à variável $\left(\mathrm{V}_{\text {Aridez }}\right)$, foram consideradas as regiões definidas pelas Nações Unidas (1994 apud NUNEZ et al., 2010).

Já erosão é um dos principais motivos para a degradação dos solos e a desertificação. Os dados de ICV para a variável de erosão $\left(\mathrm{V}_{\text {Erosão }}\right)$ requer apenas uma estimativa da erosão hídrica para a área de estudo. A erosão devido à ação do vento não foi incluída, pois, por comparação, a erosão hídrica provoca maiores perdas de solo em escala mundial (NUNEZ et al., 2010).

Os autores utilizaram a equação universal de perda de solo (USLE; WISCHMEIER \& SMITH, 1978), pois argumentam que é um modelo quantitativo de avaliação de perdas de solo de nível internacional e amplamente aplicada. A USLE prevê a taxa média anual de erosão hídrica, em longo prazo, com base em padrão de precipitação, tipo de solo, topografia, sistema de cultivo e práticas de manejo.

Já a superexploração de aquíferos pode ser definida como a situação em que, ao longo de um período de anos, a taxa média de captação é maior do que a taxa de recarga média. A estimativa de dados no ICV para a variável $\left(\mathrm{V}_{\text {Aquífero }}\right)$ precisa levar em conta o equilíbrio hidrológico na área em estudo. 
Os incêndios florestais, causas reconhecidas da desertificação, são um dos principais fatores que influenciam a estrutura e a função dos ecossistemas terrestres em todo o mundo. Os dados de ICV para a variável de risco de incêndio $\left(\mathrm{V}_{\text {Incêndio }}\right)$ foram obtidos por meio da quantificação do percentual acumulado de superfície afetada por incêndios florestais durante os últimos 10 anos na área geográfica em estudo. Na falta de dados disponíveis, podem ser utilizados dados estatísticos durante um período de 10 anos.

Os autores usaram a classificação das ecorregiões de Bailey (1996; 1998), pois tem como base as condições de macro clima e as formações vegetais prevalentes, além de estar disponível em um formato compatível para uso no SIG, através do qual os fatores de caracterização foram calculados. A configuração de cada layer (uma para cada variável) foi baseada na coleção de mapas e dados estatísticos de diversas fontes de informação:

- $\mathrm{CF}_{\text {Aridez }}^{\mathrm{i}}$ (fator de caracterização para a variável aridez para cada ecorregião, i) foi baseado no mapa de índice de aridez global do Global Agro-Ecological Zoning 2000 da FAO e IIASA (FISCHER et al., 2000 apud NUNEZ et al., 2010).

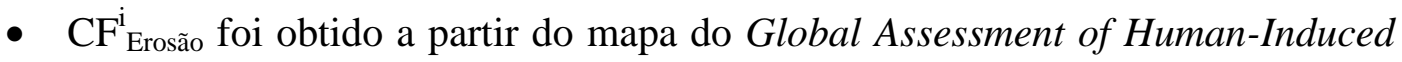
Soil Degradation (GLASOD; ISRIC, 2008).

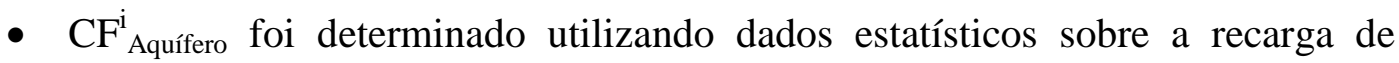
aquíferos e as taxas de exploração por país, publicados pela EEA (1999), EMWIS (2007), FAO (2007a apud NUNEZ et al., 2010), e WRI (2007).

- $\mathrm{CF}^{\mathrm{i}}$ Incêndio também foi obtido a partir de dados estatísticos a nível nacional publicado pela FAO (2006; 2007b; 2008 apud NUNEZ et al., 2010) e UNEP (2002 apud NUNEZ et al., 2010).

Uma vez que as informações sobre cada uma das quatro variáveis foi compilada, foi realizado o georreferenciamento no SIG, permitindo a sobreposição das ecorregiões de Bailey com as quatro variáveis de desertificação.

Assim, o fator de caracterização para cada ecoregião pode ser calculado como a soma dos fatores para cada uma das quatro variáveis.

Após a sobreposição, apenas 8 das 15 ecorregiões apresentaram índice de aridez média como árido, semiárido ou seco sub-úmido. Estas ecorregiões são: marinha, Mediterrâneo, pradaria, savana, estepe temperado, estepe tropical / subtropical, deserto temperado e tropical 
deserto / subtropical, que representam 38\% da superfície total do terreno. Nas sete ecorregiões restantes, $\mathrm{CF}_{\text {Aridez é igual a } 0 .}^{\mathrm{i}}$

Embora o modelo desenvolvido por Nunez et al. (2010) pode ser uma abordagem simplificada, ele pode ser calibrado e aprimorado quando aplicado a estudos de casos específicos.

O trabalho de Nunez et al. (2010) ganha destaque na perspectiva deste trabalho uma vez que o problema da desertificação no Brasil atinge a porção semi-árida do país, basicamente concentrada na Região Nordeste, cujas características físico-ambientais, tais como a evapotranspiração elevada, ocorrência de secas, solos de pouca profundidade, alta salinidade, baixa fertilidade e reduzida capacidade de retenção de água, limitam seu potencial produtivo.

\subsection{O modelo de Müller-Wenk e Brandão (2010)}

O estudo lida com a liberação e armazenamento de carbono na vegetação ou solo e seu impacto climático. A relevância do estudo de Müler-Wenk \& Brandão (2010) se justifica pela capacidade dos solos de reter carbono ou de emitir os gases relacionados ao efeito estufa, evidenciando seu papel ativo na regulação do clima.

O uso da terra em uma determinada área influencia o sistema climático de várias formas, em especial:

- $\quad$ Os fluxos de $\mathrm{CO}_{2}$ entre a terra e a atmosfera podem ser modificados devido a uma mudança do armazenamento de carbono da área de vegetação e do solo, influenciando a absorção da radiação solar pela atmosfera (forçamento radiativo).

- $\quad$ O fluxo de gases de efeito estufa (além do $\mathrm{CO}_{2}$ ) pode ser modificado.

- $\quad$ Pode haver a mudança no albedo da área, influenciando a reflexão da radiação solar na superfície da Terra.

- A evapotranspiração da área pode ser modificada, influenciando a precipitação e a reflexão da radiação solar por nuvens.

O foco principal do estudo é a influência do uso da terra sobre as transferências de $\mathrm{CO}_{2}$ entre atmosfera e terra (incluindo solo e vegetação). O objetivo foi quantificar essa influência para cada uma das principais zonas biogeográficas da Terra e para cada um dos principais tipos de uso da terra humana (solo urbano, floresta, pastagens e terras agrícolas). 
$\mathrm{O}$ indicador do impacto é expresso em tonelada de $\mathrm{CO}_{2}$, o que significa que o indicador de impacto tradicionalmente utilizado na ACV para as emissões fósseis e potencial de aquecimento global industrial também é aplicável para os impactos climáticos do uso da terra. Nesta primeira proposta, os autores concentram-se no fluxo de carbono na forma de $\mathrm{CO}_{2}$ e não incluem os fluxos de outros gases de efeito estufa.

Os autores se concentraram nos fluxos de $\mathrm{CO}_{2}$ causados pelo uso da terra no sentido estrito, incluindo mudanças na qualidade do solo e da vegetação, não tratando de fluxos causados pelo uso de máquinas ou materiais auxiliares (como combustíveis e fertilizantes).

$\mathrm{Na} A C V$, o indicador amplamente utilizado para as emissões de $\mathrm{CO}_{2}$ provenientes da queima de combustíveis fósseis e processos técnicos semelhantes são expressas em tonelada de $\mathrm{CO}_{2}$. Para facilitar a interpretação dos resultados é desejável utilizar este mesmo indicador também para as emissões de origem do uso da terra. No entanto, o efeito climático não depende apenas da quantidade transferida, mas também sobre o tempo médio da respectiva quantidade de $\mathrm{CO}_{2}$ que permanece no ar.

De acordo com Müller-Wenk \& Brandão (2010), se uma série de ocupações da terra segue após a transformação da terra, o relaxamento é adiado pelo número de anos $N$, destas ocupações. No entanto, o prolongamento correspondente por $N$ anos da permanência do $\mathrm{CO}_{2}$ no ar é um impacto, o qual é atribuído aos $N$ anos de ocupações e não para a transformação inicial de terra.

Como o tempo exato não é bem conhecido, os autores assumem a hipótese simplificada de que o tempo médio de permanência no ar do carbono é a metade do tempo de relaxamento.

O carbono emitido a partir da queima de combustíveis fósseis e processos industriais semelhantes tem um tempo médio de permanência no ar de 157 anos. Para a transformação da terra, o tempo médio de permanência do carbono no ar é de $50 \%$ do tempo de relaxamento (o tempo necessário para inverter a transformação). Já para a ocupação da terra, o tempo médio de permanência do carbono no ar é igual ao tempo de ocupação, porque o carbono transmitido ao ar por uma transformação da terra anterior estende sua estadia pelo período de ocupação.

A referência para determinar os fluxos de carbono a partir do uso da terra é o teor de carbono da VNP que está associada a cada uma das localizações geográficas do globo. Segundo os autores, valores aproximados do estoque de carbono por hectare na vegetação e no solo estão disponíveis a partir de estudos de campo para os principais tipos de VNP.

Neste modelo são necessários, portanto, dados relativos à quantidade de carbono transferido de vegetação / solo para o ar, por hectare, bem como sobre o tempo médio de 
permanência no ar. Este conjunto de dados deve estar disponível para todas as zonas climáticas do globo e dentro de cada zona climática para todos os tipos de transformações de terras e ocupações de terra. Para permanecer dentro de limites dos requisitos de dados, as zonas climáticas foram agregadas nos seis biomas que mais sofrem com o uso da terra: florestas tropicais, florestas temperadas, florestas boreais, pastagens tropicais e pastagens temperadas.

Os autores optaram por trabalharem com dados de estoque de carbono do German Advisory Council on Global Change (WBGU), pois fornecem dados de fluxos de carbono em nível global.

Além disso, os autores partem ainda de pressupostos como:

- Transformações de floresta para área cultivada transferem para o ar $100 \%$ de carbono da vegetação e $25 \%$ do carbono do solo.

- Transformações de floresta para pastos transferem para o ar $100 \%$ do carbono da vegetação e $0 \%$ do carbono do solo.

- Transformações de floresta para áreas artificiais transferem para o ar 100\% de carbono da vegetação e $25 \%$ do carbono do solo.

- Transformações de pastos para áreas cultivadas transferem para o ar $25 \%$ do carbono do solo. $\mathrm{O}$ mesmo se aplica às transformações de pastagem para áreas artificiais.

Segundo Müller-Wenk \& Brandão (2010), as fontes de dados para determinar o número de anos de recuperação são incompletas e de pouca consistência, sendo apenas estimativas grosseiras. Assim, as seguintes fontes de dados foram utilizadas:

- WBGU (1998) o qual contém informações sobre as taxas médias de armazenamento de carbono anual na vegetação e no solo.

- IPCC (2000) o qual complementa as informações sobre as taxas de armazenamento de carbono na vegetação e no solo por hectare, para alguns tipos de transformação da terra.

Para os autores, apesar do excelente trabalho do IPCC, ainda existe limitações quanto aos dados disponíveis sobre o teor de carbono na vegetação e no solo, e dados sobre as transferências de carbono para a atmosfera devido a determinados tipos de uso da terra. 
6 ANÁliSE DA APLICABILIDADE E REGIONALIZAÇÃO DOS MODELOS DE CARACTERIZAÇÃO E RECOMENDAÇÕES PARA A AVALIAÇÃO DOS IMPACTOS DO USO DA TERRA NO BRASIL

6.1 Análise comparativa dos modelos de caracterização de impactos do uso da terra

A relação de características dos modelos descritos neste trabalho é apresentada no Quadro 6 a seguir, classificadas de acordo com os procedimentos metodológicos anteriormente estabelecidos no Capítulo 2. 


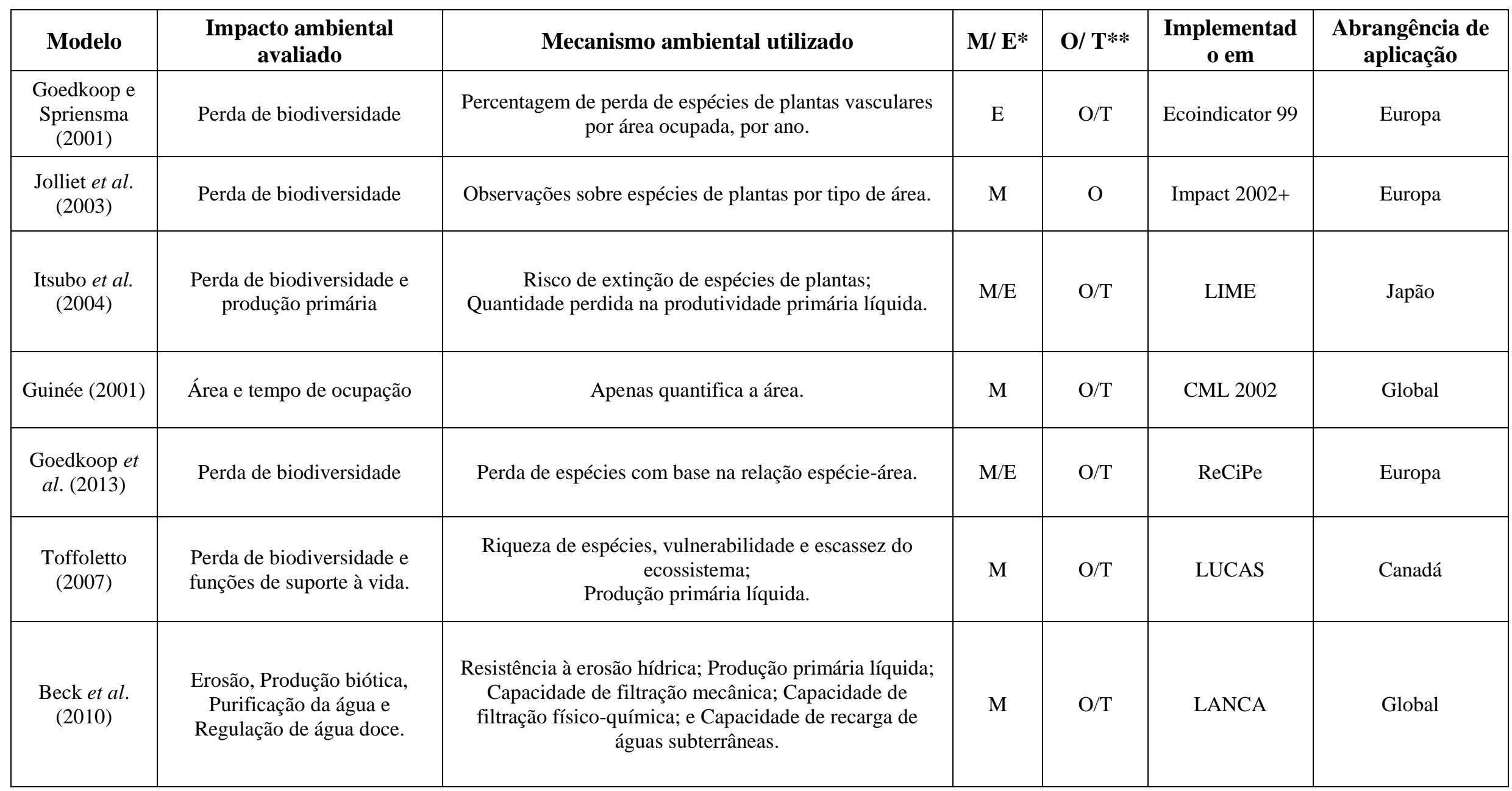

Quadro 6: Características dos modelos de caracterização para impactos do uso da terra: Abordagem midpoint (M) ou endpoint (E), Impactos de ocupação (O) e transformação (T), Implementado em método de AICV e Abrangência de aplicação (Continua).

* Abordagem midpoint ou endpoint.

**Ocupação ou transformação da terra 


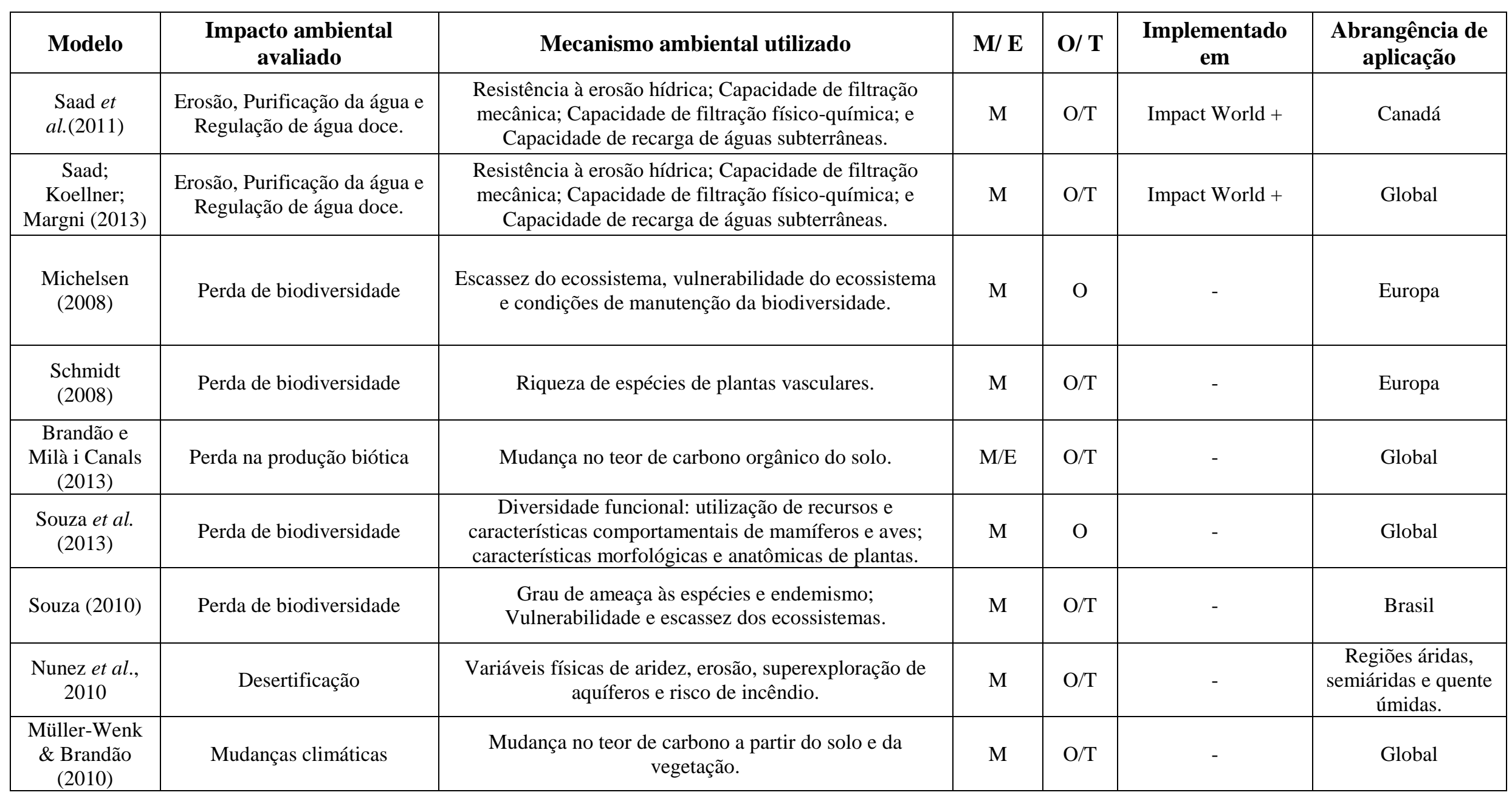

Quadro 6: Características dos modelos de caracterização para impactos do uso da terra: Abordagem midpoint (M) ou endpoint (E), Impactos de ocupação (O) e transformação (T), Implementado em método de AICV e Abrangência de aplicação (Conclusão).

* Abordagem midpoint ou endpoint.

**Ocupação ou transformação da terra 
A partir das características listadas no Quadro 6 é possível observar que a maioria das abordagens se concentra na avaliação da perda de biodiversidade, principalmente através de indicadores de riqueza de espécies. Contudo, é possível observar que os estudos mais recentes incluem outras vias de impacto, até então não comumente empregadas, como no caso do modelo de Nunez et al. (2010) e Müller-Wenk \& Brandão (2010). Destaca-se também a proposta de Beck et al. (2010), a qual introduz novos indicadores de maneira a abranger diversos impactos ambientais antes negligenciados, como erosão, purificação e regulação da água. Já o estudo de Guinée (2001), implementado no método CML 2002, não apresenta um modelo específico de avaliação de impacto, o que compromete sua aplicação no sentido de não abranger a magnitude dos impactos ambientais causados pelo uso da terra.

Quanto às intervenções consideradas nos modelos de caracterização, a maioria contempla tanto processos de ocupação quanto de transformação.

Por fim, ao analisar a região específica para a qual os fatores de caracterização de cada modelo foram desenvolvidos, nota-se que dos 16 modelos listados, muitos se limitam a regiões específicas: 5 modelos indicam a Europa (sendo três adotados pelos métodos Ecoindicator 99, Impact 2002+ e ReCiPe); e 3 se limitam a países como Japão e Canadá (ITSUBO et al., 2004; TOFFOLETTO, 2007; SAAD et al., 2011). Já o modelo de Nunez et al. (2010) é específico para regiões áridas, semiáridas e quente úmidas. Observa-se também que 6 destes modelos apresentam a área de cobertura global: Saad, Koellner, Margni (2013); Brandão \& Milà i Canals (2013); Souza et al. (2013); Beck et al. (2010); Müller-Wenk \& Brandão (2010); e Guinée (2001), o qual é implementado no método de CML 2002. Quanto a este critério, destaca-se principalmente o estudo de Souza (2010), o qual propõe um modelo adequado às particularidades do contexto ambiental do Brasil para a avaliação de impactos sobre a biodiversidade devido ao uso da terra.

No Quadro 7 a seguir são apresentadas informações complementares necessárias para o desenvolvimento do modelo e cálculo dos fatores de caracterização. 


\begin{tabular}{|c|c|c|c|c|}
\hline Modelo & Área de coleta & $\begin{array}{l}\text { Diferenciação bio- } \\
\text { geográfica }\end{array}$ & Tempo de recuperação & Situação de referência \\
\hline $\begin{array}{l}\text { Goedkoop e } \\
\text { Spriensma } \\
\text { (2001) }\end{array}$ & Europa & $\mathrm{Nd}^{*}$ & $\begin{array}{l}\text { Tempo necessário para que o ecossistema } \\
\text { atinja qualidade comparável à anterior à } \\
\text { transformação e ocupação. De forma } \\
\text { simplificada são considerados cinco anos para } \\
\text { a conversão da tipologia de agricultura para } \\
\text { áreas urbanas (e vice-versa) e } 30 \text { anos de áreas } \\
\text { naturais para áreas urbanas ou de agricultura. }\end{array}$ & $\begin{array}{l}\text { Estado original para impactos de } \\
\text { transformação. Estado natural para } \\
\text { impactos de ocupação (corresponde à } \\
\text { vegetação natural potencial, sendo } \\
\text { usado o fator de riqueza de espécies } \\
\text { para as planícies suíças). }\end{array}$ \\
\hline $\begin{array}{l}\text { Jolliet et al. } \\
\quad(2003)\end{array}$ & Europa & $\mathrm{Nd}$ & $\begin{array}{l}\text { Tempo necessário para que o ecossistema } \\
\text { atinja qualidade comparável à anterior à } \\
\text { transformação e ocupação. De forma } \\
\text { simplificada são considerados cinco anos para } \\
\text { a conversão da tipologia de agricultura para } \\
\text { áreas urbanas (e vice-versa) e } 30 \text { anos de áreas } \\
\text { naturais para áreas urbanas ou de agricultura. }\end{array}$ & $\begin{array}{l}\text { Estado original para impactos de } \\
\text { transformação. Estado natural para } \\
\text { impactos de ocupação (neste caso } \\
\text { corresponde à vegetação natural } \\
\text { potencial, sendo usado o fator de } \\
\text { riqueza de espécies para as planícies } \\
\text { suíças). }\end{array}$ \\
\hline $\begin{array}{l}\text { Itsubo et al. } \\
\text { (2004) }\end{array}$ & Japão & $\mathrm{Nd}$ & $\mathrm{Nd}$ & $\mathrm{Nd}$ \\
\hline Guinée (2001) & $\mathrm{Nd}$ & $\mathrm{Nd}$ & $\mathrm{Nd}$ & $\mathrm{Nd}$ \\
\hline $\begin{array}{l}\text { Goedkoop et al. } \\
\text { (2013) }\end{array}$ & Europa & $\mathrm{Nd}$ & $\begin{array}{l}\text { São adotados os dados de Bastian \& Schreiber } \\
\text { (1999), desenvolvendo um conjunto de } \\
\text { tempos de restauração que diferem } \\
\text { dependendo dos tipos de uso da terra antes e } \\
\text { depois da transformação. }\end{array}$ & $\begin{array}{l}\text { Tamanho da área e número de } \\
\text { espécies do tipo de uso da terra sem } \\
\text { ocupação. }\end{array}$ \\
\hline
\end{tabular}

Quadro 7: Características dos modelos de caracterização: Área de coleta, Diferenciação bio-geográfica, Tempo de recuperação e Situação de referência. (Continua)

* Informação não disponível 


\begin{tabular}{|c|c|c|c|c|}
\hline Modelo & Área de coleta & $\begin{array}{l}\text { Diferenciação bio- } \\
\text { geográfica }\end{array}$ & Tempo de recuperação & Situação de referência \\
\hline $\begin{array}{l}\text { Toffoletto } \\
\text { (2007) }\end{array}$ & Canadá & Ecozonas canadenses & $\mathrm{Nd}$ & $\mathrm{Nd}$ \\
\hline $\begin{array}{l}\text { Beck et al. } \\
\quad(2010)\end{array}$ & $\begin{array}{l}\text { O usuário é } \\
\text { responsável pela } \\
\text { inserção dos dados }\end{array}$ & País & $\mathrm{Nd}$ & $\begin{array}{l}\text { Qualidade da terra após a } \\
\text { recuperação. }\end{array}$ \\
\hline $\begin{array}{l}\text { Saad et } \\
\text { al. }(2011)\end{array}$ & Canadá & Ecozonas e Ecorregiões & $\begin{array}{l}\text { Tempo necessário para atingir o estado de } \\
\text { VNP. }\end{array}$ & Vegetação natural potencial \\
\hline $\begin{array}{l}\text { Saad; Koellner; } \\
\text { Margni (2013) }\end{array}$ & Global & $\begin{array}{l}\text { Biomas -WWF } \\
\text { Classificação Holdridge } \\
\text { (regiões e zonas) }\end{array}$ & $\begin{array}{c}\text { Estimativas sugeridas por van Dobben } \text { et al. } \\
\text { (1998) em uma escala global, para cada } \\
\text { serviço do ecossistema. }\end{array}$ & Vegetação natural potencial \\
\hline $\begin{array}{l}\text { Brandão e Milà } \\
\text { i Canals (2013) }\end{array}$ & Global & Regiões climáticas -IPCC & $\begin{array}{l}\text { Utiliza fatores do IPCC. Para atividades de } \\
\text { agricultura e silvicultura é adotado o tempo de } \\
20 \text { anos e para atividades onde o solo já foi } \\
\text { totalmente transformado, usam os dados de } \\
\text { Lindeijer et al. (1998). }\end{array}$ & Cobertura da terra (semi) natural \\
\hline $\begin{array}{l}\text { Michelsen } \\
\text { (2008) }\end{array}$ & Europa & Ecorregiões & $\mathrm{Nd}$ & $\mathrm{Nd}$ \\
\hline Schmidt (2008) & Europa & $\mathrm{Nd}$ & $\begin{array}{c}\text { Baseado em Köllner (2003), segundo latitude } \\
\text { e altitude. }\end{array}$ & Áreas naturais florestais \\
\hline
\end{tabular}

Quadro 7: Características dos modelos de caracterização: Área de coleta, Diferenciação bio-geográfica, Tempo de recuperação e Situação de referência. (Continuação) 


\begin{tabular}{|c|c|c|c|c|}
\hline Modelo & Área de coleta & $\begin{array}{l}\text { Diferenciação bio- } \\
\text { geográfica }\end{array}$ & Tempo de recuperação & Situação de referência \\
\hline $\begin{array}{l}\text { Souza et al. } \\
\quad(2013)\end{array}$ & $\begin{array}{l}\text { Brasil, Bolívia, Peru, } \\
\text { Panamá, Costa Rica, } \\
\text { México, EUA, Canadá } \\
\text { e bases globais. }\end{array}$ & Ecorregiões (WWF) & $\mathrm{Nd}$ & $\begin{array}{l}\text { Vegetação natural potencial- } \\
\text { Ecossistemas (semi) naturais. }\end{array}$ \\
\hline Souza (2010) & Brasil & Ecorregiões (WWF) & Valores corrigidos de Köllner (2003). & $\begin{array}{l}\text { Vegetação natural potencial. } \\
\text { Dados da Lista Vermelha de } \\
\text { espécies (riqueza de espécies total e } \\
\text { endêmica de cada ecorregião). }\end{array}$ \\
\hline $\begin{array}{l}\text { Nunez et al., } \\
\quad 2010\end{array}$ & Global & $\begin{array}{l}\text { Ecorregiões de Bailey } \\
\quad(1996,1998)\end{array}$ & $\mathrm{Nd}$ & $\mathrm{Nd}$ \\
\hline $\begin{array}{l}\text { Müller-Wenk \& } \\
\text { Brandão (2010) }\end{array}$ & Global & Regiões climáticas - IPCC & Baseado em WBGU (1998) e IPCC (2000) & $\begin{array}{l}\text { Teor de carbono do solo em situação } \\
\text { de vegetação natural potencial. }\end{array}$ \\
\hline
\end{tabular}

Quadro 7: Características dos modelos de caracterização: Área de coleta, Diferenciação bio-geográfica, Tempo de recuperação e Situação de referência. (Conclusão) 
Os impactos do uso da terra são altamente dependentes das condições do lugar onde eles ocorrem, ou seja, a mesma intervenção pode ter consequências diferentes dependendo da sensibilidade e qualidade da terra inerente do ambiente onde ela ocorre. Portanto, para ter resultados significativos na avaliação, a dependência local dos impactos ambientais deve ser incorporada na ACV (MILÀ I CANALS et al., 2007).

É possível observar que as áreas consideradas para coleta condizem com as regiões indicadas no Quadro 6 e ainda é predominante estudos que utilizam dados europeus nos modelos. Porém, vale destacar que quatro dos modelos (Nunez et al., 2010; Brandão \& Milà i Canals, 2013; Saad, Koellner, Margni, 2013; Müller-Wenk \& Brandão, 2010) consideram áreas dos diferentes continentes do mundo durante os cálculos de seus fatores de caracterização. Destaca-se, sobretudo a existência de dois modelos que envolvem diretamente o Brasil durante a coleta de dados para o cálculo dos fatores de caracterização: Souza (2010) e Souza et al. (2013).

Ademais, a diferenciação bio-geográfica deve ser adequada e o principal parâmetro bio-geográfico determinante da qualidade dos solos é o clima (temperatura e precipitação), além do tipo de solo, declividade, cobertura vegetal e tipo de uso do solo.

Verifica-se que não há um consenso sobre a diferenciação espacial empregada nos modelos de caracterização, porém, cinco dos dezesseis modelos adotam a classificação em ecorregiões. É possível que esta seja uma tendência para novos métodos de AICV uma vez que publicações recentes (KOELLNER et al., 2013a, 2013b) estabelecem diretrizes da UNEP e SETAC para a avaliação dos impactos do uso da terra, sugerindo a regionalização hierárquica em escala global com base no sistema de classificação de biomas e ecorregiões de Olson et al. (2001).

Outro aspecto importante na avaliação dos impactos do uso da terra na ACV refere-se ao tempo de recuperação. Como discutido, cada uma das vias de impacto requer um conjunto de tempo de recuperação, por tipo de transformação e por região climática. No entanto, como a intensidade do uso da terra em muitas partes do mundo é um fenômeno novo, o conhecimento sobre os tempos de recuperação dos ecossistemas dentro da paisagem utilizada é limitado ou dificilmente disponível.

Geralmente, o tempo de recuperação aumenta nos polos e com a altitude, dependendo também do tipo de impacto, bem como a função do ecossistema ou grupo taxonômico considerado (Jones \& Schmitz 2009). Assim, destaca-se o trabalho de Schmidt (2008) e Souza (2010), o qual adotou a correção dos dados de Köllner (2003) para os tempos de 
recuperação da Mata Atlântica, seguida de uma correção dos valores, segundo diferentes latitudes $\left(\sim 5^{\circ} \mathrm{a} \sim 35^{\circ} \mathrm{S}\right)$ e altitudes $(0 \mathrm{a} 3000 \mathrm{~m})$ presentes no Brasil.

Por fim, outro parâmetro crítico é a escolha da situação de referência, em termos de qualidade da terra, para a comparação de impactos de transformação e ocupação. Alguns estudos adotam o estágio de equilíbrio atingido pelo solo após sua recuperação como referência. Contudo, existem limitações como a definição do tempo de recuperação da terra, de acordo com cada estrutura ambiental, e a nova configuração do ecossistema.

Para estudos de ACV, o conceito de VNP e o estado (semi) natural podem ser suficientes já que os dados globais sobre tais propriedades estão disponíveis para muitas regiões biogeográficas e com qualidade satisfatória. Observa-se que a metade dos modelos analisados adota a VNP, podendo ser considerada uma tendência para próximos trabalhos. Ressalta-se, porém, que a definição de uma situação de referência é reconhecida como uma escolha de valor e ainda requer mais estudos.

Por fim, para finalizar a análise dos modelos de caracterização, são apresentados no Quadro 8 os resultados obtidos após a verificação da conformidade dos modelos em relação aos critérios de relevância ambiental e robustez científica definidos anteriormente no Capítulo 2. Esta análise final dá suporte às recomendações para a aplicação destes modelos no Brasil bem como à futuras adaptações metodológicas necessárias para uma melhor avaliação dos impactos do uso da terra no país, apresentadas na seção seguinte.

Nesta etapa, destaca-se que a existência de apenas um modelo de caracterização de avaliação de impactos na biodiversidade, desenvolvido especificamente para o contexto brasileiro: Souza (2010). Assim, para atender a toda a diversidade de impactos causada pelo uso da terra, são necessários outros modelos, pautados em conhecimentos científicos e de relevância ambiental satisfatória, que tenham o escopo de aplicação global. Os modelos de Brandão \& Milà i Canals (2013), Müller-Wenk \& Brandão (2010), Nunez et al. (2010), Saad, Koellner, Margni (2013) e Souza et al. (2013) apresentam boa conceituação segundo os requisitos definidos, sendo portanto, indicados para a aplicação na avaliação dos impactos do uso da terra. 


\begin{tabular}{|c|c|c|}
\hline \multirow{2}{*}{ Modelo } & \multicolumn{2}{|c|}{ Robustez científica e Relevância ambiental } \\
\hline & Pontos fortes & Pontos fracos \\
\hline $\begin{array}{l}\text { Goedkoop e } \\
\text { Spriensma } \\
\text { (2001) }\end{array}$ & $\begin{array}{l}\text { O modelo está pronto para implementação e sua } \\
\text { documentação está disponível. } \\
\text { O modelo considera tanto a ocupação quanto a } \\
\text { transformaçãa. }\end{array}$ & 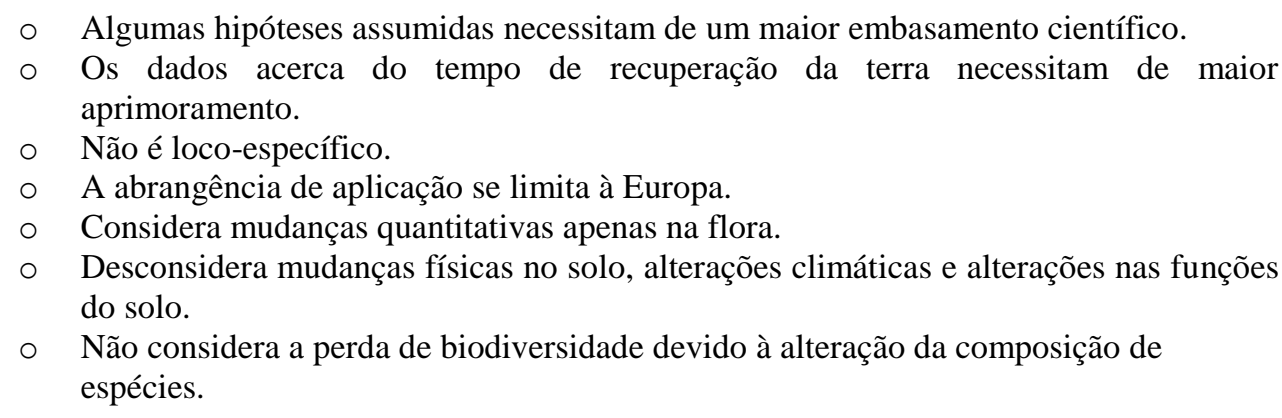 \\
\hline $\begin{array}{l}\text { Jolliet et al. } \\
\quad(2003)\end{array}$ & $\begin{array}{l}\text { O modelo está pronto para implementação e sua } \\
\text { documentação está disponível. } \\
\text { O modelo considera tanto a ocupação quanto a } \\
\text { transformaçãa. }\end{array}$ & $\begin{array}{ll}\text { ○ } & \text { Desconsidera mudanças físicas no solo, alterações climáticas e alterações nas funções } \\
& \text { do solo. } \\
\circ & \text { Algumas hipóteses assumidas necessitam de um maior embasamento científico. } \\
\circ & \text { Há um erro conceitual quanto à inserção de um fator na categoria de ocupação uma } \\
\text { vez que é mais relacionado aos impactos de transformação. } \\
\text { N Não é loco-específico } \\
\circ \text { Um tempo de remediação arbitrário de } 100 \text { anos é aplicado para a recuperação. } \\
\text { A abrangência de aplicação se limita à Europa. } \\
\circ \text { Considera mudanças quantitativas apenas na flora. } \\
\circ \text { Não considera a perda de biodiversidade devido à alteração da composição de } \\
\text { espécies. }\end{array}$ \\
\hline $\begin{array}{l}\text { Itsubo } \text { et al. } \\
\quad(2004)\end{array}$ & $\begin{array}{l}\text { Modelo específico, com base científica e pronto } \\
\text { para implementação. } \\
\text { O modelo considera tanto a ocupação quanto a } \\
\text { transformação. } \\
\text { É temporalmente específico. } \\
\text { Considera os efeitos na produção primária } \\
\text { líquida. }\end{array}$ & $\begin{array}{l}\circ \text { A abrangência de aplicação se limita ao Japão. } \\
\circ \text { Considera mudanças quantitativas apenas na flora. } \\
\circ \text { A documentação está disponível, mas existem informações publicadas apenas na } \\
\text { língua japonesa. } \\
\circ \text { Desconsidera mudanças físicas no solo e efeitos de alterações climáticas. } \\
\circ \quad \begin{array}{l}\text { Não considera a perda de biodiversidade devido à alteração da composição de } \\
\text { espécies. }\end{array}\end{array}$ \\
\hline Guinée (2001) & $\begin{array}{l}\text { O modelo tem abrangência de aplicação global. } \\
\text { ○ Pronto para implementação. }\end{array}$ & $\begin{array}{l}\text { Não apresenta cálculo da magnitude do impacto, apenas a indicação da área e tempo } \\
\text { de ocupação. } \\
\text { ○ Não é temporalmente e loco específico. } \\
\text { ○ Não apresenta cálculo da magnitude do impacto. }\end{array}$ \\
\hline
\end{tabular}

Quadro 8: Análise dos modelos de caracterização quanto à robustez científica e relevância ambiental. (Continua) 


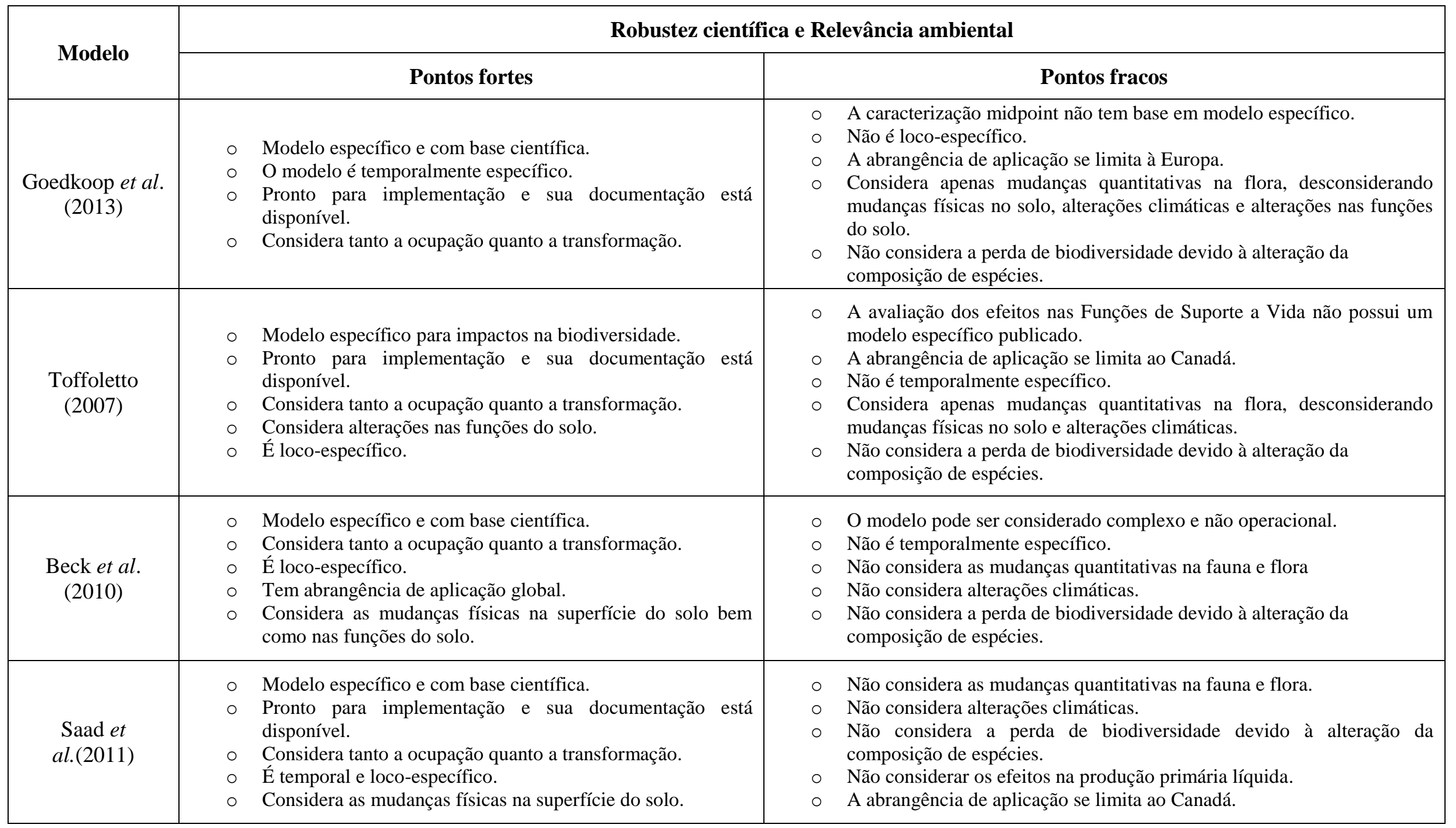

Quadro 8: Análise dos modelos de caracterização quanto à robustez científica e relevância ambiental. (Continuação) 


\begin{tabular}{|c|c|c|}
\hline Modelo & \multicolumn{2}{|c|}{ Robustez científica e Relevância ambiental } \\
\hline $\begin{array}{l}\text { Saad; Koellner; } \\
\text { Margni (2013) }\end{array}$ & $\begin{array}{ll}\circ & \text { Modelo específico e com base científica. } \\
\circ & \text { Pronto para implementação e sua documentação está } \\
\text { disponível. } & \\
\circ & \text { Considera tanto a ocupação quanto a transformação. } \\
\circ & \text { Tem abrangência de aplicação global. } \\
\circ & \text { É temporal e loco-específico. } \\
\circ & \text { Considera as mudanças físicas na superfície do solo. }\end{array}$ & $\begin{array}{l}\text { Não considera as mudanças quantitativas na fauna e flora. } \\
\text { ○ Não considera alterações climáticas. } \\
\text { ○ Não considera a perda de biodiversidade devido à alteração da } \\
\text { composição de espécies. } \\
\text { ○ão considerar os efeitos na produção primária líquida. }\end{array}$ \\
\hline Schmidt (2008) & $\begin{array}{ll} & \text { Usa um modelo específico com base científica. } \\
\circ & \text { Pronto para implementação e sua documentação está } \\
\text { disponível. } \\
\circ \\
\circ \text { É temporalmente específico. } \\
\circ & \text { Considera tanto a ocupação quanto a transformação da terra. } \\
\circ & \text { Considera a perda de biodiversidade devido à alteração da } \\
\text { composição de espécies. }\end{array}$ & $\begin{array}{ll}\circ & \text { Não é loco-específico. } \\
\circ & \text { Abrangência de aplicação se limita à Europa. } \\
\circ & \text { Considera mudanças quantitativas apenas da flora. } \\
\circ & \text { Não considera alterações climáticas, alterações nas funções do solo ou } \\
\text { mudanças físicas no solo. }\end{array}$ \\
\hline
\end{tabular}

Quadro 8: Análise dos modelos de caracterização quanto à robustez científica e relevância ambiental. (Continuação) 


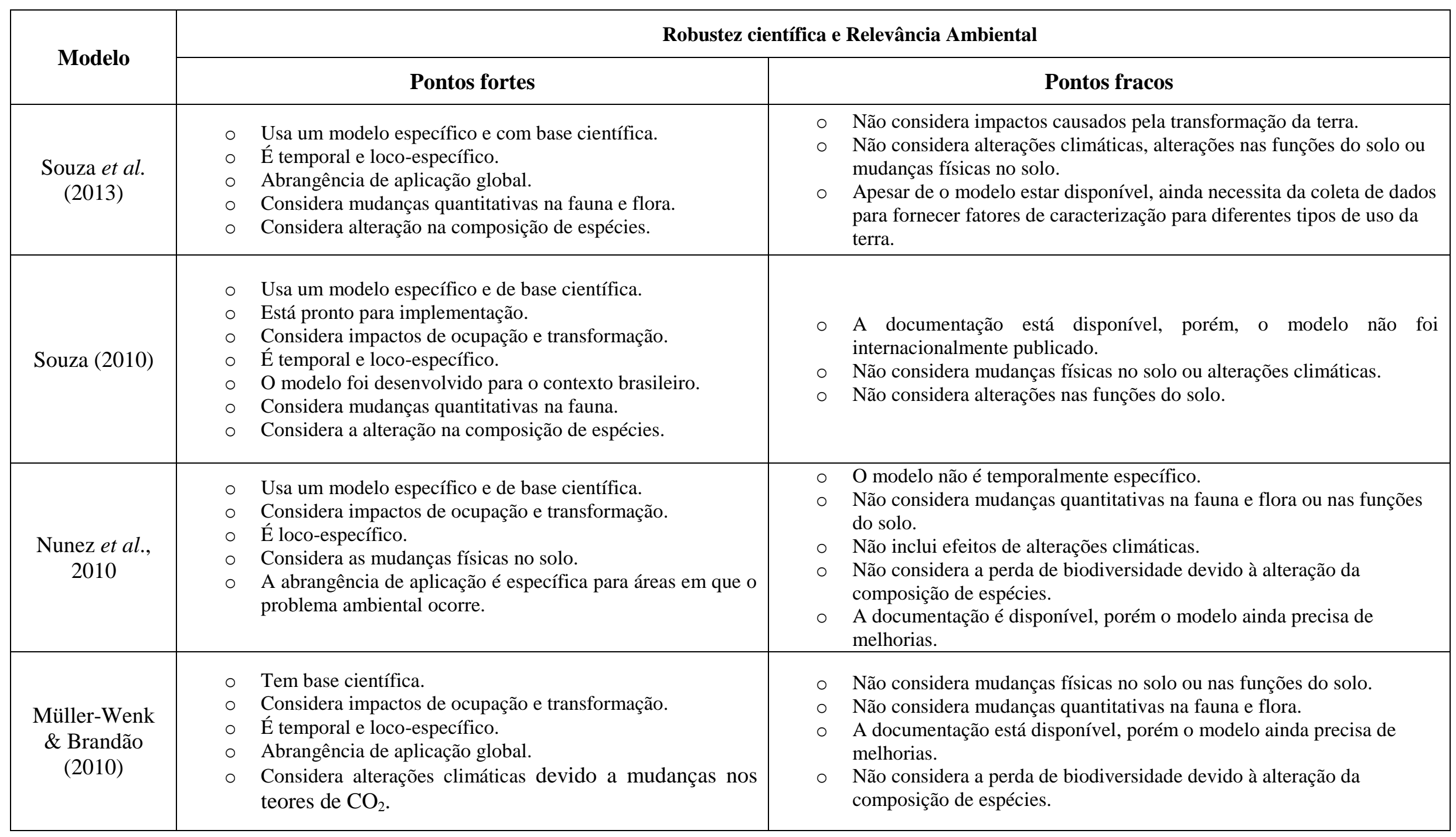

Quadro 8: Análise dos modelos de caracterização quanto à robustez científica e relevância ambiental. (Conclusão) 


\subsection{Recomendações para a avaliação dos impactos do uso da terra no Brasil}

Pode-se observar, através dos resultados apresentados no Capítulo 5 e nos quadros anteriores, que a avaliação dos impactos do uso da terra ainda apresenta aspectos conceituais e práticos que necessitam ser discutidos e adaptados a cada um dos indicadores usados. Atualmente, duas grandes linhas de indicadores são empregadas na avaliação destes impactos (Figura 23).

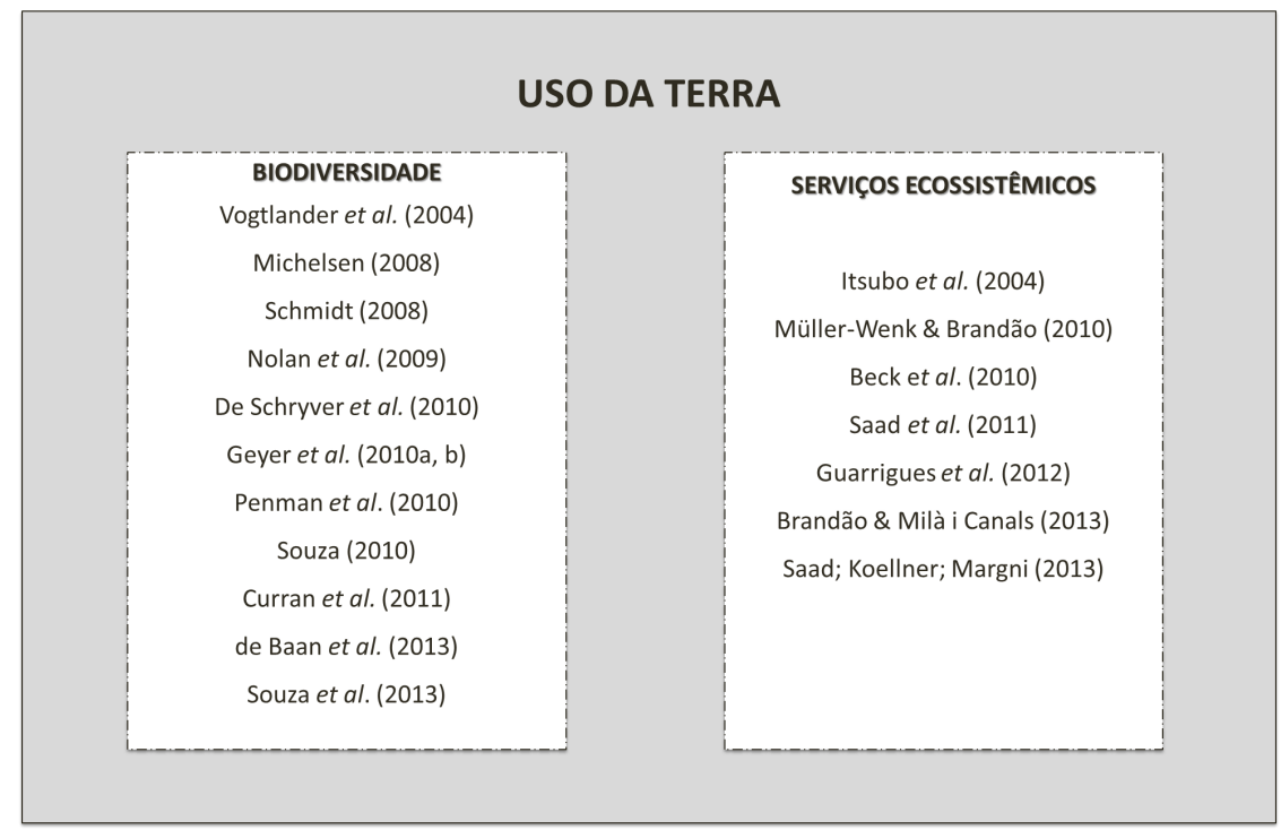

Figura 24: Abordagens de avaliação dos impactos do uso da terra na ACV.

Reconhecendo que não existe um consenso para os melhores modelos de caracterização para impactos do uso da terra (EC-JRC, 2011), foram indicados neste trabalho alguns modelos que apresentam majoritariamente pontos fortes e que levam em consideração a diferenciação espacial e a representatividade do local em seus desenvolvimentos. A Figura 24 a seguir sintetiza as recomendações apresentadas neste capítulo, indicando em qual ponto cada um dos estudos pode ser utilizado na quantificação dos impactos do uso da terra. 


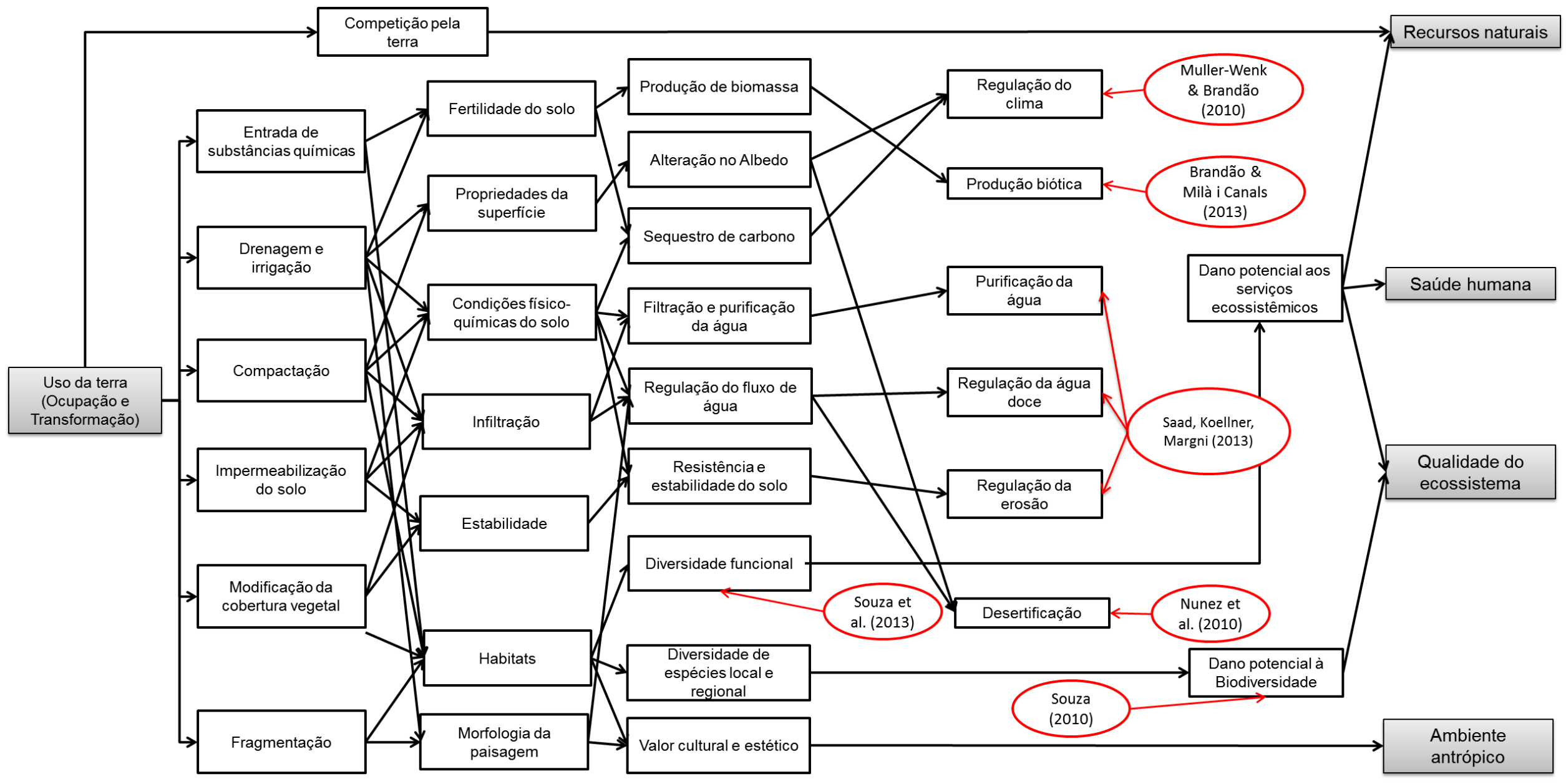

Figura 25: Cadeia de causa e efeito para impactos do uso da terra e modelos recomendados.

Fonte: Adaptado de Koellner et al. (2013b) 
A biodiversidade é um conceito multifacetado, sendo difícil expressar os impactos relacionados ao uso da terra em um único indicador. A riqueza de espécies pode ser considerada um indicador simples e com elevada disponibilidade de dados em comparação com outros indicadores de biodiversidade.

A desvantagem de usar a riqueza de espécies, no entanto, é que ela contém apenas informações limitadas sobre os muitos ângulos da biodiversidade. Em outras palavras, o indicador só registra a presença ou ausência de espécies dentro de uma área de amostragem e dá o mesmo peso a todas as espécies registradas, não importando quão abundante ou biologicamente distintas elas são. Neste sentido, o trabalho recente de Souza et al. (2013), apresenta um avanço por estudar as funções de cada uma das espécies no meio em que habitam e sua interação com as demais.

Além disso, o trabalho da mesma autora em 2010 vai ao encontro desta pesquisa, que é o aprimoramento da metodologia de ACV no que tange aos impactos do uso da terra tendo em vista o contexto ambiental brasileiro. Neste sentido, Souza (2010) contribui para uma análise detalhada das ecorregiões uma vez que o modelo sugere a inclusão de aspectos relacionados ao estado de conservação das ecorregiões (vulnerabilidade da área). Além disso, a autora considera dados regionais (mas disponíveis em escala global) e inova ao usar a diferenciação entre espécies endêmicas e não endêmicas. Por fim, destaca-se que além de ser o primeiro modelo de caracterização brasileiro para impactos na biodiversidade devido ao uso da terra, o estudo também é o primeiro a incluir espécies de vertebrados nesta análise.

Portanto, sabendo-se que os impactos do uso da terra são avaliados por duas vertentes (Figura 23), os modelos de Souza (2010) e Souza et al. (2013) apresentam-se como modelos de caracterização recomendados para a aplicação no contexto brasileiro no que tange aos impactos sobre a biodiversidade. Isto se justifica (i) pela abrangência de aplicação dos modelos; (ii) pelo fato de incluírem o Brasil na área de coleta de dados; (iii) pela regionalização, ou seja, à especificidade espacial do impacto e suas características.

A avaliação dos serviços do ecossistema e recursos do ecossistema é igualmente complexa. Estes incluem serviços de produção de alimento e água; serviços de regulação (de enchentes, secas, degradação dos solos, e doenças); serviços de suporte como a formação dos solos e os ciclos de nutrientes, e serviços culturais (como recreio, valor espiritual, valor religioso e outros benefícios não materiais).

Muitas funções ecossistêmicas do solo são difíceis de mensurar diretamente, assim, a qualidade do solo frequentemente deve ser avaliada por meio de outras propriedades (WEIL \& MAGDOFF, 2004). Neste sentido, um atributo relevante que vem sendo considerado na 
avaliação dos impactos do uso da terra na ACV é o potencial de produção biótica (PBB), uma vez que é a principal função do solo diretamente usada pelo homem (MILÀ I CANALS et al., 2007).

Sabe-se que o potencial de produção biótica (PPB) se refere à mudança na capacidade produtiva ou a capacidade do ecossistema de sustentar a futura produção de biomassa e depende, principalmente, de aspectos como o clima (temperatura e precipitação), tipo de solo, declividade, cobertura vegetal, a história do uso da terra e práticas de manejo. Como consequência, os impactos sobre PPB dependem não só do uso da terra em si, mas também da sensibilidade do ecossistema onde a atividade está localizada.

Apesar do grande número de propriedades que determinam o PPB, a adoção do teor de carbono orgânico do solo (COS) como um indicador é uma simplificação razoável, apoiada por evidências de que estes estão intimamente relacionados (CHRISTENSEN \& JOHNSTON, 1997). A base conceitual para esta sugestão reside no fato de que o teor de matéria orgânica do solo é um elo entre os dois.

$\mathrm{O}$ teor de matéria orgânica afeta a maioria das propriedades químicas, físicas e biológicas do solo, desempenhando um papel importante como um constituinte do solo e como fonte de alimento e energia para a biota. Influencia também a textura e estrutura do solo que, juntos, determinam a produtividade geral de sistemas de cultivo, influenciando a disponibilidade de nutrientes.

Segundo Brandão \& Milà i Canals (2013), o teor de matéria orgânica do solo é melhor quantificado pelo COS, uma vez que está intimamente relacionado com outros indicadores de qualidade do solo, tais como a capacidade de troca catiônica, biota e estrutura do solo. O COS está ligado também à capacidade de retenção de água no solo, disponibilidade de nutrientes, estabilidade estrutural e compactação do solo.

Uma vez que o COS e os seus componentes estão relacionados com um conjunto de características químicas, físicas e biológicas, bem como às variações temporais e espaciais, pode ser considerado um bom indicador para ser usado na AICV, como sugerido por Brandão \& Milà i Canals (2013). Tendo em vista a falta de uma metodologia específica para as condições brasileiras embasada neste indicador, recomenda-se a utilização deste modelo como alternativa. Esta recomendação se justifica tanto pelo embasamento científico demonstrado, quanto pelo fato de apresentar uma abrangência de aplicação global.

Outro aspecto relevante refere-se ao solo como parte do ciclo hidrológico, regulando a recarga de aquíferos e dos cursos de água superficiais, fontes naturais de disponibilização de água doce. Dessa forma, se os solos perdem sua vitalidade natural, ocorre o comprometimento 
da oferta de água em abundância e em qualidade necessárias aos ecossistemas naturais e manejados. Da mesma maneira, a erosão do solo é também um grave problema ambiental causado pela transformação e ocupação da terra.

No caso destes impactos sobre as funções ecológicas do solo (resistência à erosão, filtração mecânica, filtração físico-química e recarga de águas subterrâneas), a metodologia desenvolvida por Beck et al. (2010) propõe diferentes indicadores calculados como fluxos elementares, não podendo ser combinados ou ponderados em nível midpoint. Saad, Koellner, Margni (2013) aprimoraram este estudo de maneira a operacionalizar fatores de caracterização globais. Este modelo também pode ser recomendado para a aplicação no contexto brasileiro, bem como servir de referência para o desenvolvimento de metodologias específicas para o país. Isto se justifica pelo fato de ser um modelo consistente e permitir a avaliação quantitativa de atributos relevantes da degradação dos solos.

Ainda sobre os serviços dos ecossistemas, poucos estudos focam em mecanismos de impacto diferentes dos acima citados. Porém, destaca-se o trabalho de Nunez et al. (2010) e Müler-Wenk \& Brandão (2010), ambos de cobertura global. O primeiro se destaca pela abordagem de impactos de desertificação, causados por atividades como super-exploração da terra, o pastoreio, a agricultura mecanizada, as práticas inadequadas de irrigação, exploração madeireira ilegal e excessiva, os incêndios florestais e desmatamento. As principais consequências da desertificação são a incapacidade de terras já degradadas a se recuperar e a expansão da área de deserto (PINEDA, 2011). Já o estudo de Müler-Wenk \& Brandão (2010), o qual foca no impacto climático do uso da terra, destaca-se pela importância das emissões de $\mathrm{CO}_{2}$ no forçamento radiativo e devido à parcela substancial que a mudança do uso da terra representa como uma fonte de emissão de $\mathrm{CO}_{2}$ (IPCC, 2007).

Por fim, sabendo-se que muito trabalho ainda precisa ser feito para melhorar a avaliação destes impactos na $\mathrm{ACV}$, principalmente no que diz respeito à diferenciação espacial, tem-se como resultado final da análise realizada neste trabalho um guia com elementos-chave bem como possíveis fontes de dados a serem considerados em futuros estudos (Figura 25).

A construção deste esquema, resultando da revisão bibliográfica, envolveu a adaptação de guias previamente publicados por Souza (2010) e Koellner et al. (2013b). Desta forma, a figura sintetiza os parâmetros propostos para a modelagem, os quais resultam da análise dos modelos existentes e do estudo realizado sobre o mecanismo ambiental de impactos do uso da terra. Para a indicação de fontes de dados para cada um dos itens listados no esquema foram indicados aqueles estudos considerados condizentes às novas diretrizes da UNEP e SETAC de 
avaliação dos impactos do uso da terra (KOELLNER, 2013b) e estudos que envolvem a busca de dados mais precisos em relação aos diferentes usos da terra no Brasil. Por fim, cabe lembrar que tanto a adaptação do guia quanto a indicação das fontes de dados foram resultados da extensa revisão bibliográfica sobre o tema. 


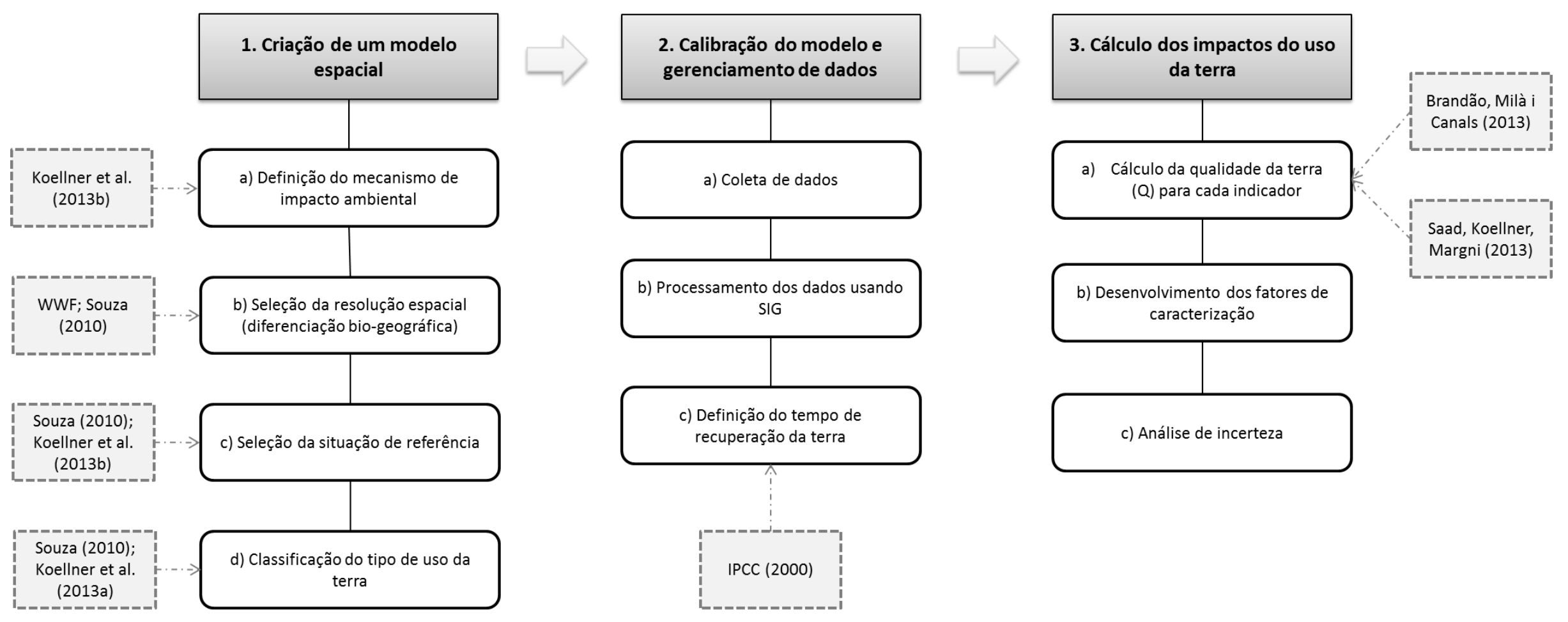

Figura 26: Elementos chave e possíveis fontes de dados para a construção de uma metodologia de avaliação de impactos do uso da terra para o contexto brasileiro.

Fonte: Adaptado de Koellner et al. (2013b) e Souza (2010) 
É possível depreender do guia adaptado de Koellner et al. (2013b) e Souza (2010), alguns itens passíveis de regionalização:

1. Criação do modelo espacial: nesta etapa entende-se que a seleção da diferenciação bio-geográfica, a seleção da situação de referência e a classificação do tipo de uso da terra são itens que possibilitam a especificidade espacial do impacto e suas características.

2. Calibração do modelo e gerenciamento dos dados: nesta etapa a possibilidade de regionalização é evidente, sobretudo por se tratar da etapa de coleta e processamento dos dados, podendo ser utilizado o SIG de maneira a levar em consideração os diferentes atributos geográficos, dependentes da localização do uso da terra. Também entende-se que na fase de definição do tempo de recuperação da terra existe a possibilidade da inserção de dados específicos do local. 


\section{CONCLUSÕES}

Sendo a ACV uma metodologia utilizada para a avaliação sistemática dos impactos ambientais associados a um produto ou serviço, fica evidente a necessidade da inclusão do uso da terra e seus impactos, principalmente na avaliação de produtos ou serviços que envolvam a agricultura, silvicultura, mineração e atividades de transporte.

Os termos uso da terra e mudança no uso da terra são usados em diferentes contextos, o que algumas vezes leva a equívocos. No campo da $\mathrm{ACV}$, o uso da terra é definido como um tipo específico de intervenção ambiental, definido nos resultados do inventário do ciclo de vida, o qual ocasionará modificações na habilidade da terra em realizar suas funções (MILÀ i CANALS, 2003). Assim, o uso da terra nas formas de ocupação e transformação de maneira análoga a uma emissão ou a extração de recursos naturais são itens que pertencem à análise de inventário, enquanto os impactos do uso da terra referem-se aos impactos ambientais potenciais, avaliados na AICV, os quais estão relacionados à um conjunto diversificado de danos ambientais que vão desde impactos sobre a diversidade biológica, produtividade da terra, ciclo do carbono até impactos sobre os valores estéticos, recreativos e culturais.

Em resumo, a avaliação dos impactos ambientais do uso da terra na ACV mudou significativamente ao longo dos anos, desde a publicação do trabalho de Lindeijer et al. (2002) e a primeira fase da Iniciativa do Ciclo de Vida da UNEP/SETAC com o estudo de Milà i Canals et al. (2007). Isto significa que o uso da terra, antes considerado apenas como o espaço ou área ocupada, hoje é avaliado na AICV por modelos relativamente complexos que incluem diferentes vias de impacto.

Como resultado desta pesquisa foi possível observar que, apesar de existirem diferentes abordagens na literatura, existe uma tendência de alinhamento na maneira como o uso da terra é tratado na $\mathrm{ACV}$, principalmente quanto ao mecanismo ambiental destes impactos. Isto se deve, sobretudo, à publicação recente de diretrizes específicas (KOELLNER et al., 2013a; KOELLNER et al., 2013b; de BAAN et al., 2013; SOUZA et al., 2013). Uma vez que os estudos acima citados foram publicados no decorrer do presente trabalho, destacase neste momento a importância do caráter cíclico de processamento da revisão bibliográfica sistemática, o qual possibilitou a inserção de novos estudos sobre o tema.

Além de realizar um estudo aprofundado da temática do uso da terra na ACV, o presente trabalho atingiu seu objetivo ao identificar e analisar a aplicabilidade e a regionalização de dezesseis principais modelos de caracterização. 
Nota-se que muitos dos modelos existentes na literatura não são sensíveis para o problema ambiental avaliado ou envolvem elementos ambíguos e arbitrários. Muitos modelos também apresentam limitações quanto à abrangência de aplicação direcionada para regiões geográficas específicas, bem como quanto aos dados utilizados, comumente advindos de países europeus. Além disso, levando-se em consideração a magnitude dos impactos do uso da terra, a grande extensão territorial brasileira e suas diferentes condições climáticas e ambientais, conclui-se que um indicador único não é suficiente para expressar tais impactos.

Ressalta-se que na análise realizada sobre a robustez científica e relevância ambiental não se buscou apontar um modelo de caracterização que cumprisse com todos os requisitos, mas sim indicar os pontos fortes e fracos de cada modelo, sendo estes critérios vistos como uma contribuição para a identificação de modelos passíveis de serem regionalizados e em quais parâmetros isto é possível.

É possível concluir que ainda existem importantes pontos a serem definidos quando se pretende avaliar os impactos do uso da terra na ACV. O primeiro deles refere-se ao ICV, sendo fundamental definir como classificar o uso da terra, de maneira que permita a troca de dados entre inventários, ou seja, é desejável a padronização da classificação e regionalização do uso da terra. Assim, neste trabalho alguns sistemas de classificação de cobertura de terra existentes e abordagens globais para definir regiões biogeográficas foram revisados a fim de auxiliar na adoção de um sistema de classificação do uso da terra adequado para a ACV.

Outro fator importante quando se trata da avaliação dos impactos do uso da terra refere-se à escolha de uma situação de referência, em termos da qualidade potencial da terra. Apesar de existirem diferentes propostas, ainda não há um consenso sobre a melhor escolha, sendo então uma lacuna a ser estudada em próximos estudos. O mesmo se diz da definição do tempo de recuperação, o qual pode ser definido como o tempo entre o fim da ocupação e o momento em que um tipo de cobertura do solo atinge o mesmo potencial inicial, o que não implica que o mesmo tipo de ecossistema é restaurado. Pode ser também definido como o tempo necessário para alcançar o potencial máximo da qualidade da terra após uma atividade. A estimativa deste tempo de recuperação afeta significativamente os resultados uma vez a maioria dos impactos do uso da terra estão relacionados à transformação da terra.

Por fim, identifica-se como um dos fatores de maior relevância na temática a representatividade local de cada ecossistema e dos diferentes tipos de uso da terra. A regionalização dos modelos de caracterização permite, portanto, obter resultados mais precisos e realistas na $\mathrm{ACV}$, o que vem motivando os bancos de dados atuais a obterem mais informações detalhadas e regionalizadas para todos os processos. 
Seguindo essa premissa, para avaliação de impactos sobre a biodiversidade, recomenda-se o trabalho de Souza (2010), visto que é um modelo desenvolvido especificamente para o contexto brasileiro e, ao contrário da maioria dos trabalhos, propõem o uso de diferentes grupos taxonômicos (anfíbios, aves, mamíferos e répteis) na avaliação, também levando em conta o grau de ameaça às espécies, definido na Lista Vermelha de Espécies.

Já para aqueles impactos que não dispõe de modelos desenvolvidos para o Brasil, são indicados aqueles que apresentam abrangência de aplicação global. Neste sentido, cinco modelos são recomendados de maneira a atender às duas grandes vias de impactos (biodiversidade e serviços ecossistêmicos):

- Brandão \& Milà i Canals (2013) para a avaliação de impactos sobre a produção biótica.

- Müller-Wenk \& Brandão (2010) para a avaliação de impactos sobre as alterações climáticas devido ao uso da terra.

- Nunez et al. (2010) para a avaliação de impactos de desertificação.

- Saad, Koellner, Margni (2013) para a avaliação de impactos sobre as funções ecológicas do solo (resistência à erosão, regulação e purificação da água).

- Souza et al. (2013) para a avaliação de impactos sobre a diversidade funcional.

Nota-se que, no momento, as metodologias para caracterização dos impactos à biodiversidade devido o uso da terra estão bem desenvolvidas, porém ainda existe um desafio científico na comunidade de ACV, que é a regionalização de modelos de caracterização para impactos do uso da terra sobre os serviços ecossistêmicos. Neste sentido, este trabalho aponta um guia para a adaptação de metodologias de AICV voltado ao contexto brasileiro de maneira a possibilitar o cálculo de fatores de caracterização regionalmente específicos para estes impactos.

Como consequência da multifuncionalidade da terra, a quantificação dos impactos do uso da terra requer a modelagem de vários aspectos, como fatores ecológicos, diferenças climáticas e geofísicas, além de especificidades de cada bioma, existindo ainda grandes incertezas na avaliação. Cabe aqui ressaltar que este trabalho tem o foco nos aspectos e impactos ambientais, portanto, as abordagens econômica e social não estão em seu escopo.

Conclui-se que trabalhos futuros devem não só se dedicar ao levantamento de dados, mas também buscar o aprimoramento dos principais elementos que permeiam a avaliação dos 
impactos do uso da terra na ACV, ou seja, a escolha adequada da situação de referência e do tempo de recuperação; a questão da alocação dos impactos da transformação da terra; e a consideração sobre os efeitos indiretos do uso da terra.

Para isso, é essencial que o aprofundamento da discussão seja desenvolvido de forma multidisciplinar, incluindo especialistas de diferentes áreas, como da avaliação de impacto ambiental, ciências do solo e biologia da conservação. 


\section{REFERÊNCIAS BIBLIOGRÁFICAS}

ABELL, R. et al. Freshwater ecoregions of the world: a new map of biogeographic units for freshwater biodiversity conservation. BioScience 58:403-414, 2008.

ALKEMADE, R. et al. GLOBIO3: a framework to investigate options for reducing global terrestrial biodiversity loss. Ecosystems 12:374-390, 2009.

ASSOCIAÇÃO BRASILEIRA DE NORMAS TÉCNICAS - ABNT. NBR ISO 14040: Gestão Ambiental - Avaliação do Ciclo de Vida - Princípios e Estrutura: ABNT, 2009a.

NBR ISO 14044: Gestão Ambiental - Avaliação do Ciclo de Vida - Requisitos e Orientações. Brasil: ABNT, 2009b.

BAILEY, R. G. Ecosystem geography. Springer, New York, 1996.

.Ecoregions: the ecosystem geography of the oceans and continents. Springer, New York, 1998.

BAITZ, M. Bedeutung der funktionsbasierten Charakterisierung von Flächeninanspruchnahmen in ndustriellen Prozesskettenanalysen. Life cycle engineering. University of Stuttgart, Stuttgart, p 172, 2002.

BARE, J. Recommendation for land use impact assessment: first steps into framework, theory, and implementation. Clean Techn Environ Policy, Berlin/Heidelberg, v. 13, n. 1, p. 7-18, 2011.

BARE, J. C. TRACI: the Tool for the Reduction and Assessment of Chemical and Other Environmental Impact. Journal of Industrial Ecology, v. 6, n. 3-4, p. 49-78. 2003.

BARTHOLOMÉ, E.; BELWARD, A. S. GLC2000: a new approach to global land cover mapping from Earth observation data. Int J Remote Sens 26:1959-1977, 2005.

BASTIAN, O.; SCHREIBER, K. F. Analyse und ökologische Bewertung der Landschaft. Fischer Verlag, Jena, Stuttgart, 1994.

BATJES, N. H. ISRIC-WISE - Global Soil Profile Data. Wageningen, 2002.

BECK, T. et al. LANCA - land use indicator value calculation in life cycle assessment. Fraunhofer, Stuttgart, 2010.

BIE, C. A. J. M. de; LEEUWEN, J. A. van; ZUIDEMA, P. A. The land use database: a knowledge-based software program for structured storage and retrieval of user-defined land use data sets: user's reference manual. Version 1.04 for MS-DOS. [S.1.]: ITC: FAO: UNEP: WAU, 1996.

BIOLCHINI, J.C.A., et al. Scientific research ontology to support systematic review in software engineering. Advanced Engineering Informatics, v.21, n.2, p.133-151, 2007. 
BOSSARD, M.; FERANEC, J.; OTAHEL, J. CORINE land cover technical guideAddendum 2000. Commission of the European Communities Copenhagen, Denmark, 2000.

BRANDÃO, M.; MILÀ I CANALS, L. Global characterisation factors to assess land use impacts on biotic production. International Journal of Life Cycle Assessment, v. 18, n. 6, p. 1243-1252, 2013.

BRANDÃO, M.; MILÀ I CANALS, L.; CLIFT, R. Soil organic carbon changes in the cultivation of energy crops: implications for GHG balances and soil quality for use in LCA. Biomass Bioenerg 35(6):2323-2336, 2011.

BRASIL. Ministério do Desenvolvimento, Indústria e Comércio Exterior. Conselho Nacional de Metrologia, Normalização e Qualidade Industrial - CONMETRO. Resolução nº 04, de 15 de dezembro de 2010. Dispõe sobre a Aprovação do Programa Brasileiro de Avaliação do Cíclo de Vida e dá outras providências. Disponível em: <http://www.inmetro.gov.br/legislacao/resc/pdf/RESC000236.pdf〉. Acesso em: Set. 2012.

CESCHIA E. et al. Management effects on net ecosystem carbon and GHG budgets at European crop sites. Agric Ecosyst Environ 139(3):363-383, 2010.

CHIARUCCI, A., et al. The concept of potential natural vegetation: an epitaph? J Veg Sci 21:1172-1178, 2010.

CHOUDHURY, K.; JANSEN, L. J. M. Terminology for Integrated Resources Planning and Management. Rome: Food and Agriculture Organization of the United States; Land and Water Development Division, 1999.

COLTRO, L (Org.) Avaliação do Ciclo de Vida como Instrumento de Gestão. 1. ed. Campinas: CETEA/ITAL, v. 1. 75p. 2007.

CONFORTO, E. C.; AMARAL, D.C.; SILVA, S.L. Roteiro para Revisão Bibliográfica Sistemática: aplicação no desenvolvimento de produtos e gerenciamento de projetos. In: 8o. Congresso Brasileiro de Gestão de Desenvolvimento de Produto - CBGDP 2011, Porto Alegre-RS. 8, 2011.

CRAWLEY, M. J.; HARRAL, J. E. Scale dependence in plant biodiversity. Science, volume 291, p 264-268, 2001.

COUNTRYSIDE SURVEY 2000 (CS2000). Survey of Broad Habitats and Landscape features, 2000.

CUNHA, A. A.; GUEDES, F. B. Mapeamentos para conservação e recuperação da biodiversidade na Mata Atlântica: em busca de uma estratégia espacial integradora para orientar ações aplicadas. Ministério do Meio Ambiente (MMA), Secretaria de Biodiversidade e Florestas. Brasília, DF. 216p. 2013.

DE BAAN, L.; ALKEMADE, R.; KOELLNER, T. Land use impacts on biodiversity in LCA: a global approach. International Journal of Life Cycle Assessment, v. 18, n. 6, p. 12161230, 2013. 
DE SCHRYVER, A.; GOEDKOOP, M. Impacts of Land Use: a lifecycle impact assessment method which comprises harmonised category indicators at the midpoint and the endpoint level. In: GOEDKOOP, Mark, et al. ReCiPe 2008. Amersfoort: PréConsultants. Cap. 10, p. 98-115, 2009.

Di GREGORIO, A.; JANSEN L. J. M Land Cover Classification System (LCCS) classification concepts and user manual. Environment and Natural Resources Service (SDRN), Food and Agricultural Organization of the United Nations, Rome, 2005.

DÍAZ, S.; CABIDO, M. Vive la différence: plant functional diversity matters to ecosystem processes. Trends Ecol Evol 16(11):646-655, 2001.

EC-JRC - JOINT RESEARCH CENTRE OF THE EUROPEAN COMMISSION. Analysis of existing environmental impact assessment methodologies for use in life cycle assessment - background document. ILCD Handbook - International Reference Life Cycle Data System, European Union. 2010a.

. Framework and Requirements for Life Cycle Impact Assessment Models and Indicators. ILCD Handbook - International Reference Life Cycle Data System, European Union. 2010b.

General guide for Life Cycle Assessment - Detailed guidance. ILCD Handbook International Reference Life Cycle Data System, European Union. 2010c.

Recommendations based on existing environmental impact assessment models and factors for life cycle assessment in European context. ILCD Handbook International Reference Life Cycle Data System, European Union. 2011.

ELKINGTON, J. Cannibals with Forks: The triple bottom line of the $21^{\text {st }}$ Century. New Society Publishers, Stoney Creek, 1998.

EMWIS. Mediterranean groundwater report. Technical report on groundwater management in the Mediterranean and the Water Framework Directive. Euro-Mediterranean Information System on know-how in the Water Sector, Mediterranean Groundwater Working Group (MED-EUWI WG on groundwater). 2007.

EUROPEAN ENVIRONMENTAL AGENCY (EEA) Groundwater quality and quantity in Europe. Technical report no. 22, European Environment Agency, Copenhagen. 1999.

EUROPEAN ENVIRONMENTAL AGENCY (EEA) CORINE Land Cover. European Environmental Agency, Luxembourg. 2000.

FINNVEDEN, G., et al. Recent developments in Life Cycle Assessment. Journal of Environmental Management. Vol. 91, n.1, p. 1-21, 2009.

FLYNN et al. Loss of functional diversity under land use intensification across multiple taxa. Ecol Lett 12(1):22-33, 2009.

FLYNN, H. C. et al, Quantifying global greenhouse gas emissions from land use change for crop production. Glob Change Biol, 2011. 
FRISCHKNECHT, R.; JUNGBLUTH, N. Ecoinvent: overview and methodology. Swiss Centre for Life Cycle Inventories, Duebendorf. 2007.

GARDI, C. et al. Atlas de suelos de América Latina y el Caribe, Comisión Europea Oficina de Publicaciones de la Unión Europea, L-2995 Luxembourg, 176 pp, 2014.

GIBSON, L. et al. Primary forests are irreplaceable for sustaining tropical biodiversity. Nature 478:378-383, 2011.

GOEDKOOP et al. ReCiPe 2008: A life cycle impact assessment method which comprises harmonised category indicators at the midpoint and the endpoint level. First edition (revised). Report I: Characterisation. Ruimte em Milieu Ministerie van Volkshuisvesting, Ruimtelijke Ordening en Milieubeheer. 2013.

GOEDKOOP, M.; SPRIENSMA, R. The Eco-Indicator 99: a damage oriented method for Life Cycle Impact Assessment. 132p. 2001. Disponível em: <http://www.pre.nl/download/EI99_methodology_v3.pdf>. Acesso em 16/12/2012.

GUINÉE, J.B. Handbook on life cycle assessment - operational Guide to the ISO Standards. Int. J. LCA 6 (5), 255. 2001.

GUINÉE, J. B., et al. Part 1: LCA in perspective. In: GUINÉE, Jeroen B. Handbook on Life Cycle Assessment: Operational Guide to the ISO Standards.1. ed. Dordrecht: Kluwer Academic Publishers, v.7, 2002. p. 708. (Ecoefficiency in Industryand Science). Disponível em: <http://cml.leiden.edu/research/industrialecology/researchprojects/finished/new-dutchlca-guide.html>. Acesso em 10/10/2012.

HAUSCHILD, M. Z.; POTTING, J. Spatial differentiation in Life Cycle Impact Assessment: the EDIP2003 Methodology. Copenhagen: Environment, Danish Ministry of the, 2005. 195 p. (Report Environmental News, 80).

HAUSCHILD, M.; WENZEL H. Scientific background. Environmental assessment of products, vol. 2. London,UK:Chapman\&Hall; 1998.

HAXELTINE, A.; PRENTICE, C. E. BIOME3: an equilibrium biosphere model based on ecophysiological constraints, resource vailability and competition among plant functional types. Glob Biogeochem Cycles 10(4):693-709, 1996.

HEIJUNGS, R, et al. Environmental life cycle assessment of products. Guide and backgrounds. CML, Leiden University, Leiden, The Netherlands. 1992.

HERTWICH, E. G. Life Cycle Approaches to Sustainable Consumption: A Critical Review. Environmental Science \& Technology. Vol. 39, n.13, p. 4672-4684. 2005.

HOLDRIDGE, L. R. Determination of world plant formations from simple climatic data. Science 105(2727):367-368, 1947.

IBGE. Manual Técnico de Uso da Terra. 2. ed., Rio de Janeiro: IBGE, 2006. 
IMPACT WORLD+. Disponível em: 〈http://www.impactworldplus.org/en/presentation.php> Acesso em: Agosto, 2012.

IPCC. Good practice guidance for land use, land-use change and forestry. Institute for Global Environmental Strategies (IGES) for the Intergovernmental Panel on Climate Change. Kanagawa, Japan. 2003.

IPCC. IPCC Guidelines for National Greenhouse Gas Inventories. Institute for Global Environmental Strategies (IGES) for the Intergovernmental Panel on Climate Change. Kanagawa, Japan. 2006.

ITSUBO, N. et al. Weighting Across Safeguard Subjects for LCIA through the Application of Conjoint Analysis, International Journal of LCA, 2004, 9 (3) pp. 196-205.

ITSUBO, N.; INABA, A. A new LCIA method: LIME has been completed. International Journal of Life Cycle Assessment, v. 8, n. 5, p. 305. 2003.

JOLLIET, O., et al. IMPACT 2002+: a new Life Cycle Impact Assessment methodology. International Journal of Life Cycle Assessment, v. 8, n. 6, p. 324-330. 2003.

JONES, H. P, SCHMITZ, O. J. Rapid recovery of damaged ecosystems. PLoS One 4(e5653):1-6, 2009.

JORGENSEN, T. Towards more sustainable management systems: through life cycle management and integration. Journal of Cleaner Production. V. 16, n. 10 p. 1071-1080, 2008.

KAPLAN, J. O. et al. Climate change and arctic ecosystems II: Modeling, paleodata-model comparisons, and future projections. J Geophys Res 108(D19):8171, 2003.

KLÖPFFER, W. Comments to the present state of LCIA and possible improvements. Global LCA Village, p. 14. 1998.

KOELLNER, T. Species-pool effect potentials (SPEP) as a yardstick to evaluate land-use impacts on biodiversity. Journal of Cleaner Production, n. 8, p. 293-311, 2000.

Land Use in Product Life Cycles and Ecosystem Quality. Frankfurt am Main: Peter Lang. 2003, 271p.

KOELLNER, T.; SCHOLZ, R. Assessment of land use impacts on the natural environment. Part 2: Generic characterization factors for local species diversity in Central Europe. International Journal of Life Cycle Assessment, v. 13, n. 1, p. 32-48, $2008 \mathrm{a}$.

Assessment of land use impacts on the natural environment. Appendix: CORINE Plus land-cover definitions. Int J Life Cycle Assess 13:48-1-48-3, 2008b.

KOELLNER, T. et al. Principles for life cycle inventories of land use on a global scale. International Journal of Life Cycle Assessment, v. 18, n. 6, p. 1203-1215, 2013a. 
UNEP-SETAC guideline on global land use impact assessment on biodiversity and ecosystem services in LCA. International Journal of Life Cycle Assessment, v. 18, n. 6, p. 1188-1202, 2013 b.

KOELLNER, T.; GEYER, R. Global land use impact assessment on biodiversity and ecosystem services in LCA. International Journal of Life Cycle Assessment, v. 18, n. 6, p. 1185-1187, 2013.

KÖLlnER, T. Land Use in Product Life Cycles and its Consequences for Ecosystem Quality. PhD thesis No. 2519, University St. Gallen, 2001.

LEVY, Y.; ELLIS, T.J. A system approach to conduct an effective literature review in support of information systems research. Informing Science Journal, v.9, p.181-212, 2006.

LINDEIJER, E. Review of land use impact methodologies. Journal of Cleaner Production, n. 8, p. 313-319, 2000.

LINDEIJER, E. et al. Impact assessment of resources and land use. In: Udo de Haes H, Finnveden G, Goedkoopet M (eds) Life-cycle impact assessment: striving towards best practice. Society of Environmental Toxicology and Chemistry (SETAC), Pensacola, pp 1164, 2002.

LINDEIJER, W. et al. Biodiversity and life support indicators for land use impacts in LCA. IVAM and IBN/DLO, 1998.

MA. Millennium ecosystem assessment. Ecosystems and human well-being: current state and trends. Island Press, Washington, 2005.

MARKS, R. Anleitung zur Bewertung des Leistungsvermögens des Landschaftshaushaltes. Forschungen zur deutschen Landeskunde, 1. Auflage, Trier, 1989.

MENDES, N. C. Métodos e modelos de caracterização para a Avaliação de Impacto do Ciclo de Vida: análise e recomendações para a aplicação no Brasil. 141. Dissertação (Mestrado) - Escola de Engenharia de São Carlos, Universidade de São Paulo, São Carlos, 2013.

MILÀ I CANALS, L. et al. Key elements in a framework for land use impact assessment within LCA. International Journal of Life Cycle Assessment, v. 12, n. 1, p. 5-15, 2007.

MILÀ I CANALS, L.; RIGARLSFORD, G.; SIM, S. Land use impact assessment of margarine. International Journal of Life Cycle Assessment, v. 18, n. 6, p. 1265-1277, 2013.

MILÀ I CANALS, L.; ROMANYA, J.; COWELL, S. Method for assessing impacts on life support functions (LSF) related to the use of 'fertile land' in life cycle assessment (LCA). J Clean Prod 15 (15):1426, 2007.

MOUCHET, M. A.; VILlÉGER, S.; MASON, N. W. H.; MOUILlOT, D. Functional diversity measures: an overview of their redundancy and their ability to discriminate community assembly rules. Funct Ecol 24(4):867-876, 2010. 
MÜLLER-WENK, R. Universität St. Gallen. Land use the main threat to species: How to include land use in LCA. St. Gallen, 1998. 45 p.

MÜLLER-WENK, R.; BRANDÃO, M. Climatic impact of land use in LCA-carbon transfers between vegetation soil and air. Int J Life Cycle Assess 15:172-182, 2010.

MULROW, C.D. Systematic reviews rationale for systematic reviews. British Medical Journal, v.309, pp.597-599, 1994.

NUNEZ, M. et al. Assessing potential desertification environmental impact in life cycle assessment. International Journal of Life Cycle Assessment, v. 15, n. 1, p. 67-78, 2010.

OLSON, D. M.; DINERSTEIN, E. The global 200: a representation approach to conserving the Earth's most biologically valuable ecoregions. Conserv Biol 12:502-515, 1998.

OLSON, D. M. et al. Terrestrial ecoregions of the worlds: a new map of life on Earth. BioScience 51:933-938, 2001.

OWENS, J. W. Life Cycle Impact Assessment: the use of subjective judgments in classification and characterization. International Journal of Life Cycle Assessment, v. 3, n. 1, p. 43-46. 1998.

PBMC. Contribuição do Grupo de Trabalho 2 ao Primeiro Relatório de Avaliação Nacional do Painel Brasileiro de Mudanças Climáticas. Sumário Executivo do GT2. PBMC, Rio de Janeiro, Brasil. 2013, 28 p.

PENNINGTON, D. W. et al. Life cycle assessment Part 2: Current impact assessment practice. Environment International, v. 30, n. 5, p. 721-739, 2004.

PETCHEY, O. L.; GASTON, K. J. Functional diversity (FD), species richness and community composition. Ecol Lett 5(3):402-411. 2002.

758.2006 .

. Functional diversity: back to basics and looking forward. Ecol Lett 9(6):741-

PETCHEY, O. L.; O'GORMAN, E. J.; FLYNN, D. F. B. A functional guide to functional diversity measures. In: Naeem S, Bunker DE, Hector A, Loreau M, Perrings C (eds) Biodiversity, ecosystem functioning, and human wellbeing: an ecological and economic perspective. Oxford University Press, Oxford, 2009, p 384.

PFISTER, S. et al. Trade-offs between land and water use: regionalized impacts of energy crops. In: Proceedings of the 7th International Conference on LCA in the Agri-Food Sector, 2010.

PINEDA, M. N. (2011). Modelling location-dependent environmental impacts in life cycle assessment: water use, desertification and soil erosion: Application to energy crops grown in Spain. Tese de doutorado - Universidad Autônoma de Barcelona. Bellaterra, Espanha. 
REEVES, D. W. The role of soil organic matter in maintaining soil quality in continuous cropping systems. Soil Till Res 43(1-2):131. 1997.

RIBEIRO, F. M. Inventário de ciclo de vida da geração hidrelétrica no Brasil- Usina de Itaipu: primeira aproximação. Dissertação (Programa Interunidades de Pós Graduação em Energia) Universidade de São Paulo (PIPGE/ USP). São Paulo, 2003.

RICKLEFS, R. E.; MILLER, G. L. Climat, Topographie et diversité de la Nature. In: Université DB (ed) Ecologie. De Boek \& Larcier, Paris, France, pp 138-167, 2005.

ROSENBAUM, R. K. et al. Regionalisation of nonglobal LCIA categories such as water/landuse, toxicity, acidification, and Ozone formation - if at all, when and how does it make sense? In: 2nd International Seminar on Society \& Materials SAM2. 2008, Nantes, France. Proceedings of 2nd Seminar on Society \& Materials (SAM2). 2008.

SAAD, R. et al. Assessment of land use impacts on soil ecological functions: development of spatially differentiated characterization factors within a Canadian context. International Journal of Life Cycle Assessment, 16(3), 198-211. 2011.

SAAD, R.; KOELLNER, T.; MARGNI, M. Land use impacts on freshwater regulation, erosion regulation, and water purification: a spatial approach for a global scale level. International Journal of Life Cycle Assessment, v. 18, n. 6, p. 1253-1264, 2013.

SCHMIDT, J. Development of LCIA characterisation factors for land use impacts on biodiversity. J Clean Prod 16(18):19-29, 2008.

SCHWERTMANN, U.; VOGL, W.; KAINZ, M. Bodenerosion durch Wasser. Vorhersage des Abtrags und Bewertung von Gegenmaßnahmen. Ulmer Verlag, Stuttgart, 1987.

SOUZA, D. M. Proposta de um modelo de caracterização de impactos do uso da terra, segundo indicadores de biodiversidade, em AICV: cálculo de fatores de caracterização, para ecorregiões brasileiras. Tese (Doutorado em Engenharia Ambiental), Universidade Federal de Santa Catarina. Florianópolis, 2010.

SOUZA, D. M. et al. Land use impacts on biodiversity in LCA: proposal of characterization factors based on functional diversity. International Journal of Life Cycle Assessment, v. 18, n. 6, p. 1231-1242, 2013.

SOUZA, S. R. Normalização de Critérios Ambientais Aplicados à Avaliação do Ciclo de Vida. Dissertação (Mestrado), Universidade Federal de Santa Catarina, Florianópolis, 2008.

SPALDING, M.D. et al. Marine ecoregions of the world: a bioregionalization of coastal and shelf areas. Bioscience 57:573-583, 2007.

STEEN, B. A systematic approach to environmental priority strategies in product development (EPS). Chalmers University of Technology. Göteborg, 1999 (CPM Report).

TEEB. A Economia dos Ecossistemas e da Biodiversidade. Relatório para o Setor de Negócios. Sumário Executivo,2010. 
TELLER, A. et al. Chapter 7: Soil. In: EEA \& European Commission DG XI, 1995. Europe's Environment: the Dobris Assessment. European Environment Agency. Copenhagen, 1995.

TOFFOLETTO, L. et al. LUCAS - A New LCIA Method Used for a Canadian Specific Context. International Journal of Life Cycle Assessment, v. 12, n. 2, p. 93, 2007.

UDO DE HAES, H. A. et al. Life Cycle Impact Assessment: striving towards the best practice. Brussels: SETAC, 2002. 249 p.

UNITED NATIONS ENVIRONMENT PROGRAMME (UNEP). Assessing Global Land Use: Balancing Consumption with Sustainable Supply. A Report of the Working Group on Land and Soils of the International Resource Panel, 2014.

Life Cycle Impact Assessment Programme. Life Cycle Initiative, 2010.

Life Cycle Management - A business guide to sustainability. [S.1]. 2007.

Year Book 2012, United Nations Environment Programme, Nairobi. 2012.

UNITED NATIONS ENVIRONMENT PROGRAMME (UNEP); SOCIETY OF ENVIRONMENTAL TOXICOLOGY AND CHEMISTRY (SETAC). Life Cycle Management: How business uses it to decrease footprint, create opportunities and make value chains more sustainable. [S.1], 2009.

WBGU . The accounting of biological sinks and sources under the Kyoto Protocol - a step forwards or backwards for global environmental protection? 1998.

WEIDEMA, B. P.; LINDEIJER, E. Physical impacts of land use in product life cycle assessment: Final report of the EURENVIRON-LCAGAPS sub-project on land use. Lyngby: Department of Manufacturing Engineering and Management, Technical University of Denmark, 2001.

WESTHOFF, V.; VAN DER MAAREL, E. The Braun-Blanquet approach. In: WHITTAKER, R. H. (Ed) Ordination and classification of communities. Handbook of Vegetation Science. Junk, The Hague, pp 617-726, 1973.

WISCHMEIER, W.H; SMITH, D.D. Predicting rainfall erosion losses - a guide to conservation planning. USDA, agricultural handbook, No. 537, United States Department of Agriculture, 1978.

WRI. Water resources and freshwater ecosystems, Searchable database World Resources Institute. 2007. 